\title{
MICROSTRUCTURE AND MECHANICAL PROPERTIES OF CARBON NANOTUBE REINFORCED ALUMINUM MATRIX COMPOSITE
}

\author{
by \\ Zhi Li \\ Bachelor of Engineering in Metallic Materials Engineering \\ Jilin University, China, 2009 \\ A thesis \\ presented to Ryerson University \\ in partial fulfillment of the \\ requirements for the degree of \\ Master of Applied Science \\ in the program of \\ Mechanical and Industrial Engineering
}

Toronto, Ontario, Canada, 2018

(C) Zhi Li, 2018 


\section{Author's Declaration}

I hereby declare that I am the sole author of this thesis. This is a true copy of the thesis, including any required final revisions, as accepted by my examiners.

I authorize Ryerson University to lend this thesis to other institutions or individuals for the purpose of scholarly research.

I further authorize Ryerson University to reproduce this thesis by photocopying or by other means, in total or in part, at the request of other institutions or individuals for the purpose of scholarly research.

I understand that my thesis may be made electronically available to the public. 


\title{
Abstract \\ MICROSTRUCTURE AND MECHANICAL PROPERTIES OF CARBON NANOTUBE REINFORCED ALUMINUM MATRIX COMPOSITE
}

\author{
Zhi Li \\ Master of Applied Science, Mechanical and Industrial Engineering, \\ Ryerson University, 2018
}

The carbon nanotube (CNT) was first discovered by Iijima in 1991. Carbon nanotubes have remarkable mechanical, electrical and thermal properties. Aluminum alloys are commonly used in various fields due to low density, good mechanical properties and excellent corrosion resistance. To enhance their strength, aluminum matrix composites reinforced by carbon nanotube have been recently developed.

In the present work, the composite composed of $2 \mathrm{wt} . \%$ carbon nanotubes as the reinforcement and aluminum alloy 6061 as the matrix has been studied. It is fabricated by powder metallurgy and friction stir processing (FSP) followed by heat treatment. The main objectives of the research are to characterize the microstructure, mechanical properties as well as deformation behaviors. Optical microscopy, X-ray diffraction test, compression tests, tension tests, fractography and low cycle fatigue tests have been conducted. The prediction model for yield strength and the calculation model for Young's modulus are analyzed and discussed. 


\section{Acknowledgements}

I would like to express my sincere gratitude to my supervisors Dr. Jacob Friedman and Dr. Daolun

Chen. I could not have finished the research without their strong support and continuous encouragement. I truly appreciate their inspiring guidance and their patience. I have gained precious knowledge of how to think and behave like a professional researcher.

I would like to thank my colleagues and friends for their help and support. Many thanks to Dr. Fatma Mokdad for her lead and help at the beginning of my research. I am also thankful to Mr. Sohail Mohammed for his assistance. My appreciation also to Mr. Bernoulli Andilab, Mr. Eli Vandersluis and Mr. Payam Emadi for the time we spent together on the team of Material Advantage Ryerson Chapter.

I am especially thankful to Mr. Alan Machin and Dr. Qiang Li for their friendliness, technical support and generous help. I would also like to thank Mr. Joseph Amankrah and Mr. Roy Churaman for all their assistance and the convenient access to the laboratory facilities.

Last but not least, I am sincerely grateful to all my family members. My parents love me and always have my back. My deepest gratitude goes to my wife for her understanding and support, accompanying me during the tough times. 


\section{Table of Contents}

Author's Declaration...................................................................................................... ii

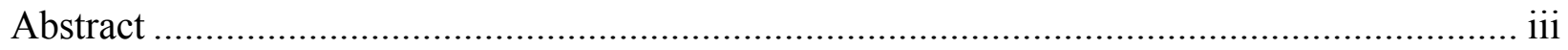

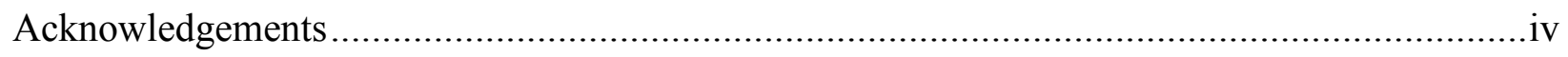

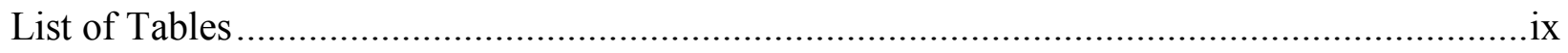

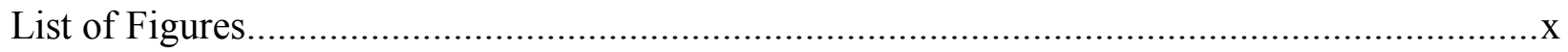

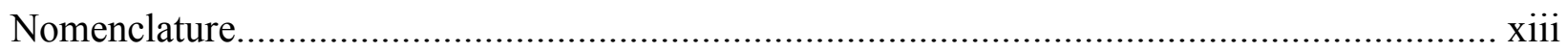

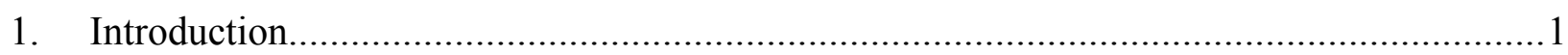

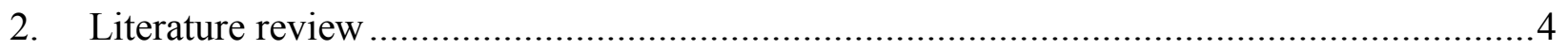

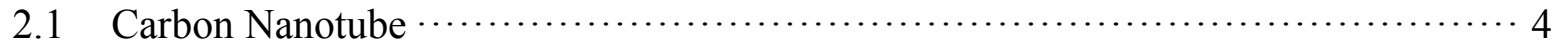

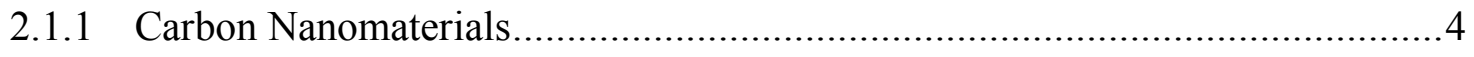

2.1.2 Properties of Carbon Nanotube ............................................................ 6

2.1.3 Applications of Carbon Nanotube ........................................................ 6

2.1.4 Synthesis of Carbon Nanotube .......................................................

2.2 Aluminum Alloys and Aluminum Matrix Composites $\cdots \ldots \ldots \ldots \ldots \ldots \ldots \ldots \ldots \ldots \ldots \ldots$

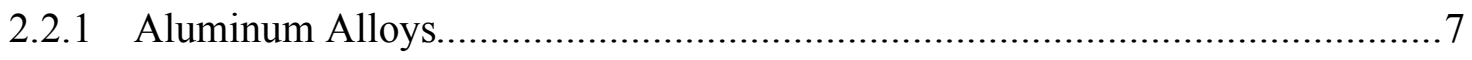

2.2.2 Aluminum Matrix Composites ................................................................. 8

2.2.3 Applications of $\mathrm{CNT} / \mathrm{Al}$ Composites ..............................................

2.2.4 Fabrication Techniques of CNT/ Al Composites ...................................

2.2.5 Challenges in Bulk Production .......................................................... 11 


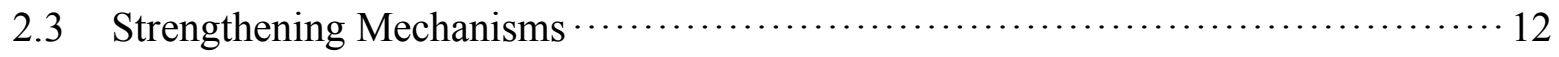

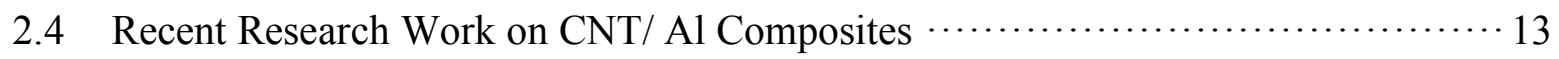

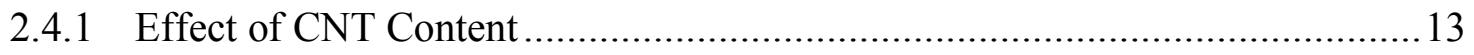

2.4.2 Effect of CNT Diameter.............................................................. 16

2.4.3 Effect of Fabrication Processing and Heat Treatment ............................... 16

2.4.4 Research on Fatigue Properties .......................................................... 17

2.4.5 Research on Corrosion Properties...................................................... 19

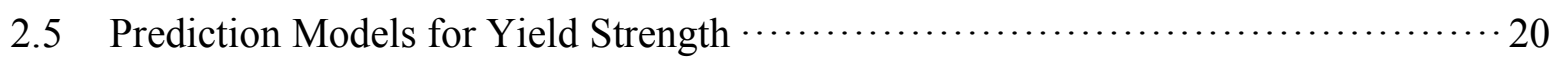

2.5.1 Arithmetic Summation Method .............................................................2 20

2.5.2 Compounding Method ................................................................... 21

2.5.3 Quadratic Summation Method.................................................................22

2.5.4 Comparison and Discussion .............................................................. 23

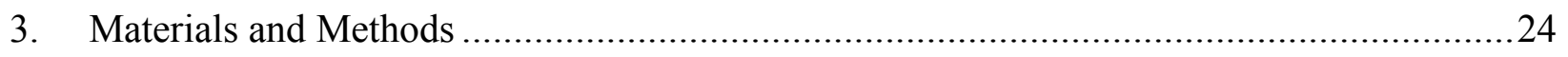

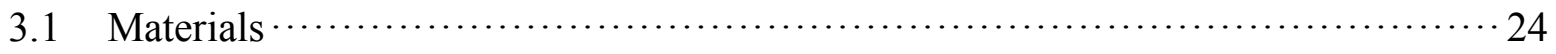

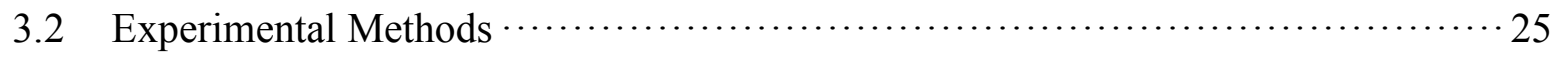

3.2.1 Optical Microscopy ....................................................................2.

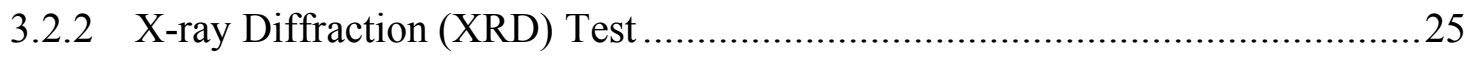

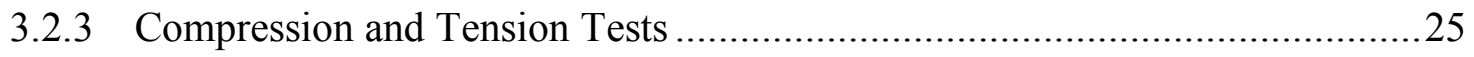

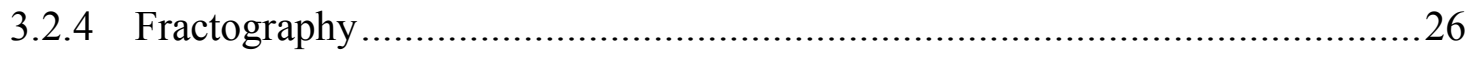

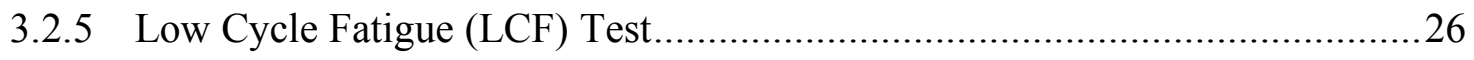


4. Results and Discussions

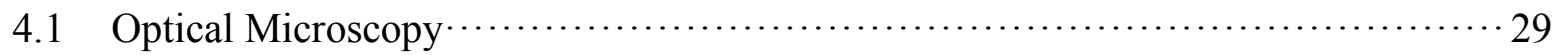

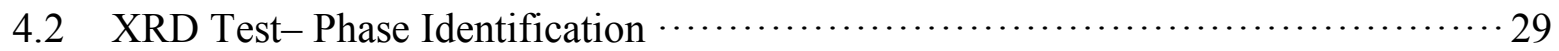

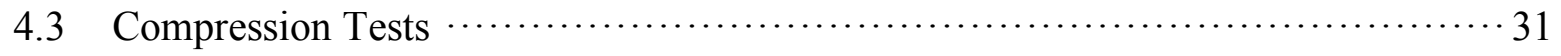

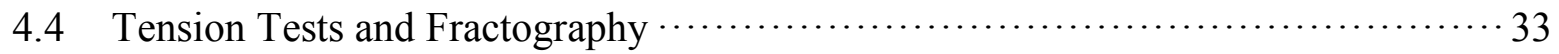

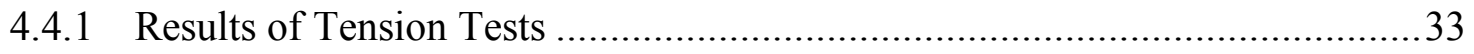

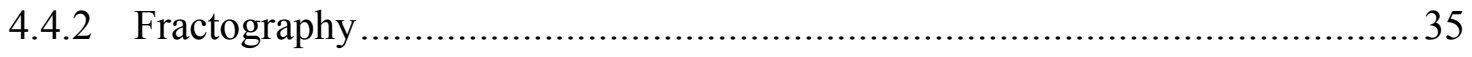

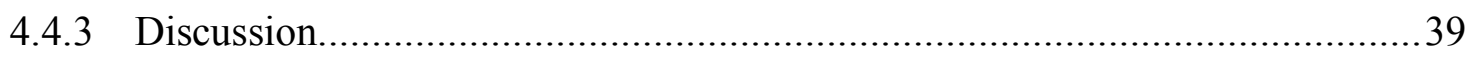

4.4.4 Strength Coefficient K and Strain Hardening Exponent n..........................41

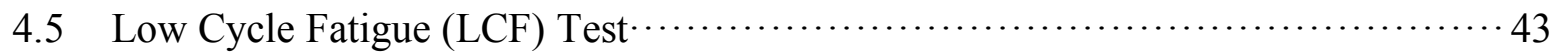

5. Calculation Model for Young's Modulus..................................................................49

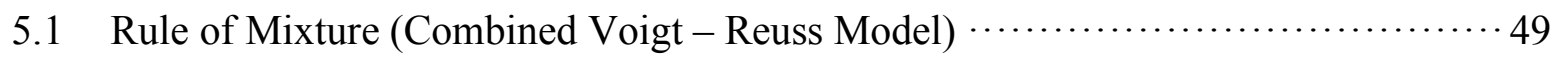

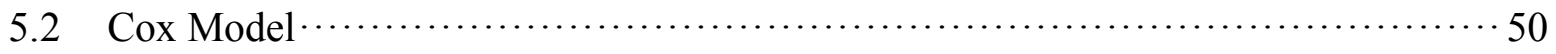

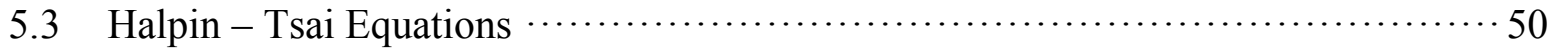

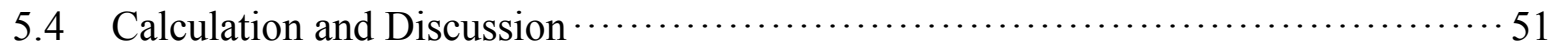

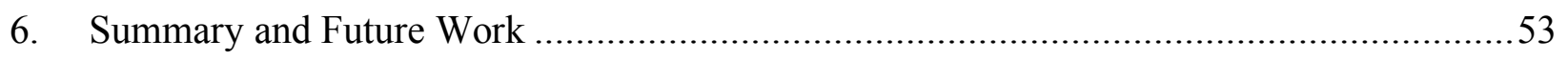

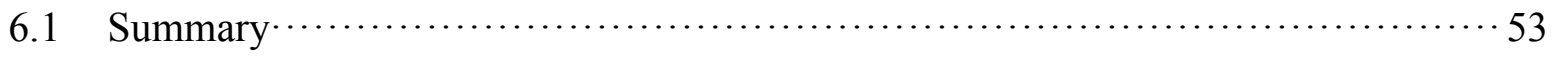

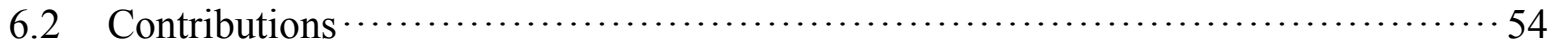

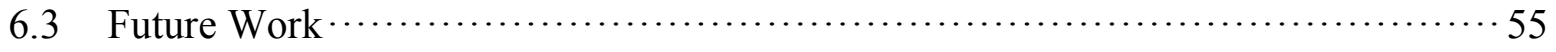

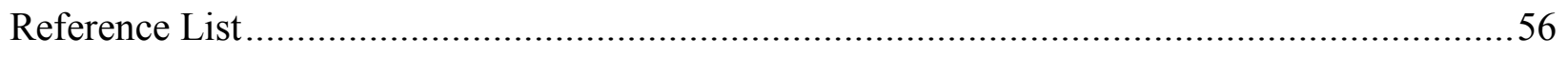




\section{List of Tables}

Table 2.1 Chemical composition of some 6 XXX series aluminum alloys [19].......................

Table 2.2 Typical mechanical properties of some 6 XXX series aluminum alloys [19]..............8

Table 2.3 Mechanical properties of $\mathrm{Al}$ and $\mathrm{CNT} / \mathrm{Al}$ composites [50]...............................15

Table 3.1 Detailed parameters of LCF tests...........................................................28

Table 4.1 Yield and compressive strength of specimens parallel to the FSP direction..............33

Table 4.2 Yield and compressive strength of specimens perpendicular to the FSP direction .....33

Table 4.3 Parameters obtained from low cycle fatigue tests ......................................47

Table 5.1 Comparison of calculated values of Young's moduli ..........................................52 


\section{List of Figures}

Fig. 1.1 Numbers of publications about CNT and CNT reinforced composite (Source:

Www.scopus.com)

Fig. 1.2 Numbers of publications about different CNT reinforced MMCs (Source:

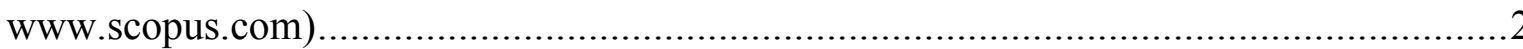

Fig. 2.1 The illustration of relationship among graphene, fullerene, carbon nanotubes and graphite [4]

Fig. 2.2 Single-walled and multi-walled carbon nanotubes.............................................5

Fig. 2.3 Three types of single-walled carbon nanotube [7] ..............................................5

Fig. 2.4 Stress-strain curves of CNT/ Al composite with CNT content from 0 to 2 wt.\% [46] .. 14

Fig. 2.5 Tensile strength of the composites with CNT content from 0 to 5 wt.\% [48] ............. 14

Fig. 2.6 Tensile strength of CNT/ Al composite with different content of CNT [49] .............. 15

Fig. 2.7 Yield strength of CNT/ Al composite with different content of CNT [49] ................15

Fig. 2.8 Tensile strength of composites with CNT of different diameters [54].................... 16

Fig. 2.9 Maximum stresses versus number of cycles to failure for AlSi alloy and AlSi-2 wt.\%

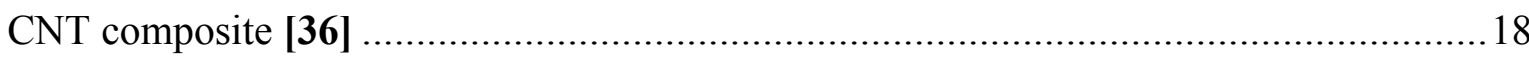

Fig. 2.10 Stress-life (S-N) diagrams for CNT/ Al composites [61] ................................. 18

Fig. 2.11 Fatigue life of MWCNT/ Al 2024 composites [62]........................................ 19

Fig. 3.1 Powder metallurgy process to fabricate the material used in the current research [73].24

Fig. 3.2 Demonstration of FSP and multi-pass FSP (a) FSP [56], (b) multi-pass FSP [74].......25

Fig. 3.3 Specimen dimensions for tension test......................................................26 
Fig. 3.4 Specimen used in low cycle fatigue test

Fig. 3.5 Specimen dimension requirement according to the ASTM standard E606/ 606M - 1227

Fig. 4.1 Microstructures observed from different orientations (a) microstructure observed from the surface parallel to the FSP direction, (b) microstructure observed from the surface

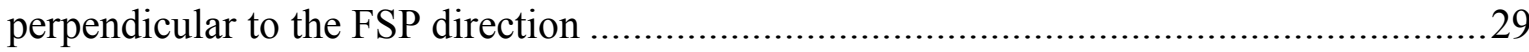

Fig. 4.2 X-ray diffraction patterns of the 2.0 wt. $\%$ CNT/ $6061 \mathrm{Al}$ composite ........................30

Fig. 4.3 TEM micrograph of the extruded CNT/ Al composite [27] (a) Micrograph of the entire grain boundary, (b) the $\mathrm{Al} 4 \mathrm{C} 3$ between the $\mathrm{Al}$ matrix and grain boundary......................30

Fig. 4.4 Compression tests results of specimens parallel to the FSP direction.........................32

Fig. 4.5 Compression tests results of specimens perpendicular to the FSP direction ................32

Fig. 4.6 Stress-strain curves of tension test................................................................. 34

Fig. 4.7 Mechanical properties of the composite and the base alloy..................................34

Fig. 4.8 Fracture surfaces of the specimen after tension test (a) A dimple rupture surface, (b) propagation area, (c) deep voids because of the CNT agglomerates, (d) micro crack and (e) the CNT bridging and CNT pull-out inside micro crack. ..........................................36

Fig. 4.9 Illustration of CNT agglomerates [36] (a) Microstructure in a low magnification, (b)

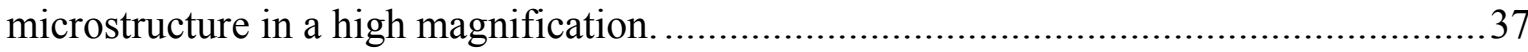

Fig. 4.10 Demonstration of CNT bridging and CNT pull-out [82] (a) Crack bridging mechanisms, (b) CNT pull-out and rupture.

Fig. 4.11 Schematic images of the crack patterns [36]. .38

Fig. 4.12 Different fracture patterns in CNT reinforced aluminum matrix composite [83] (a) Fracture through weak grain boundary, (b) fracture through grain boundary caused by entangled CNTs and partially melted particle, (c) intragranular fracture because of nano voids and (d) fracture due to CNT pull-out..... 
Fig. 4.13 Stress-strain curves of AlSi alloy and 2 wt.\% CNTs / AlSi composite [36] 40

Fig. 4.14 Stress-strain curves of CNT/ 2009 Al composites (a) Stress-strain curves of FSP-rolled CNT/ $2009 \mathrm{Al}$ composites with different CNT content [74] (b) stress-strain curves of 4.5\% vol. \% CNT/ $2009 \mathrm{Al}$ composites with different FSP passes [55] 40

Fig. 4.15 Two-step yielding phenomenon of CNT/ Cu nanocomposite [85] 41

Fig. 4.16 Log-log true stress and true plastic strain curve .42

Fig. 4.17 Actual stress-plastic strain curve and the fitted function curve. 43

Fig. 4.18 Strain amplitude versus numbers of cycles to failure 44

Fig. 4.19 Stress amplitude versus numbers of cycles to failure 45

Fig. 4.20 Typical stress-strain hysteresis loops at the $1.0 \%$ strain amplitude. 45

Fig. 4.21 The comparison of monotonic and cyclic stress-strain curve 48 


\section{Nomenclature}

\section{Symbol}

\section{Greek}

$\sigma_{y}$
$\sigma_{y m}$
$\sigma_{y c}$
$\sigma_{y^{\prime}}$
$\varepsilon$

\section{English}

$\mathrm{R}$

f

E

$E_{L}$

$E_{T}$

$E_{C}$

$E_{f}$

$E_{M}$

$V_{f}$

$V_{M}$

1

r

d

Abbreviations

ASM

ASTM

$\mathrm{CMC}$

\section{Description}

Yield strength

Yield strength of the matrix

Yield strength of the composite

Cyclic yield strength

Strain

Ratio

Frequency

Young's modulus

Young's modulus along the longitudinal direction

Young's modulus along the transverse direction

Young's modulus of the composite

Young's modulus of the fiber (reinforcement)

Young's modulus of the matrix

Volume fraction of the fiber (reinforcement)

Volume fraction of the matrix

Length of CNT

Radius of CNT

Diameter of CNT
American Society for Metals

American Society for Testing and Materials

Ceramic matrix composite 


$\begin{array}{ll}\text { CNT } & \text { Carbon nanotube } \\ \text { CVD } & \text { Chemical vaper deposition } \\ \text { FSP } & \text { Friction stir processing } \\ \text { ISO } & \text { International Organization for Standardization } \\ \text { LCF } & \text { Low cycle fatigue } \\ \text { MMC } & \text { Metal matrix composite } \\ \text { MWCNT/ MWNT } & \text { Multi-walled carbon nanotube } \\ \text { PMC } & \text { Polymer matrix composite } \\ \text { SEM } & \text { Scanning electron microscopy } \\ \text { SWCNT/SWNT } & \text { Single-walled carbon nanotube } \\ \text { UTS } & \text { Ultimate tensile strength } \\ \text { XRD } & \text { X-ray diffraction } \\ \text { YS } & \text { Yield strength }\end{array}$




\section{Introduction}

People are facing increasingly severe problems due to climate change and environment pollution. Transportation systems, especially vehicles, make substantial contributions to these issues. In order to improve the fuel efficiency and reduce the emissions of greenhouse gases such as $\mathrm{CO}_{2}$, one of the most effective methods is to increase the application of light-weight materials in vehicles, such as advanced high strength steel, aluminum, magnesium and composites.

The lightweight materials such as aluminum alloys have many advantages: low density, good formability and ductility. To enhance their strength, aluminum matrix composites reinforced by particles such as carbon nanotube (CNT) have been recently developed.

A number of investigations have been conducted on CNT and CNT reinforced composites since the last decade. Fig. 1.1 shows the numbers of publications on CNT and CNT composites. Almost $1 / 3$ of the publications about CNT are related to CNT composites. Fig. 1.2 demonstrates the numbers of publications on various CNT reinforced metal matrix composites (MMCs). Among different metal matrices, aluminum is the most reported matrix.

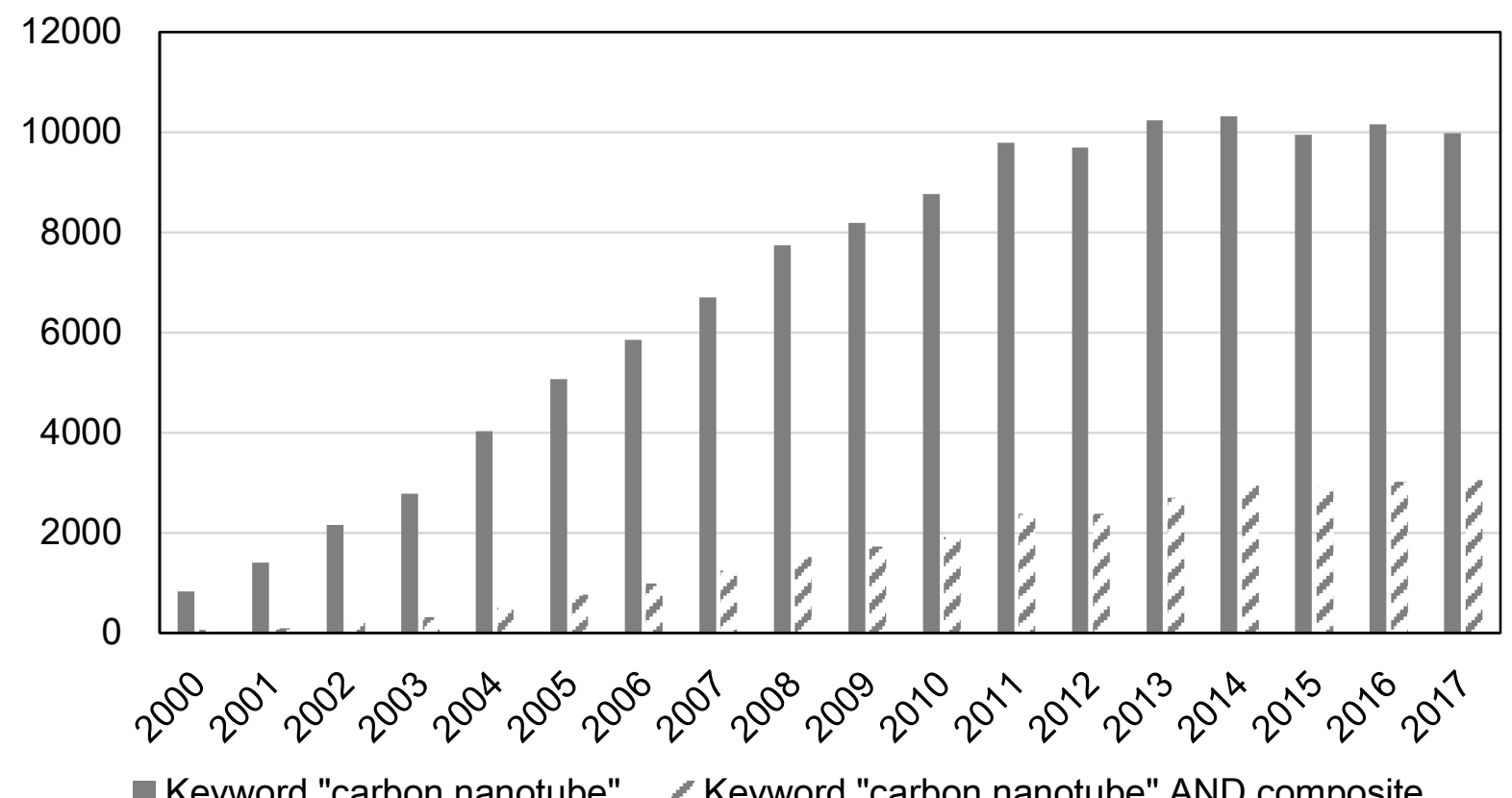

Fig. 1.1 Numbers of publications about CNT and CNT reinforced composite (Source: www.scopus.com) 


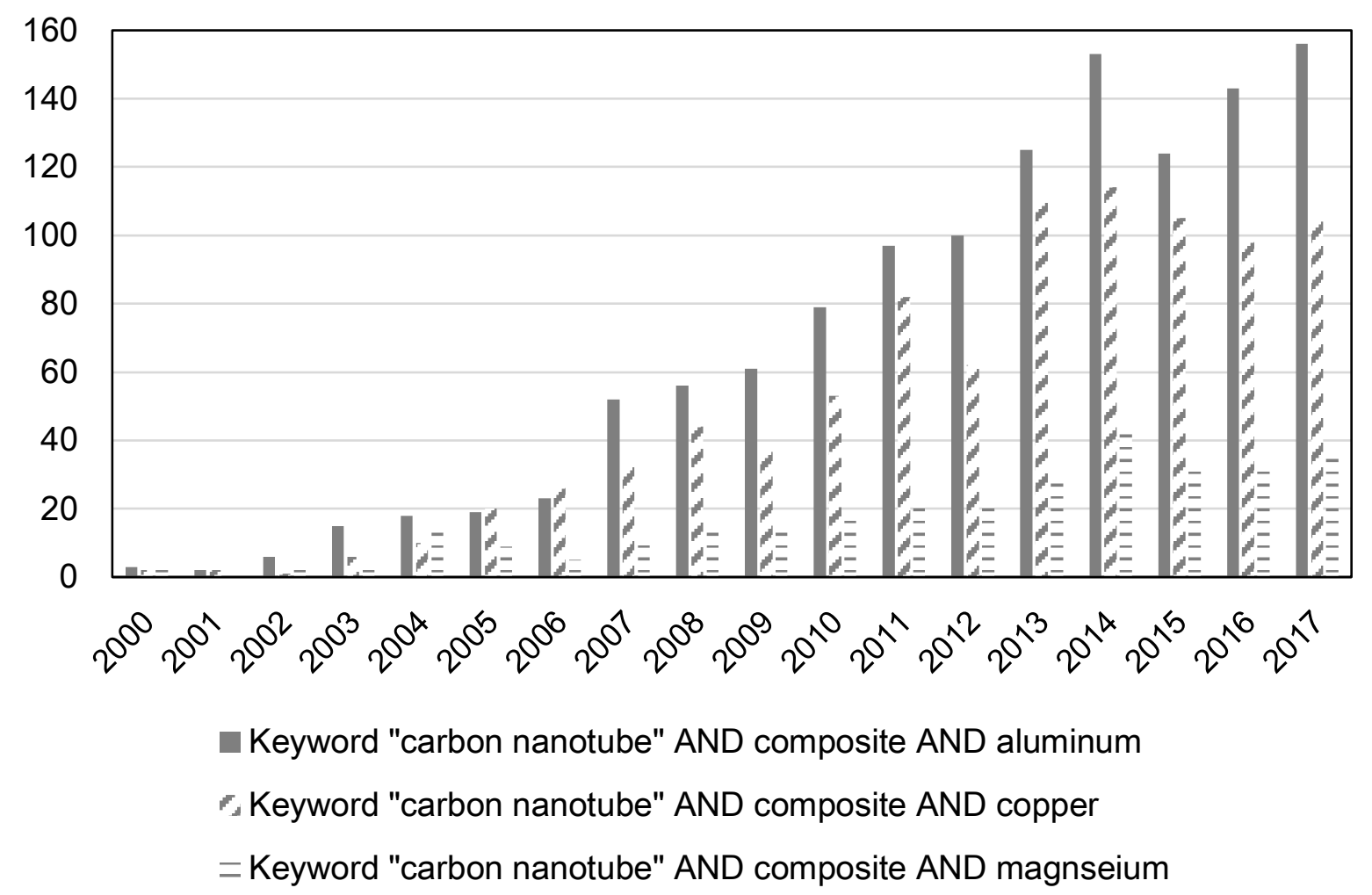

Fig. 1.2 Numbers of publications about different CNT reinforced MMCs (Source: www.scopus.com)

Briefly speaking, the main objective of the current study is to accomplish characterization of the CNT reinforced 6061 aluminum matrix composite in three aspects:

(1) Analyze the microstructure and identify phases in the composite.

(2) Evaluate deformation behavior of the composite by conducting compression tests, tension tests and low cycle fatigue tests.

(3) Summarize strengthening mechanisms of the composite and analyze two mathematical models: prediction model for yield strength and calculation model for Young's modulus.

The novelty of the current research lies in two aspects:

(1) Strain-controlled low cycle fatigue tests were carried out to evaluate fatigue behaviors of the composite, while other researchers mainly used force-controlled fatigue tests. By conducting 
strain-controlled fatigue tests, the deformation behavior with large scale plastic strain and the cyclic stress-strain relationship could be obtained and analyzed.

(2) Two mathematical models were systematically studied. The author put forward a prediction model for yield strength in modified Clyne model format based on four strengthening mechanisms of the composite, and verified the calculation models for Young's modulus by comparing the calculated values to the experimental value.

The structure of the thesis is organized in six parts:

After some brief introduction in Chapter I "Introduction", Chapter II "Literature Review" covers some background information of CNT reinforced aluminum matrix composites, including structures, properties and synthesis methods of CNT, fabrication techniques and strengthening mechanisms of CNT/ Al composites, recent investigations and the prediction models for yield strength. In Chapter III "Materials and Methods", the studied materials and all the experimental methods are introduced. Chapter IV "Results and Discussions" shows the results obtained from the current investigations and a brief discussion. In Chapter V “Calculation Model for Young's Modulus", the calculation models for Young's modulus are discussed, and the calculated values are compared with experimental value. Finally, Chapter VI "Summary and Future Work" presents some conclusions drawn from the current studies and possible future work. 


\section{Literature review}

\subsection{Carbon Nanotube}

\subsubsection{Carbon Nanomaterials}

Carbon nanotube (CNT) was first discovered by Iijima [1] in 1991, and was described as hollow, nano-sized tubes composed of graphite carbon. Carbon nanotube is one of the three most significant carbon nanomaterials, while the other two are fullerene and graphene. In 1985, Kroto et al. [2] first discovered fullerene, also known as C60 or Buckyball. In 2004, Novoselov and Geim et al. [3] extracted graphene from bulk graphite. The discoveries of carbon nanotubes, fullerene and graphene are recognized as the three major milestones in the history of carbon nanomaterials research.

While fullerene has a cage structure and graphene is a flat monolayer of graphite, the carbon nanotube can be visualized as a sheet of graphene rolled into a tube (Fig. 2.1).

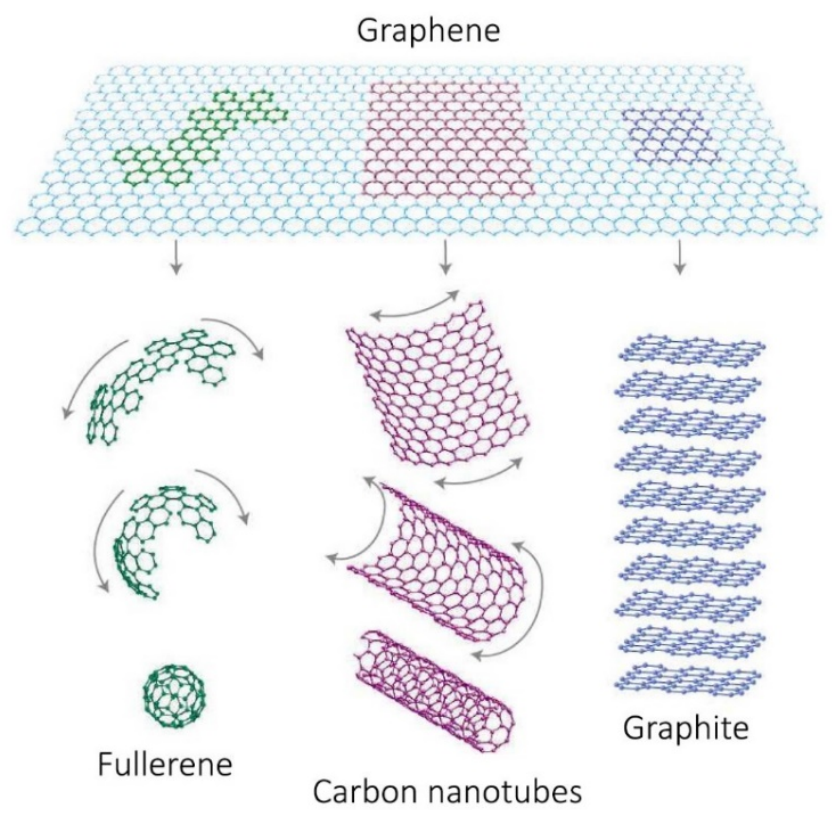

Fig. 2.1 The illustration of relationship among graphene, fullerene, carbon nanotubes and graphite [4] 
Carbon nanotubes can be divided into two categories according to their structures: single-walled carbon nanotube (SWNT/ SWCNT) and multi-walled carbon nanotube (MWNT/ MWCNT), as shown in Fig. 2.2. The carbon nanotube observed in 1991 was actually MWNT. A few years later, Iijima et al. [5] and Bethune et al. [6] independently reported the synthesis of SWNT. MWNT is an array of nanotubes nested like rings of a tree trunk, while SWNT consists of a single graphene sheet seamlessly rolled into a tube. Three different types of SWNT structures can be obtained when rolled along different orientations, including armchair, zigzag and chiral [7] (Fig. 2.3).
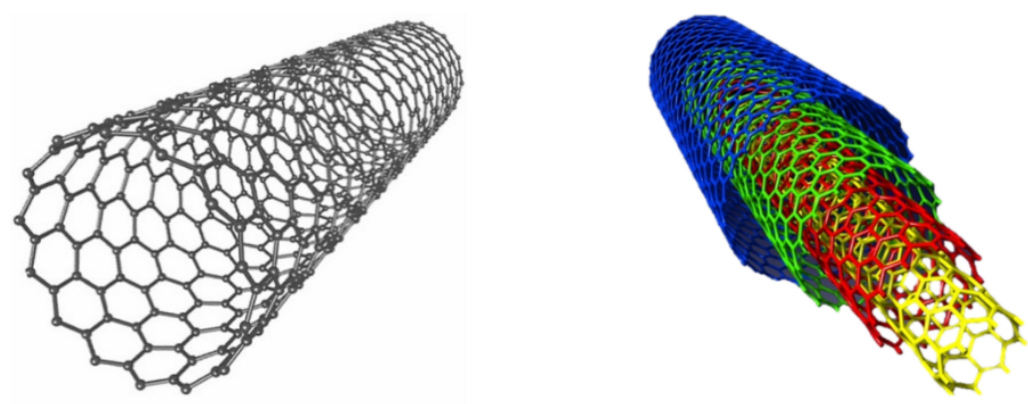

Fig. 2.2 Single-walled and multi-walled carbon nanotubes

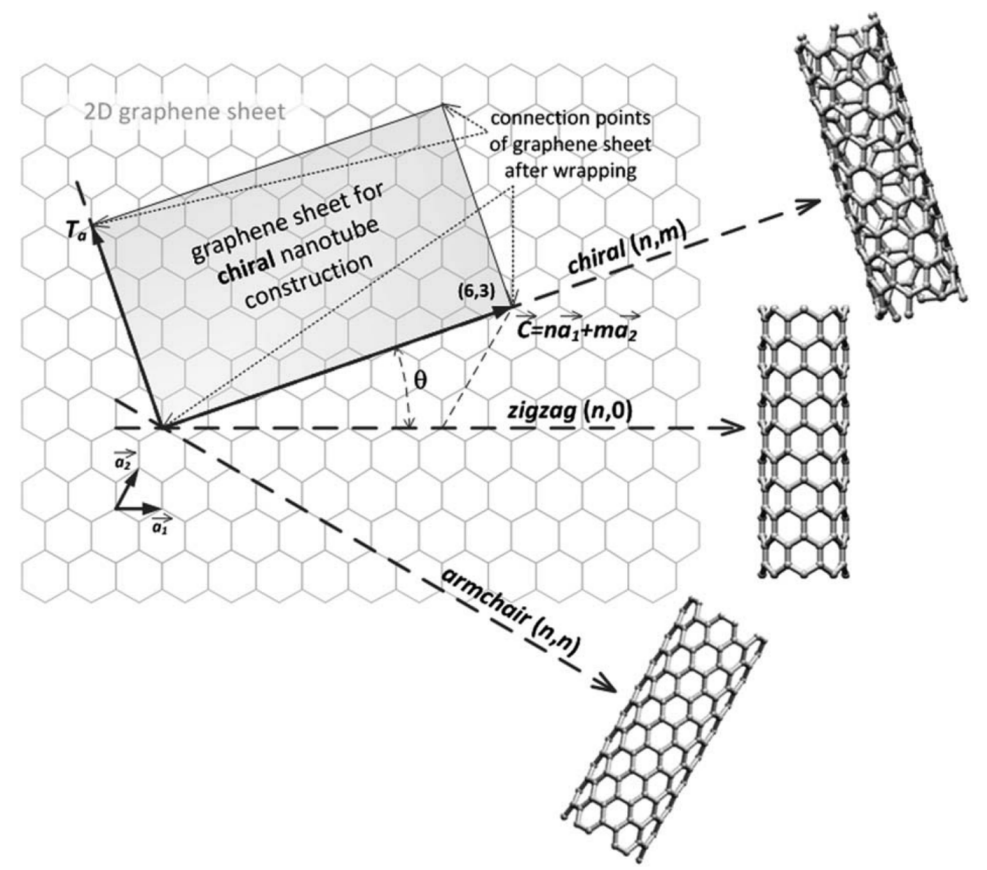

Fig. 2.3 Three types of single-walled carbon nanotube [7] 
Several differences exist between SWNTs and MWNTs. For instance, bulk synthesis of SWNTs is difficult even with a catalyst, and the purity is usually poor; while MWNTs with high purity can be easily produced without a catalyst. In addition, SWNTs are easy to characterize and twist; while they are difficult for MWNTs due to the complex structure [8].

\subsubsection{Properties of Carbon Nanotube}

Carbon nanotubes have remarkable mechanical properties, such as extremely high strength and stiffness. It is reported that SWNTs have an average Young's modulus of $1.25 \mathrm{TPa}$ [8], while MWNTs show an average value of $1.8 \mathrm{TPa}$ [10]. In contrast, steel has a Young's modulus of 210 $\mathrm{GPa}$ and the typical value of aluminum alloy is $70 \mathrm{GPa}$. The tensile strength of carbon nanotubes is up to $150 \mathrm{GPa}$ [11], nearly 5 times that of carbon fibers. Furthermore, carbon nanotubes also have extraordinary electrical and thermal properties [12].

\subsubsection{Applications of Carbon Nanotube}

The first major commercial application of MWNTs was electric conducting components added in polymer. Carbon nanotubes can be used in a wide variety of fields, such as electro-chemical devices, field emission devices, sensors, energy storage and probes for scanning probe microscopy, etc. [13][14]. Carbon nanotubes can be also used as reinforcements in different materials to fabricate composites, including polymer matrix composite (PMC), ceramic matrix composite (CMC) and metal matrix composite (MMC).

\subsubsection{Synthesis of Carbon Nanotube}

Carbon nanotubes can be synthesized by chemical and physical methods. Three major kinds of methods have been developed, namely electric arc discharge, laser ablation and chemical vapor deposition (CVD) [15][16][17].

(1) Electric arc discharge is a type of classic technique. An arc is created between the graphite cathode and anode in this process. By means of a catalyst containing $\mathrm{Co}, \mathrm{Ni}, \mathrm{Fe}$ and $\mathrm{Y}$ powders, carbon nanotubes are condensed on the cathode surface. 
(2) Laser ablation is one of the superior methods to synthesize carbon nanotubes with fine quality and high purity. A high power laser is focused onto the graphite target, and carbon is vaporized from the target at high temperature $\left(1200{ }^{\circ} \mathrm{C}\right)$. The vapors are carried by Helium or Argon gas from the high temperature chamber into a cooled collector positioned downstream. The nanotubes will self-assemble from carbon vapor and condense on the walls of the flow tube.

(3) Chemical vapor deposition (CVD) is now the most commonly used method and is becoming the standard method. Carbon nanotubes are produced through a controlled reaction of the decomposition of a hydrocarbon gas (methane, carbon monoxide or acetylene) on a metal catalyst such as Ni, Fe or Co. The CVD method costs less, and can achieve large-scale production with high purities. However, the properties are inferior to those produced by the former two methods because of the presence of defects.

Both arc discharge and laser ablation need a high temperature environment. Nowadays, these methods have been replaced by CVD techniques at a lower temperature $\left(<800^{\circ} \mathrm{C}\right)$. Furthermore, the orientation, alignment, length, diameter, purity and density of CNTs can be precisely controlled in the CVD method. For example, plasma enhanced CVD (PECVD) can produce aligned arrays of carbon nanotubes with the desired diameter and length [18].

\subsection{Aluminum Alloys and Aluminum Matrix Composites}

\subsubsection{Aluminum Alloys}

Aluminum alloys have a number of advantages, such as low density, good mechanical properties, excellent corrosion resistance, as well as good formability and machinability. Aluminum alloys are widely used in various industrial fields, such as construction, automotive, aerospace and railway transportation. According to the chemical compositions and production methods, they can be classified into two categories: cast aluminum alloys and wrought aluminum alloys. Compared with cast aluminum alloys, wrought aluminum alloys usually have better ductility and fewer inside defects. They can be produced by rolling, extruding and forging, etc.

6XXX series aluminum alloy is the alloy with the principle alloying elements of magnesium and silicon. In spite of the strength being less than as $2 \mathrm{XXX}$ and $7 \mathrm{XXX}$ series alloys, they have better 
extrusion ability and formability. The chemical compositions and typical mechanical properties of some 6XXX series aluminum alloys are shown in Table 2.1 and Table 2.2. Among all the 6XXX alloys, 6061 is the most commonly used one due to its medium strength and excellent formability and extrusion ability.

Table 2.1 Chemical composition of some 6XXX series aluminum alloys [19]

\begin{tabular}{|c|c|c|c|c|c|c|c|c|c|}
\hline Alloy & $\mathrm{Si}$ & $\mathrm{Fe}$ & $\mathrm{Cu}$ & $\mathrm{Mn}$ & $\mathrm{Mg}$ & $\mathrm{Cr}$ & $\mathrm{Zn}$ & $\mathrm{Ti}$ & $\mathrm{Al}$ \\
\hline 6063 & $\begin{array}{c}0.20- \\
0.6\end{array}$ & $\leq 0.35$ & $\leq 0.10$ & $\leq 0.10$ & $\begin{array}{c}0.45- \\
0.9\end{array}$ & $\leq 0.10$ & $\leq 0.10$ & $\leq 0.15$ & Balance \\
\hline 6061 & $\begin{array}{c}0.40- \\
0.8\end{array}$ & $\leq 0.7$ & $\begin{array}{c}0.15- \\
0.40\end{array}$ & $\leq 0.15$ & $0.8-1.2$ & $\begin{array}{c}0.04- \\
0.35\end{array}$ & $\leq 0.25$ & $\leq 0.15$ & Balance \\
\hline 6351 & $0.7-1.3$ & $\leq 0.50$ & $\leq 0.10$ & $\begin{array}{c}0.40- \\
0.8\end{array}$ & $\begin{array}{c}0.40- \\
0.8\end{array}$ & $\leq 0.20$ & $\leq 0.20$ & $\leq 0.15$ & Balance \\
\hline
\end{tabular}

Table 2.2 Typical mechanical properties of some 6XXX series aluminum alloys [19]

\begin{tabular}{ccccc}
\hline \multirow{2}{*}{ Alloy } & $\begin{array}{c}\text { Temper } \\
\text { designation }\end{array}$ & $\begin{array}{c}\text { Yield Strength/ } \\
\mathrm{MPa}\end{array}$ & $\begin{array}{c}\text { Tensile Strength/ } \\
\mathrm{MPa}\end{array}$ & Elongation/ \% \\
\hline \multirow{2}{*}{6063} & $\mathrm{~T} 4$ & 90 & 170 & 22 \\
& $\mathrm{~T} 6$ & 215 & 240 & 12 \\
6061 & $\mathrm{~T} 4$ & 145 & 240 & 22 \\
& $\mathrm{~T} 6$ & 275 & 310 & 12 \\
& $\mathrm{~T} 4$ & 150 & 250 & 20 \\
\hline
\end{tabular}

\subsubsection{Aluminum Matrix Composites}

Aluminum alloy is a widely used matrix for composites. Micron-sized ceramic particles, such as Silicon Carbide $(\mathrm{SiC})$ and Aluminum Oxide $\left(\mathrm{Al}_{2} \mathrm{O}_{3}\right)$ [20], are commonly used as additives in aluminum matrix composites. Some other particles are also used such as Boron (B), Boron Carbide 
$\left(\mathrm{B}_{4} \mathrm{C}\right)$ and Titanium Carbide (TiC) [21]. With the addition of these particles, improvement in strength can be achieved. However, machinability becomes poorer due to the large size and high hardness of the micron-sized reinforcements [22]. Nano-sized reinforcements have been considered as a solution to overcome the machining challenge.

Compared with the micron-sized reinforcements, carbon nanotubes have much better mechanical properties and smaller size, which is beneficial to its properties and machinability. However, it is difficult to achieve perfect dispersion of the CNTs in the aluminum matrix. Furthermore, interfacial chemical reactions between CNTs and aluminum matrix may lower the strength and reduce the efficiency of the reinforcement in nano-composites [23]. Many studies have been conducted to improve the processing and properties of CNT reinforced aluminum matrix composites, but these problems are still unable to be solved completely.

\subsubsection{Applications of CNT/ Al Composites}

At present, CNT reinforced aluminum matrix composites are still in the research phase of development without commercial applications. However, they have potentials in the application of automotive and aerospace industries for manufacturing brake shoes, cylinder liners and aircraft landing gears thanks to their low density, high strength and good wear resistance. They could be also used in sports industry to produce bicycles and rackets [24].

\subsubsection{Fabrication Techniques of CNT/ Al Composites}

During the fabrication process, the integration of CNTs in the matrix must be achieved. This is a critical step because it controls the microstructure, and in turn determines the properties.

Carbon nanotubes are added as reinforcement in aluminum alloy by a variety of processing techniques. The processing methods can be divided into two categories according to the state of raw materials, including liquid state processing and solid state processing [25]. Liquid state processing mainly includes casting and infiltration. Solid state processing is the most widely used method to fabricate CNT reinforced metal matrix composite. The initial materials are processed in the solid state without phase transformation at room temperature. Various processing methods 
have been developed, including casting, powder metallurgy, thermal spraying and friction stir processing (FSP).

\section{(1) Casting}

Casting, as a process of melting and solidification, is the most conventional processing technique for making metal matrix composites (MMCs). It has also been utilized to produce CNT reinforced MMCs. Several methods have been developed, such as stir casting, die casting, and squeeze casting [26]. Due to the low cost and short processing time, casting is fit for mass production. However, it has some disadvantages. The process may cause damage to CNTs, and the suspended CNTs tend to form clusters due to surface tension.

\section{(2) Powder metallurgy}

Many studies on Al/ CNT composites have been carried out using the powder metallurgy method, such as spark plasma sintering (SPS) and ball milling.

Spark plasma sintering (SPS)

Spark plasma sintering (SPS) is a variation of hot pressing in which the heat is provided by a pulsed DC current passing through the die or the powders during consolidation. Spark discharges at the particle interfaces produce rapid heating, enhancing the sintering rate. SPS is an attractive process for fabricating CNT/ Al composites because of its short time processing, which is beneficial to restricting the reactions in the interfacial area [27]. However, there are also limitations on the product geometry and expensive equipment is required.

\section{Ball milling}

The high-energy ball milling is an efficient method to promote CNT dispersion into aluminum powders [28]. Materials are ground into extremely fine powders in high-energy ball milling. High pressure is generated by repeated collision between balls [29]. The grinding action results in effective dispersion of CNTs in the aluminum matrix by breaking up the entangled CNTs. In the 
meantime, it also brings some adverse effect. It would contaminate the powders and cause severe damage to the CNTs because of its high-energy input and the prolonged treatment [30].

\section{(3) Thermal spraying}

Thermal spraying can be described as the spraying of molten or semi-molten particles onto a substrate to form a coating/ deposit by means of impact and solidification [24]. According to the heat source, different methods can be used in thermal spray processes such as plasma spraying [31], high velocity oxy-fuel (HVOF) spraying [32] or cold spraying [33]. The plasma spraying is the one commonly used. It can produce CNT/ Al powders easily, but the CNT clusters also appear at high CNT concentration.

\section{(4) Friction stir processing (FSP)}

Friction stir processing (FSP) is a metal working technique based on the basic principles of friction stir welding (FSW) [34]. A rotating tool is used with a specially designed pin and a shoulder to a single piece of material. The tool moves along a certain desired path through the workpiece by revolving in a stirring motion. FSP can achieve properties changes in the material via severe and localized plastic deformation. FSP has been demonstrated to be an effective method of incorporating reinforcing nano-sized particles into the metal matrix, and homogenizing the microstructure of heterogeneous materials.

\subsubsection{Challenges in Bulk Production}

During the fabrication process, CNT can easily suffer structural damage. CNTs tend to agglomerate together due to their large aspect ratio and strong Van der Waals force [35]. Furthermore, the poor wetting properties between aluminum and CNT make the CNT distribution problem even worse. The CNT clustering would deteriorate the physical and mechanical properties of the composites [24].

The problems that researchers have to solve include how to cause minimum structural damage to CNT, maintain the chemical and structural stability of CNT, keep the chemical reactions between 
CNT and aluminum matrix to a reasonable level, as well as minimize the agglomeration and clustering of CNT. Various measures have been taken to overcome these challenges, in order to acquire better structural stability of CNT, uniform dispersion of CNT, and a stronger interfacial bonding between CNT and aluminum matrix. In addition, researchers have also tried to obtain a better alignment of CNT.

\subsection{Strengthening Mechanisms}

The uniform dispersion of carbon nanotubes in the aluminum alloy matrix has an outstanding strengthening effect on the mechanical properties. It is widely accepted that there are mainly four strengthening mechanisms in the CNT/ Al composites, namely load transfer, thermal mismatch, Orowan looping and grain refinement strengthening [36]. These mechanisms are generally thought to exist and work simultaneously.

\section{(1) Load transfer}

The basis of load transfer theory is the shear lag model suggested by Kelly and Tyson [37] for fiber reinforced composites. Interfacial bonding can be generated in the composite, and the load could be transferred from the matrix to the reinforcement because of the interfacial shear stress. The formation of $\mathrm{Al}_{4} \mathrm{C}_{3}$ is necessary for effective load transfer between the reinforcement and matrix [38].

\section{(2) Thermal mismatch}

Carbon nanotubes have a coefficient of thermal expansion of up to $1 \times 10^{-6} \mathrm{~K}^{-1}$, while aluminum exhibits a much greater coefficient of thermal expansion of $23.6 \times 10^{-6} \mathrm{~K}^{-1}$ [39]. There is an apparent mismatch of the thermal expansion coefficient between the aluminum matrix and the carbon nanotubes, causing the "prismatic punching" of dislocations at the interface that leading to work hardening of the matrix. The dislocation density becomes higher, which in turn would contribute to further strengthening.

\section{(3) Orowan looping}


The motion of the dislocation is inhibited by nano-sized carbon nanotubes, leading to bending of these dislocations between the carbon nanotubes. This produces a back stress [40], which prevents further dislocation movement and results in an increase of strength. The Orowan looping in aluminum alloys is presented as the strength improvement caused by fine precipitates.

\section{(4) Grain refinement strengthening}

Grain refinement is a very significant mechanism for strengthening and has been often overlooked by many researchers. Carbon nanotubes act as barriers for the growth of aluminum grains, leading to a significant reduction of grain size. It has been reported by a number of researchers [41][42][43] that the grain size of $\mathrm{CNT} / \mathrm{Al}$ composites is much smaller than that of aluminum alloy. According to the Hall-Petch effect, the grain boundaries will cause misorientation between neighboring grains [42] and block the dislocation movement, which will improve the strength.

\subsection{Recent Research Work on CNT/ Al Composites}

The CNT/ Al composites have been widely studied by researchers all around the world in recent years. The research topics cover the fabrication, processing, microstructure and mechanical properties, etc. Furthermore, the researchers conducted experiments to explore the influences of different factors on properties, such as carbon nanotubes content, diameter and heat treatment, etc.

\subsubsection{Effect of CNT Content}

The first major factors taken into consideration affecting the mechanical properties of CNT/ Al composites is the content of carbon nanotubes. Many previous studies have reported that the content of carbon nanotubes has a significant effect on mechanical properties, including hardness, yield strength, tensile strength and Young's modulus of the composite.

Srivastava et al. [44] reported that micro hardness went up as the content of CNT increased. Park et al. [45] studied the composite with the CNT content from 0 to $0.5 \mathrm{wt} . \%$. Within this range, the strength of the composite had a significant improvement as the increase of CNT content. It was reported by Pérez-Bustamante et al. [46] and Liao et al. [47] that the CNT content had a positive 
effect when the CNT content was no more than 2 wt.\%, as shown in Fig. 2.4. Esawi et al. [48] stated that the strength were enhanced as the CNT content increased within a specific range. The best result was obtained when the content of CNT was $2 \mathrm{wt} . \%$, while further addition of CNT caused a deterioration in strength (Fig. 2.5). The same conclusion was drawn by Carvalho et al. [49] and Liao et al. [50], as shown in Fig. 2.6, Fig. 2.7, and Table 2.3.

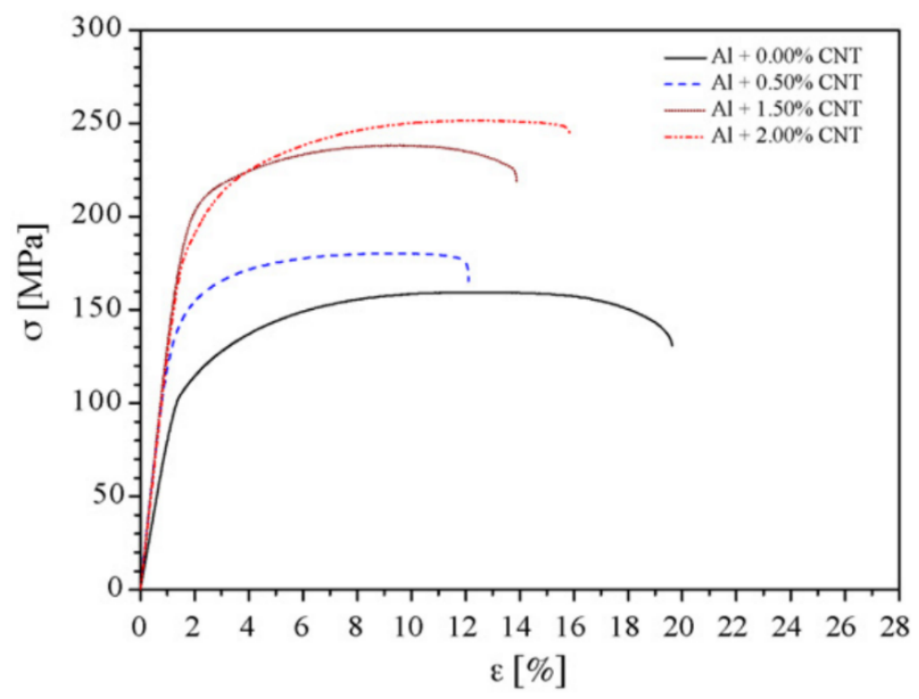

Fig. 2.4 Stress-strain curves of CNT/ Al composite with CNT content from 0 to 2 wt.\% [46]

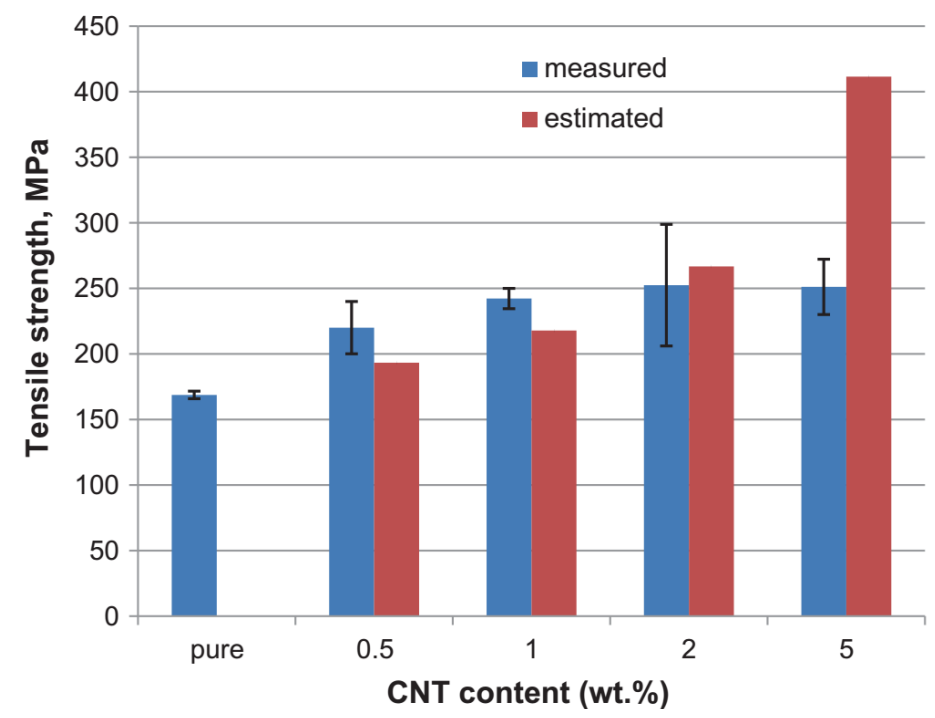

Fig. 2.5 Tensile strength of the composites with CNT content from 0 to $5 \mathrm{wt}$ \% [48] 


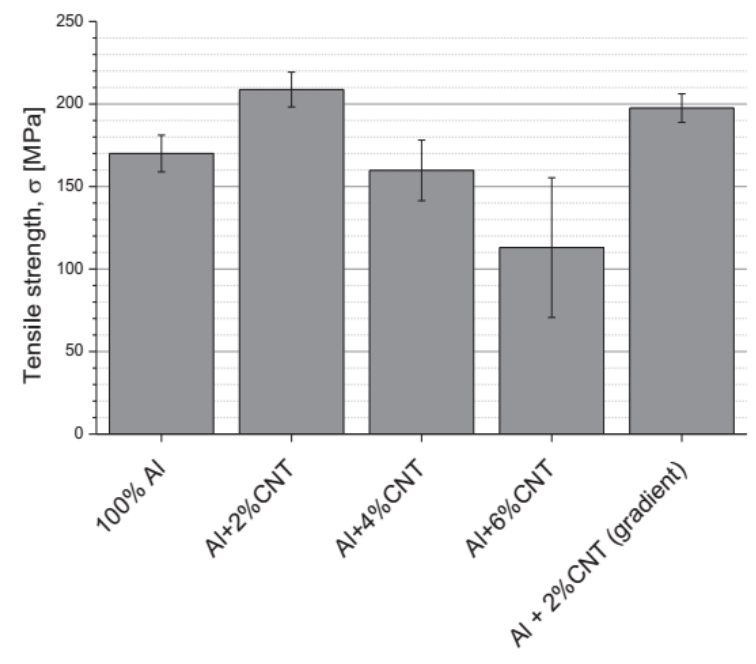

Fig. 2.6 Tensile strength of $\mathrm{CNT} / \mathrm{Al}$ composite with different content of CNT [49]

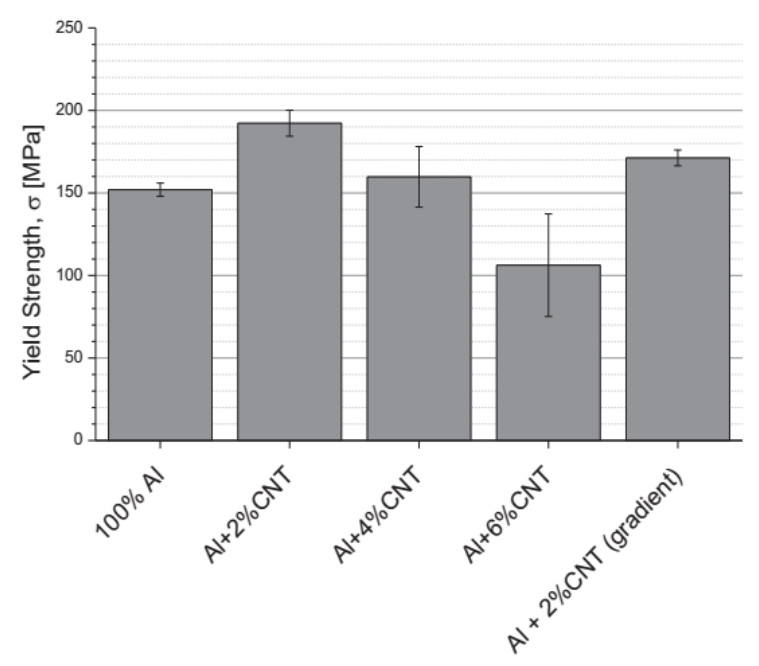

Fig. 2.7 Yield strength of CNT/ Al composite with different content of CNT [49]

Table 2.3 Mechanical properties of $\mathrm{Al}$ and $\mathrm{CNT} / \mathrm{Al}$ composites [50]

\begin{tabular}{|c|c|c|c|c|c|c|}
\hline \multirow[b]{2}{*}{ Materials } & \multicolumn{3}{|c|}{ Density } & \multirow{2}{*}{$\begin{array}{c}\text { Vicker } \\
\text { hardness } \\
{[\mathrm{HV}]}\end{array}$} & \multirow{2}{*}{$\begin{array}{c}\sigma_{\mathrm{UTS}} \\
{[\mathrm{MPa}]}\end{array}$} & \multirow{2}{*}{$\begin{array}{c}\text { Ductility } \\
{[\%]}\end{array}$} \\
\hline & $\begin{array}{c}\text { Theoretical } \\
{\left[\mathrm{g} / \mathrm{cm}^{3}\right]}\end{array}$ & $\begin{array}{c}\text { Experimental } \\
{\left[\mathrm{g} / \mathrm{cm}^{3}\right]}\end{array}$ & $\begin{array}{c}\text { Relative } \\
{[\%]}\end{array}$ & & & \\
\hline Al-0.0 wt.\% MWCNT & 2.70 & 2.67 & 98.93 & 40.00 & 136 & 28 \\
\hline Al-0.5 wt.\% MWCNT & 2.69 & 2.70 & 100.34 & 60.10 & $180(\uparrow 32 \%)$ & 21 \\
\hline Al-1.0 wt.\% MWCNT & 2.68 & 2.69 & 100.31 & 67.39 & $259(\uparrow 90 \%)$ & 21 \\
\hline Al-2.0 wt.\% MWCNT & 2.66 & 2.72 & 101.94 & 81.00 & $300(\uparrow 120 \%)$ & 18 \\
\hline Al-3.0 wt.\% MWCNT & 2.65 & 2.68 & 101.39 & 103.78 & $247(\uparrow 82 \%)$ & 15 \\
\hline
\end{tabular}

Note: Arrow $(\uparrow)$ : increased percentage in ultimate tensile strength compared with monolithic Al.

This can be explained by the dispersion of CNTs. The agglomeration of carbon nanotubes is a major factor affecting mechanical properties. This problem is difficult to solve because of the size difference between carbon nanotubes particles and the metal powders as well as their attractive Van der Waals interactions [51]. More CNT clustering happens when the content of CNT is larger than 2 wt.\%, causing a deterioration of strength. 


\subsubsection{Effect of CNT Diameter}

Esawi et al. [54] investigated the effect of CNT diameter on the mechanical properties of CNT/ Al composites fabricated by high-energy ball milling. It was found that large diameter CNTs were dispersed more easily into the aluminum matrix than the smaller diameter CNTs because the smaller diameter CNTs had a stronger tendency to agglomerate. As shown in Fig. 2.8, the $40 \mathrm{~nm}$ CNTs provide more strengthening effect than the $140 \mathrm{~nm} \mathrm{CNTs} \mathrm{up} \mathrm{to} \mathrm{a} \mathrm{CNT} \mathrm{content} \mathrm{of} 1.5 \mathrm{wt} . \%$, and it is reversed at $2 \mathrm{wt} . \%$ and $5 \mathrm{wt} . \%$ because the CNTs with larger diameter provides additional strengthening.

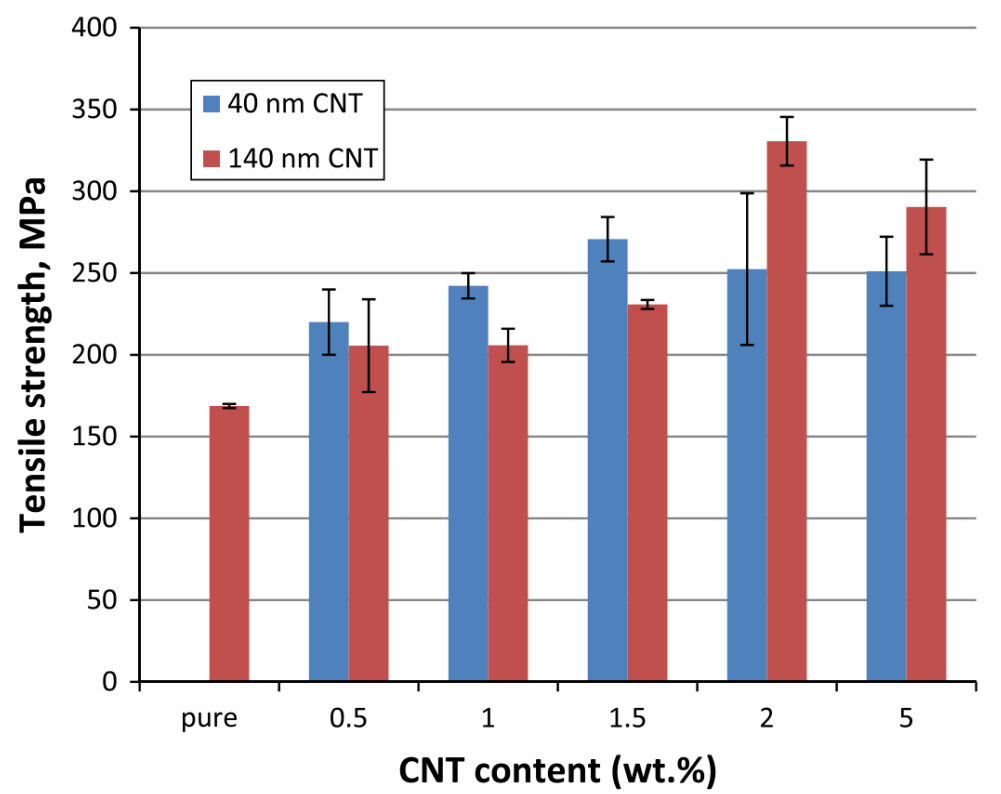

Fig. 2.8 Tensile strength of composites with CNT of different diameters [54]

\subsubsection{Effect of Fabrication Processing and Heat Treatment}

There are some other factors affecting the microstructure and mechanical properties, such as the number of passes in friction stir processing (FSP), ball milling condition, and heat treatment.

Several researchers studied the influence of some key parameters of FSP. Liu et al. found that the CNTs were cut and shortened after FSP due to the shear stress, and the length of CNTs decreased as the number of FSP passes increased [55]. He noticed that FSP could reduce the CNT clusters and make the CNTs better dispersed into the matrix. The distribution homogenization was improved as the number of FSP pass increased. Therefore, better CNTs dispersion was achieved 
in $\mathrm{CNT} / \mathrm{Al}$ composite with 4-pass FSP than that with 1-pass [56]. Similarly, Izadi et al. [57] found that the distribution of CNTs in the matrix after 3-pass was better than that after 2-pass FSP.

Liu et al. [29], Choi et al. [30], Esawi et al. [58] carried out research on the influence of ball milling condition. Liu et al. [29] found that ball milling improved the dispersion of CNTs in the aluminum matrix. The best interfacial bonding between CNTs and aluminum matrix was obtained with $6 \mathrm{~h}$ ball milling time. When the ball milling time was longer $(8-12 \mathrm{~h})$, the strength was no longer improved but the CNTs were severely damaged. Similar conclusions were drawn by Choi et al. [30]. In contrast, Esawi et al. [58] found the mechanical properties were better with the ball milling time of $3 \mathrm{~h}$ than $6 \mathrm{~h}$ because the cold working effect of the ball milling process were reduced.

Some researchers studied the effect of heat treatment on the mechanical properties of CNT/ Al composites since many aluminum alloys are heat-treatable. Zhang et al. [59] studied the CNT/ $\mathrm{SiC} / \mathrm{Al} 6061$ hybrid composite fabricated by squeeze casting, and found that the heat treatment improved the bond strength between $\mathrm{CNT}$, $\mathrm{SiC}$ and $\mathrm{Al}$, which enhanced the strength of the composite. However, Zhao et al. [60] investigated the CNT/ Al 6061 composite made by FSP and found that the T6 heat treatment strengthening effect was insignificant.

\subsubsection{Research on Fatigue Properties}

Several researchers have conducted investigations on fatigue properties of CNT/ Al composites. Force-controlled fatigue tests were mainly used in current studies. Carvalho et al. [36] carried out the force-controlled tension-tension type fatigue tests with the stress ratio $\mathrm{R}=0.1$ and the frequency of $16 \mathrm{~Hz}$. The results are shown as Fig. 2.9. It can be seen from Fig. 2.9 that under identical loading conditions, the $2 \mathrm{wt} \% \mathrm{CNT} / \mathrm{AlSi}$ composite has a longer fatigue life than the unreinforced AlSi alloy. This can be attributed to the strengthening of the interfaces and the crack path deflection due to the CNTs at the interfaces. 


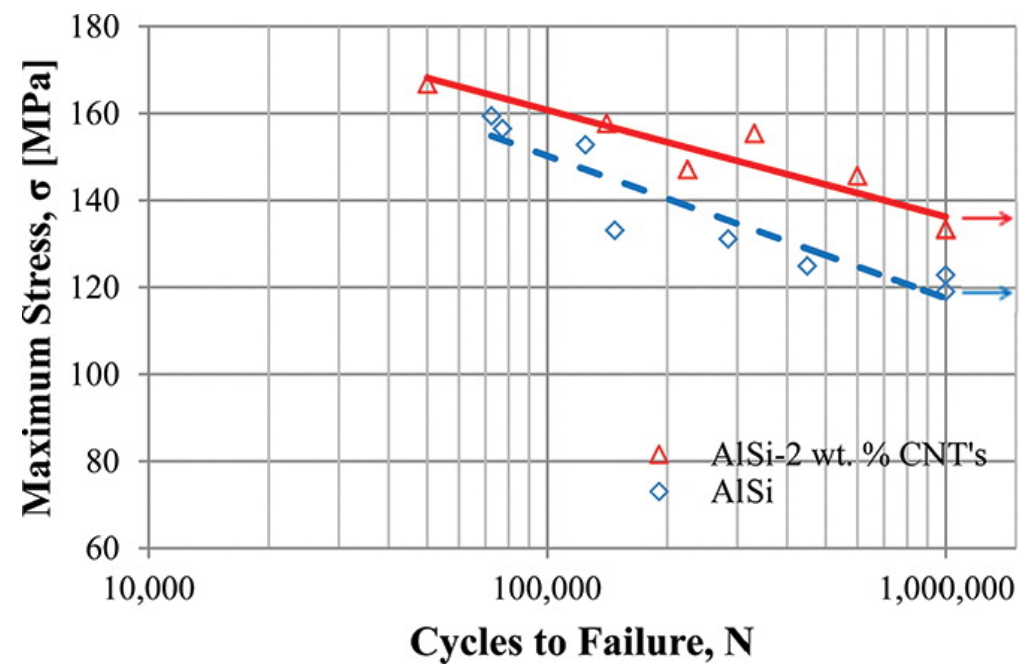

Fig. 2.9 Maximum stresses versus number of cycles to failure for AlSi alloy and AlSi-2 wt.\% CNT composite [36]

Liao et al. [61] conducted force-controlled fatigue tests under tension-tension load, with the stress ratio $\mathrm{R}=0.1$ and frequency of $5 \mathrm{~Hz}$. The composites with $\mathrm{CNT}$ have longer fatigue lives in most of his experiments (Fig. 2.10). It is because the addition of CNT improves the material's damage resistance under cyclic loading.

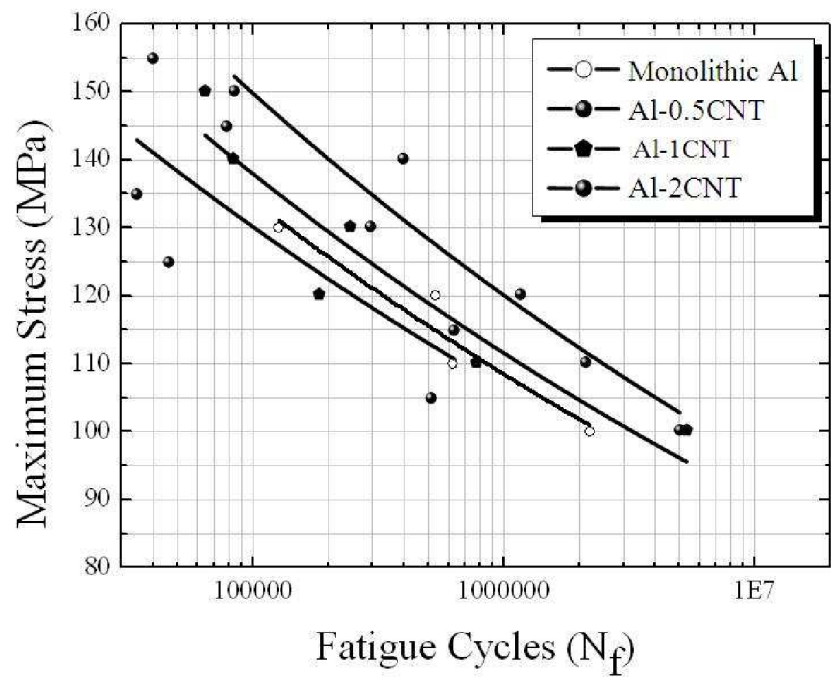

Fig. 2.10 Stress-life (S-N) diagrams for CNT/ Al composites [61] 
Shin et al. [62] studied the fatigue properties of Al 2024 alloy reinforced with multi-walled carbon nanotubes. The force-controlled tension-compression fatigue tests were conducted, with the stress ratio $\mathrm{R}=-0.5$ and a frequency of $5 \mathrm{~Hz}$. It was found that the addition of MWCNT resulted in much higher maximum stresses than 2024 aluminum alloy, and the maximum stress increased as the MWCNT content increased. (Fig. 2.11)

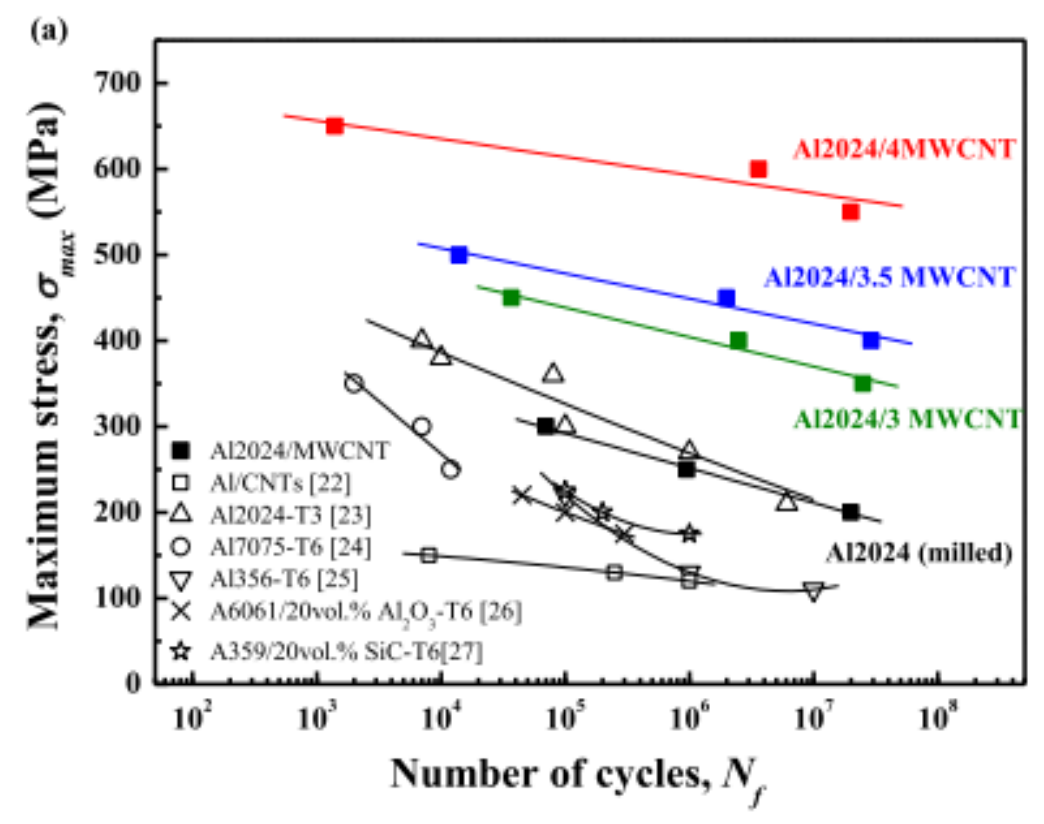

Fig. 2.11 Fatigue life of MWCNT/ Al 2024 composites [62]

\subsubsection{Research on Corrosion Properties}

Not many researchers have conducted investigations on the corrosion properties of CNT/ Al composite. Saravanan et al. [63] studied the corrosion behavior of CNT reinforced 4032 alloy. Kumar et al. [64] did research on CNT reinforced 5083 alloy. It was reported by both groups of researchers that the composites had a better corrosion resistance than the base alloys. The reason is because CNTs slow down the formation of the oxide layer by keeping the oxide layer detached from the alloy. Therefore, the corrosion rate is reduced, leading to an improvement of the corrosion properties. 


\subsection{Prediction Models for Yield Strength}

Several approaches have been developed to predict the yield strength of metal matrix composites (MMCs), and more recently metal matrix nano-composites (MMNCs). Three models have been proposed: arithmetic summation, compounding and quadratic summation. All the strengthening factors including load transfer, thermal mismatch, Orowan looping and grain refinement strengthening should be taken into consideration in the prediction model for yield strength. Because of the lack of detailed data, all the models will be generally discussed according to the equation expression without calculation.

\subsubsection{Arithmetic Summation Method}

The arithmetic summation method is the first developed model to predict the yield strength of MMCs [65]. Based on this method, the yield strength of the composite is the sum of improvements plus the inherent yield strength of the matrix itself, as shown as Eq. (1) and Eq. (2). It assumes that different mechanisms are simultaneously present and make contributions independently without influencing each other [66]. However, this model has been shown that the prediction usually had a higher value in yield strength compared with the experimental value [67]. Therefore, it is not generally applied in many cases.

$$
\begin{aligned}
& \sigma_{y}=\sigma_{y m}+\Delta \sigma \\
& \Delta \sigma_{C}=\Delta \sigma_{L . T .}+\Delta \sigma_{T . M .}+\Delta \sigma_{\text {orowan }}+\Delta \sigma_{G . R .}+\Delta \sigma_{E . M .} .
\end{aligned}
$$

$\Delta \sigma$ stands for the improvement of yield strength caused by certain factors as follows:
L.T Load Transfer

T.M. Thermal Mismatch

Orowan Orowan looping

G.R. Grain Refinement (Hall-Petch effect)

E.M. Elastic Modulus Mismatch 


\subsubsection{Compounding Method}

The compounding method is based on the form of equation that Ramakrishan [68] proposed to predict the yield strength of particle reinforced MMCs. The equation is expressed in Eq. (3).

$$
\sigma_{y c}=\sigma_{y m}\left(1+f_{L . T .}\right)\left(1+f_{T . M .}\right)
$$

This method was further developed by several researchers by adding more influencing factors, including Zhang and Chen [69] (Eq. (4)), and Mirza and Chen [70] (Eq. (5)) [71] (Eq. (6)).

\section{(1) Zhang and Chen}

$$
\sigma_{y c}=\sigma_{y m}\left(1+f_{\text {L.T. }}\right)\left(1+f_{\text {T.M. }}\right)\left(1+f_{\text {orowan }}\right)
$$

\section{(2) Mirza and Chen}

$$
\begin{aligned}
& \sigma_{y c}=\sigma_{y m}\left(1+f_{\text {L.T. }}\right)\left(1+f_{\text {T.M. }}\right)\left(1+f_{\text {orowan }}\right)\left(1-f_{\text {porosity }}\right) \\
& \sigma_{y c}=\sigma_{y m}\left(1+f_{\text {L.T. }}\right)\left(1+f_{\text {T.M. }}\right)\left(1+f_{\text {orowan }}\right)\left(1+f_{\text {Hall-Petch-Zener }}\right)\left(1-f_{\text {porosity }}\right)
\end{aligned}
$$

Where,

$f_{\text {porosity }}$ is the deterioration factor associated with the presence of porosity in metal matrix nanocomposites.

In this method, the increase in strength due to all the strengthening mechanisms can be treated mathematically by multiplying the matrix yield stress by an improvement factor. There are also equations to calculate each influencing factor respectively.

This type of model has two disadvantages. It takes all the influencing factors into consideration repeatedly, which might exaggerate the influence of some factors. In addition, by multiplication, the deviations of each factors are superimposed. That means the results might have large deviations even if there are only tiny errors in the calculation of single factor. 


\subsubsection{Quadratic Summation Method}

\section{(1) Clyne model}

The quadratic summation method is originally put forward by Clyne and his co-workers [72] for the composites strengthened by micron-sized reinforcements. It is assumed in this method that individual strengthening mechanism interacts with each other. Each strengthening factor makes contributions unevenly, and the improvement of the yield strength can be expressed as the Eq. (7) and Eq. (8).

$$
\begin{aligned}
& \sigma_{y c}=\sigma_{y m}+\Delta \sigma \\
& \Delta \sigma=\sqrt{\left(\Delta \sigma_{L . T .}\right)^{2}+\left(\Delta \sigma_{T . M .}\right)^{2}}
\end{aligned}
$$

When the size of reinforcement in the composite is on the micron scale, the Clyne model works well. However, there could be significant changes of the properties of composites when the size of microstructure approaches nano-scale. Therefore, the Clyne model cannot be applied directly to nanocomposites. More strengthening mechanisms should be taken into consideration for the nanocomposite, and the modification of Clyne model can be written in a similar expression.

\section{(2) Modification of Clyne model}

There are several different versions of the modified Clyne model with different factors included, such as Modified Clyne model proposed by Sanaty-Zadeh [66]:

$$
\Delta \sigma=\sqrt{\left(\Delta \sigma_{L . T}\right)^{2}+\left(\Delta \sigma_{\text {orowan }}\right)^{2}+\left(\Delta \sigma_{\text {Hall-Petch }}\right)^{2}+\left(\Delta \sigma_{E . M .}\right)^{2}+\left(\Delta \sigma_{T . M .}\right)^{2}+\left(\Delta \sigma_{W . H .}\right)^{2}}
$$

Where,

$\Delta \sigma_{W . H .}$ is the contribution caused by work hardening

The author also pointed out that the work-hardening effect during extrusion or pressing was not significant for matrices with fine grains and therefore can be neglected. If the work-hardening effect is ignored, the equation can be described as Eq. (10), which is the same as the model put forward by Kim et al. [67]. 


$$
\Delta \sigma=\sqrt{\left(\Delta \sigma_{\text {Hall-Petch }}\right)^{2}+\left(\Delta \sigma_{\text {Orowan }}\right)^{2}+\left(\Delta \sigma_{T . M .}\right)^{2}+\left(\Delta \sigma_{E . M}\right)^{2}+\left(\Delta \sigma_{L . T .}\right)^{2}}
$$

One of the latest modified model was proposed by Mokdad et al. [42], expressed as Eq. (11).

$$
\Delta \sigma=\sqrt{\left(\Delta \sigma_{L T}\right)^{2}+\left(\Delta \sigma_{T M}\right)^{2}+\left(\Delta \sigma_{\text {orowan }}\right)^{2}+\left(\Delta \sigma_{\text {Hall-Petch-Zener }}\right)^{2}}
$$

Where,

$\Delta \sigma_{\text {Hall-Petch-Zener }}$ is the contribution made by Hall-Petch effect as well as the co-existing Zener drag effect.

\subsubsection{Comparison and Discussion}

There is no general agreement on which model best presents the yield prediction model concerning the composite deformation behavior. However, it is reported by several studies that the quadratic method exhibits the best match with experimental data. By comparing and analyzing different models, the author considers the modified Clyne model works best to predict the yield strength of CNT reinforced aluminum matrix composite, and the expression is shown in Eq. (12).

$$
\Delta \sigma=\sqrt{\left(\Delta \sigma_{L . T .}\right)^{2}+\left(\Delta \sigma_{T . M .}\right)^{2}+\left(\Delta \sigma_{\text {orowan }}\right)^{2}+\left(\Delta \sigma_{\text {Hall-Petch }}\right)^{2}}
$$




\section{Materials and Methods}

\subsection{Materials}

The materials used in this research consisted of $2.0 \mathrm{wt} . \% \mathrm{CNT}$ and 6061 aluminum alloy (Al$1.1 \mathrm{Mg}-0.56 \mathrm{Si}-0.2 \mathrm{Cu}$, wt.\%). All specimens were provided by the Institute of Metal Research, Chinese Academy of Sciences. The as-received CNT/ Al composites were fabricated by a combination of powder metallurgy and friction stir processing (FSP). The 6061 Al powder particles had a spherical shape with an average diameter of $10 \mu \mathrm{m}$. The CNT (purity 95-98\%) were synthesized by chemical vapor deposition (CVD) and had entangled morphologies with an outer diameter of $20-40 \mathrm{~nm}$ and a length of $5 \mu \mathrm{m}$.

CNTs were mixed with the $6061 \mathrm{Al}$ powders in a mechanical mixer at $50 \mathrm{rpm}$ for $8 \mathrm{~h}$ with a ball to powder ratio of 1:1 by volume (Fig. 3.1). The mixed powders were first cold-compacted in a die and hot-pressed into cylindrical billets at $580{ }^{\circ} \mathrm{C}$ in a vacuum environment. The billets were then forged into disk plates. Then they were subjected to 4-pass in situ FSP at a tool rotation rate of $1200 \mathrm{rpm}$ and a moving speed of $100 \mathrm{~mm} / \mathrm{min}$. The tool has a concave shoulder with a diameter of $20 \mathrm{~mm}$, as well as a threaded cylindrical pin $6 \mathrm{~mm}$ in diameter and $4.2 \mathrm{~mm}$ in length, as shown in Fig. 3.2.

The composites were heated at $530{ }^{\circ} \mathrm{C}$ for $2 \mathrm{~h}$ to get a solid solution heat treatment and quenched in water rapidly. Then they were artificially aged at $200{ }^{\circ} \mathrm{C}$ for $12 \mathrm{~h}$ to get a $\mathrm{T} 6$ temper condition.

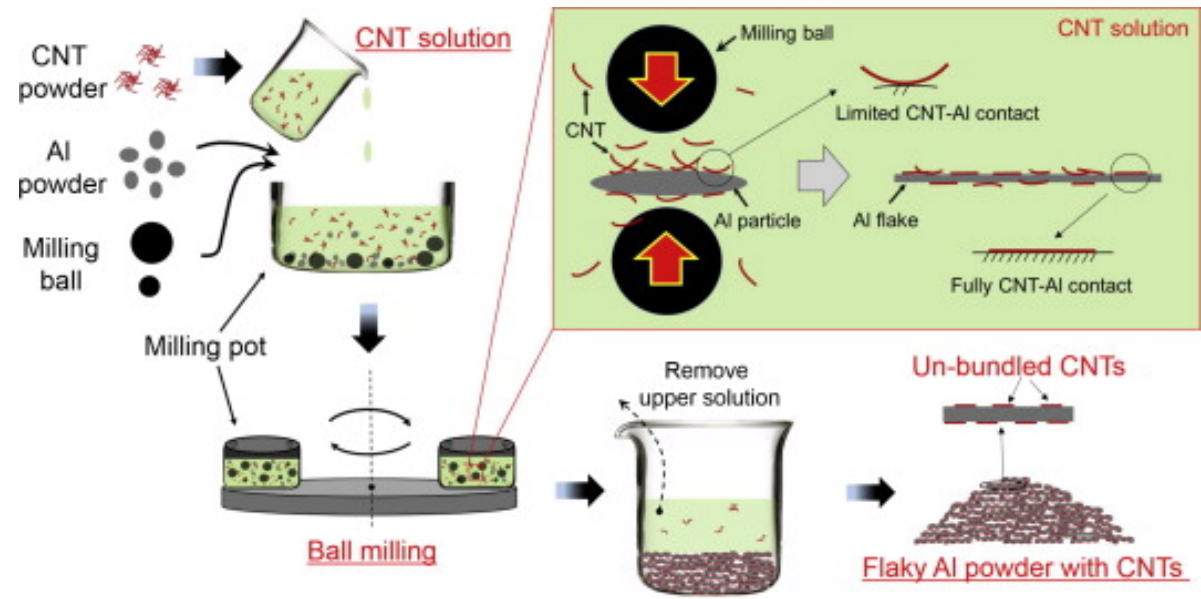

Fig. 3.1 Powder metallurgy process to fabricate the material used in the current research [73] 
(a)

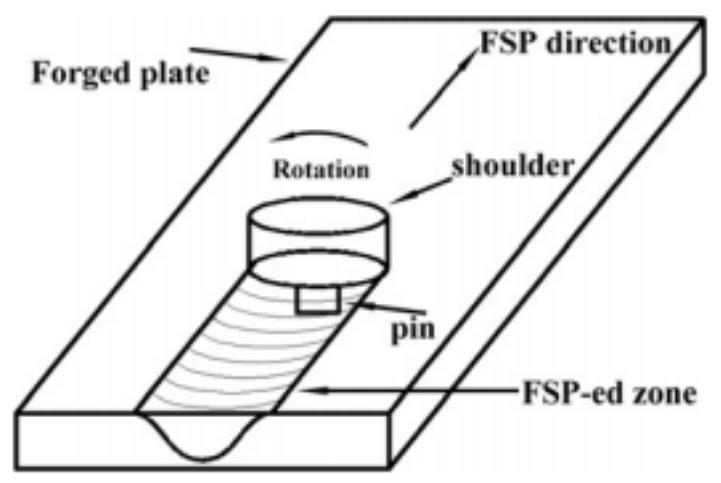

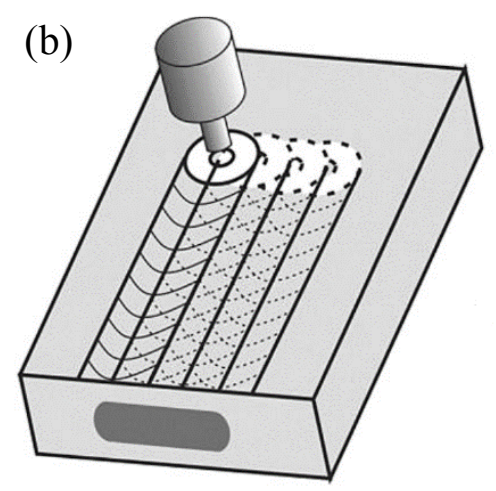

Fig. 3.2 Demonstration of FSP and multi-pass FSP (a) FSP [56], (b) multi-pass FSP [74]

\subsection{Experimental Methods}

\subsubsection{Optical Microscopy}

The optical microscopy test was carried out using an optical microscope (Nikon EPIPHOT) equipped with Clemex quantitative image analysis software. Microstructures were observed from two directions: parallel to the FSP direction and perpendicular to the FSP direction. Standard metallographic specimen preparation techniques including mounting, grinding and polishing were used following the requirements from the ASTM standard E3 - 11 (2017). To acquire the etched specimen for microscopic examination, the etchant Keller's reagent containing 1\% hydrofluoric acid $(\mathrm{HF}), 1.5 \%$ hydrochloric acid $(\mathrm{HCl})$ and $2.5 \%$ nitric acid $\left(\mathrm{HNO}_{3}\right)$ in volume fraction was used, in accordance with to the ASTM standard E407 - 11 (2015).

\subsubsection{X-ray Diffraction (XRD) Test}

X-ray diffraction (XRD) testing for phase identification was conducted with a $\mathrm{Cu} \mathrm{K}_{\alpha}$ radiation source at an accelerating voltage of $45 \mathrm{kV}$ and a current of $40 \mathrm{~mA}$ by PANalytical X-ray diffractometer system.

\subsubsection{Compression and Tension Tests}

Both compression tests and tension tests were performed using a United Electro-Mechanical Universal Testing Machine (Model: SMT-50kN) with a load frame capacity of $50 \mathrm{kN}$. 
Compression tests were conducted at room temperature at strain rates of $0.001,0.01$ and $0.1 \mathrm{~s}^{-1}$. All the specimens were divided into two groups according to the orientation: parallel to the FSP direction and perpendicular to the FSP direction. Two specimens were used under each strain condition. The specimens were cylindrical specimens with the geometry of $\phi 5 \times 8 \mathrm{~mm}$. All the experiment procedures followed the ASTM standard E9-09.

Tension tests were carried out at room temperature at a strain rate of $10^{-4} \mathrm{~s}^{-1}$, following the ASTM standard E8/ E8M - 16a. The specimens for tension test were machined based on the geometry requirement of sub-size plate-type specimens (Fig. 3.3), with the thickness of $6 \mathrm{~mm}$. The gage sections of the specimens were ground along the loading direction by using emery paper with a grit number up to 600 to remove the machining marks and to achieve a consistent surface.

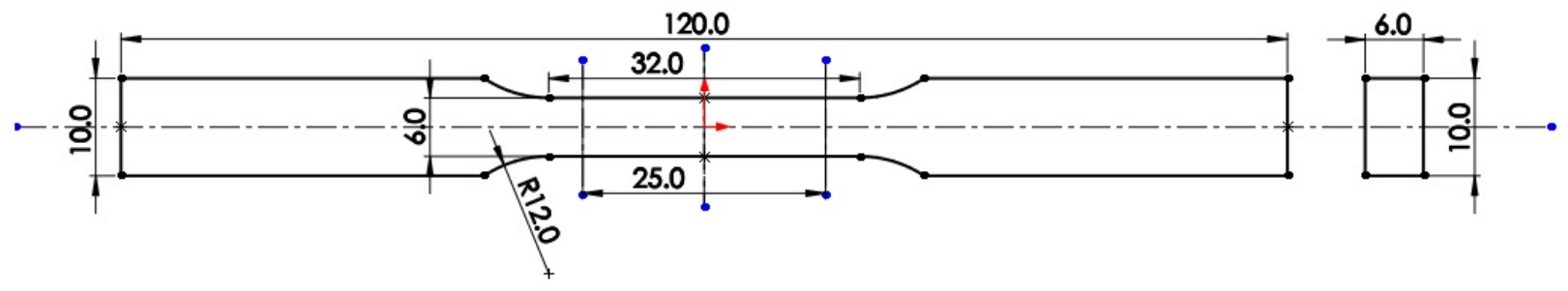

Fig. 3.3 Specimen dimensions for tension test

\subsubsection{Fractography}

The fracture surfaces of specimens after tension tests were examined via JEOL 6380LV scanning electron microscope (SEM) equipped with Oxford energy dispersive X-ray spectroscopy (EDS).

\subsubsection{Low Cycle Fatigue (LCF) Test}

Currently researchers mainly use force-controlled fatigue tests, which mainly studied the behavior of elastic deformation, with the loads mainly below the yield strength. In order to study the behavior of the composite under cyclic load in the plastic deformation range, strain-controlled low cycle fatigue (LCF) tests were conducted. Compared with force-controlled fatigue test, which can only obtain the S-N curve without more data, strain-controlled fatigue testing can obtain more information such as the stress-strain relationship and hysteresis loops. 
Strain-controlled LCF tests under tension-compression load were conducted at room temperature by using a computerized Instron 8801 servohydraulic fatigue testing system, in accordance with the ASTM standard E606/ 606M - 12. The specimens for fatigue tests were the same as those used in tension tests (Fig. 3.4). The gage sections of specimens were ground following the same procedures as done before the tension tests.

It is desirable to use the cylindrical specimens according to ASTM standard E606/ 606M - 12. The flat-sheet specimens were provided in current study. Compared with the dimension requirements from the ASTM standard E606/ 606M - 12 (Fig. 3.5), two non-standard dimensions can be found in the specimen used. The gauge length was longer than that was required, and the width of the parallel part was wider. The main principle of the specimen in the ASTM standard E606/ 606M - 12 is to keep a relative short and narrow gauge area, which will be beneficial to make the specimen crack within the gauge length.

The detailed parameters of the LCF tests are shown in Table 3.1.

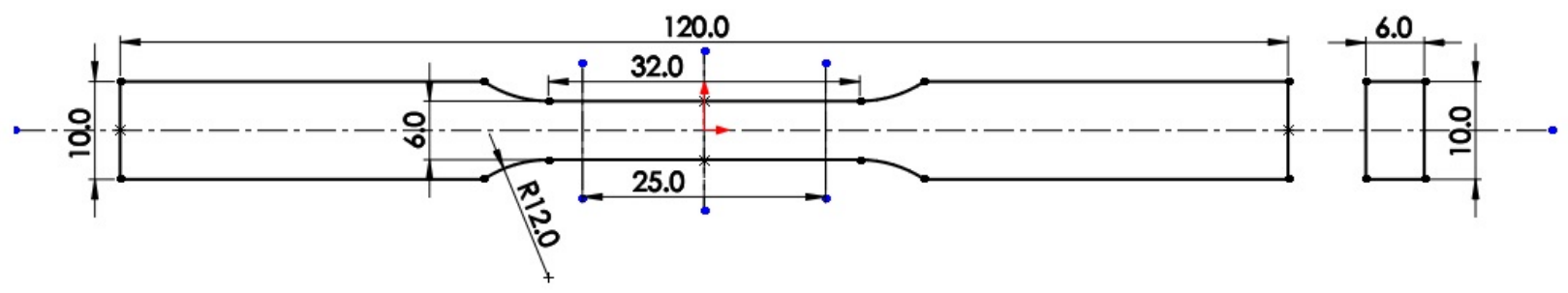

Fig. 3.4 Specimen used in low cycle fatigue test

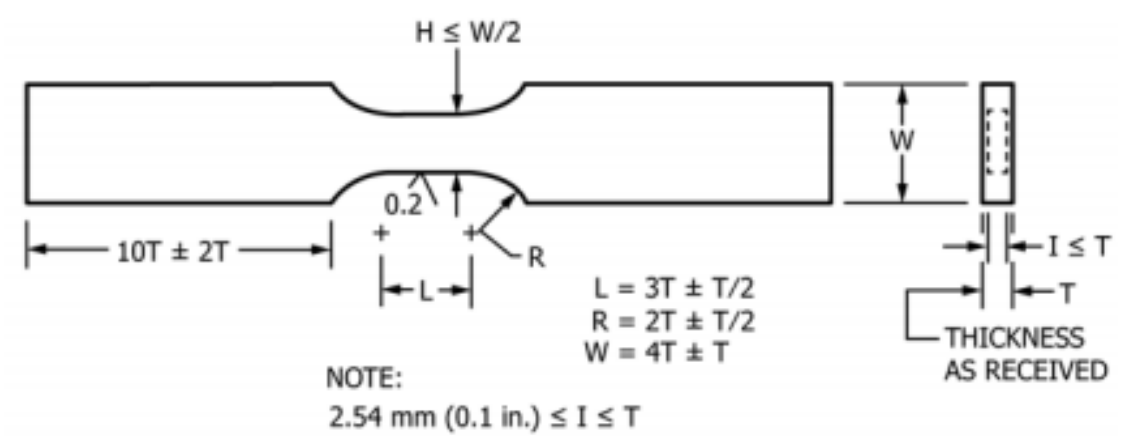

Fig. 3.5 Specimen dimension requirement according to the ASTM standard E606/ 606M - 12 
Table 3.1 Detailed parameters of LCF tests

\begin{tabular}{ccc}
\hline & Before $10^{4}$ cycles & After $10^{4}$ cycles \\
\hline Test method & Strain-controlled & Force-controlled \\
\hline Strain amplitude $\frac{\Delta \varepsilon}{2}(\%)$ & $0.2,0.4,0.6,0.8,1.0$ & \\
\hline Strain rate $\frac{\mathrm{d} \varepsilon}{\mathrm{dt}}$ & $1 \times 10^{-2} \mathrm{~s}^{-1}$ & \\
\hline Strain ratio & $\mathrm{R}=-1$ & $\mathrm{Sine}$ \\
\hline Wave type & $\mathrm{Triangle}$ & $\mathrm{f}=50 \mathrm{~Hz}$ \\
\hline Frequency & $\mathrm{f}=\frac{\mathrm{d} \varepsilon}{\mathrm{dt}}$ \\
\hline
\end{tabular}

The specimens were cyclically loaded with symmetrical tension-compression loading, i.e., with a nominal strain ratio $R_{\varepsilon}=-1$. The nominal strain rate $d_{\varepsilon} / d_{t}$ was kept constant at $1 \times 10^{-2} \mathrm{~s}^{-1}$ in order to avoid the influence of strain rates. 


\section{Results and Discussions}

\subsection{Optical Microscopy}

The microstructures from two directions are shown in Fig. 4.1. The elongated grains are observed from the surface parallel to the FSP direction, while equiaxed grains are present from the surface perpendicular to the FSP direction. The vast majority of the microstructure is aluminum matrix, while the second phase $\mathrm{Mg}_{2} \mathrm{Si}$ is barely observed. The $\mathrm{Mg}_{2} \mathrm{Si}$ phase is generally found in wrought aluminum 6061. The absence will be further discussed in the next section.
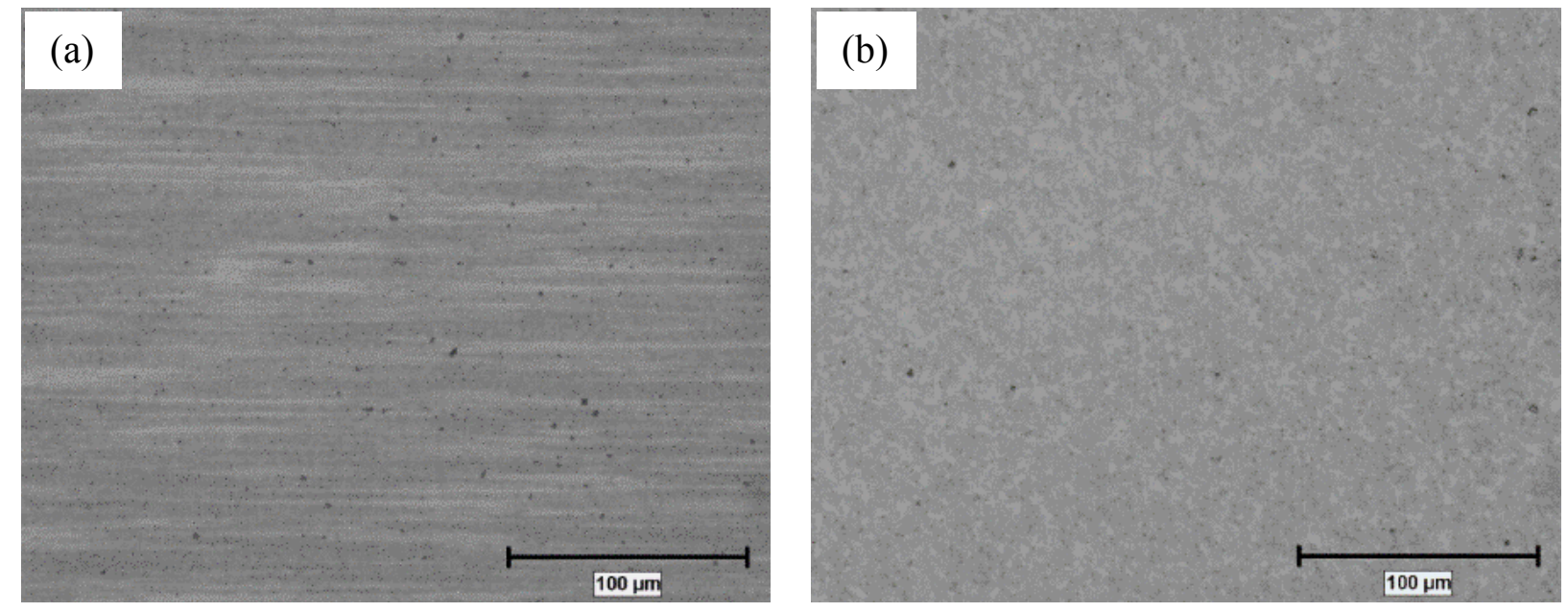

Fig. 4.1 Microstructures observed from different orientations (a) microstructure observed from the surface parallel to the FSP direction, (b) microstructure observed from the surface perpendicular to the FSP direction

\subsection{XRD Test- Phase Identification}

The result of X-ray diffraction test is shown in Fig. 4.2. Two phases are successfully identified. One is aluminum, which is the matrix of the composite, and the other is $\mathrm{Al}_{4} \mathrm{C}_{3}$, which is a carbide generated by the chemical reaction between the aluminum matrix and carbon nanotubes.

The $\mathrm{Al}_{4} \mathrm{C}_{3}$ particles are needle-shaped mono-crystal structures with average diameter of $20-40 \mathrm{~nm}$, similar to the original carbon nanotubes. [76][77] The images of $\mathrm{Al}_{4} \mathrm{C}_{3}$ are shown in Fig. 4.3. 
$(111) \quad(200)$

(220)

(311)

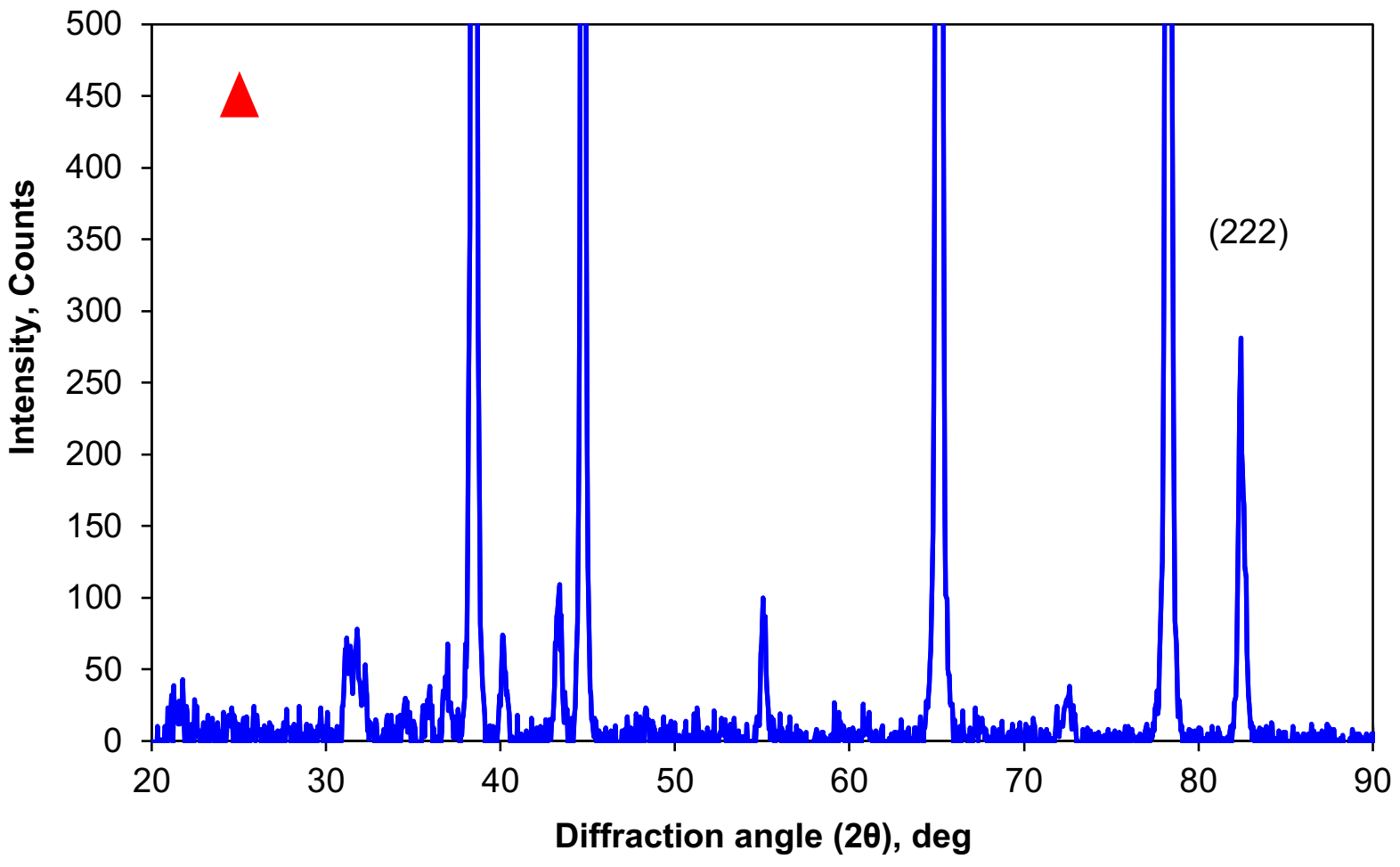

Fig. 4.2 X-ray diffraction patterns of the $2.0 \mathrm{wt} . \% \mathrm{CNT} / 6061 \mathrm{Al}$ composite

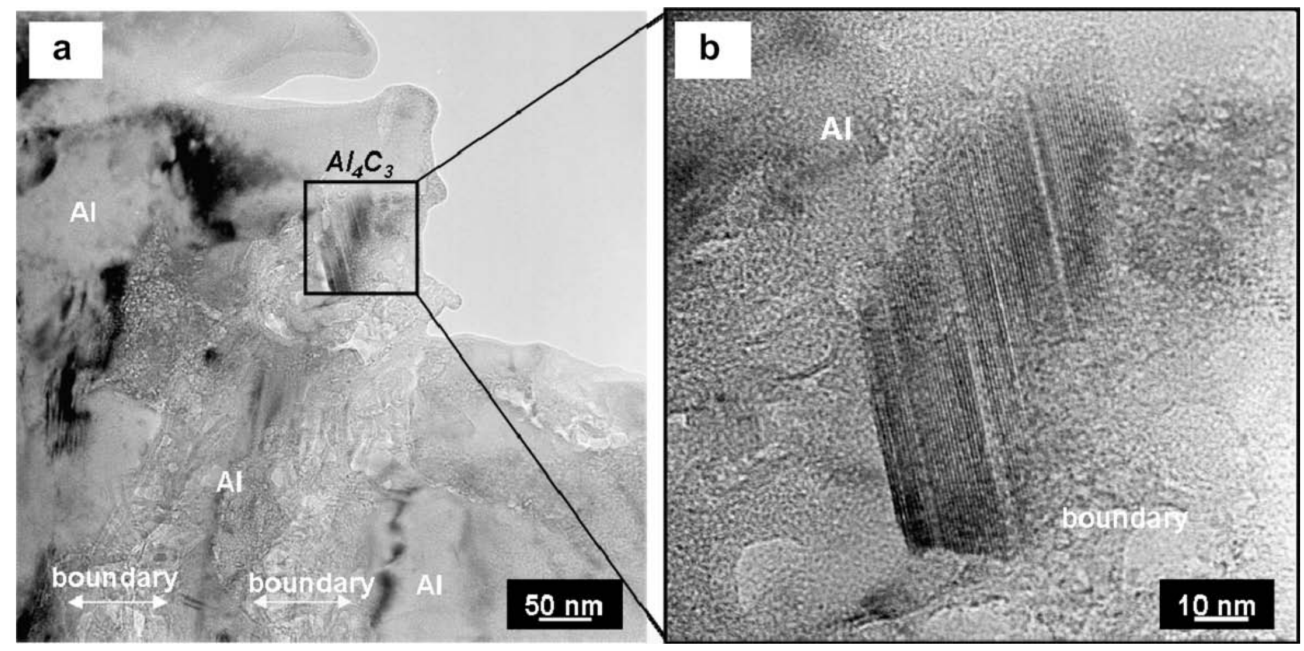

Fig. 4.3 TEM micrograph of the extruded CNT/ Al composite [27] (a) Micrograph of the entire grain boundary, (b) the $\mathrm{Al}_{4} \mathrm{C}_{3}$ between the $\mathrm{Al}$ matrix and grain boundary. 
The formation of $\mathrm{Al}_{4} \mathrm{C}_{3}$ is necessary for effective load transfer between the matrix and reinforcement [38]. In order to form a strong bonding between the aluminum matrix and CNT, a strong transition interface is required. Without an interfacial reaction, the CNT-aluminum interface would be mechanically bonded. This bonding force is largely dependent on the wettability between the matrix and CNT, which is normally weak due to the surface energy difference. Therefore, with the formation of suitable carbides through interfacial chemical reaction, the bonding was greatly enhanced. This is because the in situ formed carbides not only improve the wettability but also contribute to lock the CNTs in place during deformation.

One notable phenomenon was the absence of the $\mathrm{Mg}_{2} \mathrm{Si}$ phase. The $\mathrm{Mg}_{2} \mathrm{Si}$ phase was not observed in the microstructure as shown in the last section. The absence of $\mathrm{Mg}_{2} \mathrm{Si}$ can be also found from other researchers' work [60][78]. The $\mathrm{Mg}_{2} \mathrm{Si}$ phase should be precipitated as the second phase during the aging process, achieving precipitation strengthening. The absence is related to the fabrication process, since the composite was produced by FSP which is an unconventional method compared to regular methods such as rolling, extruding or forging. After multiple-pass FSP, the $\mathrm{Mg}_{2} \mathrm{Si}$ phase was unable to be generated or dissolved. This may explain why Zhao et al. [60] found the insignificant strengthening effect of heat treatment in T6 heat-treated CNT/ 6061 Al composites when they compared the strength between precipitate-free zones and the T6-treated composite.

\subsection{Compression Tests}

Fig. 4.4 and Fig. 4.5 show the engineering stress - engineering strain curves of compression tests obtained from different orientations and at different strain rates. It can be seen that this composite has a very low sensitivity to strain rate under the quasi-static deformation condition (strain rate no more than $10^{-1} / \mathrm{s}$ ), similar to typical aluminum. That indicates that the addition of CNT does not change the strain sensitivity. The values of yield strength and compressive strength are shown in Table 4.1 and Table 4.2. The yield strengths were obtained by the offset method according to the ASTM standard E9 - 09. The strength along the FSP direction is much higher than that perpendicular to the FSP direction. Meanwhile, the strain along the FSP direction is larger than those perpendicular to the FSP direction, indicating that the malleability is better when the specimens were along the FSP direction. 


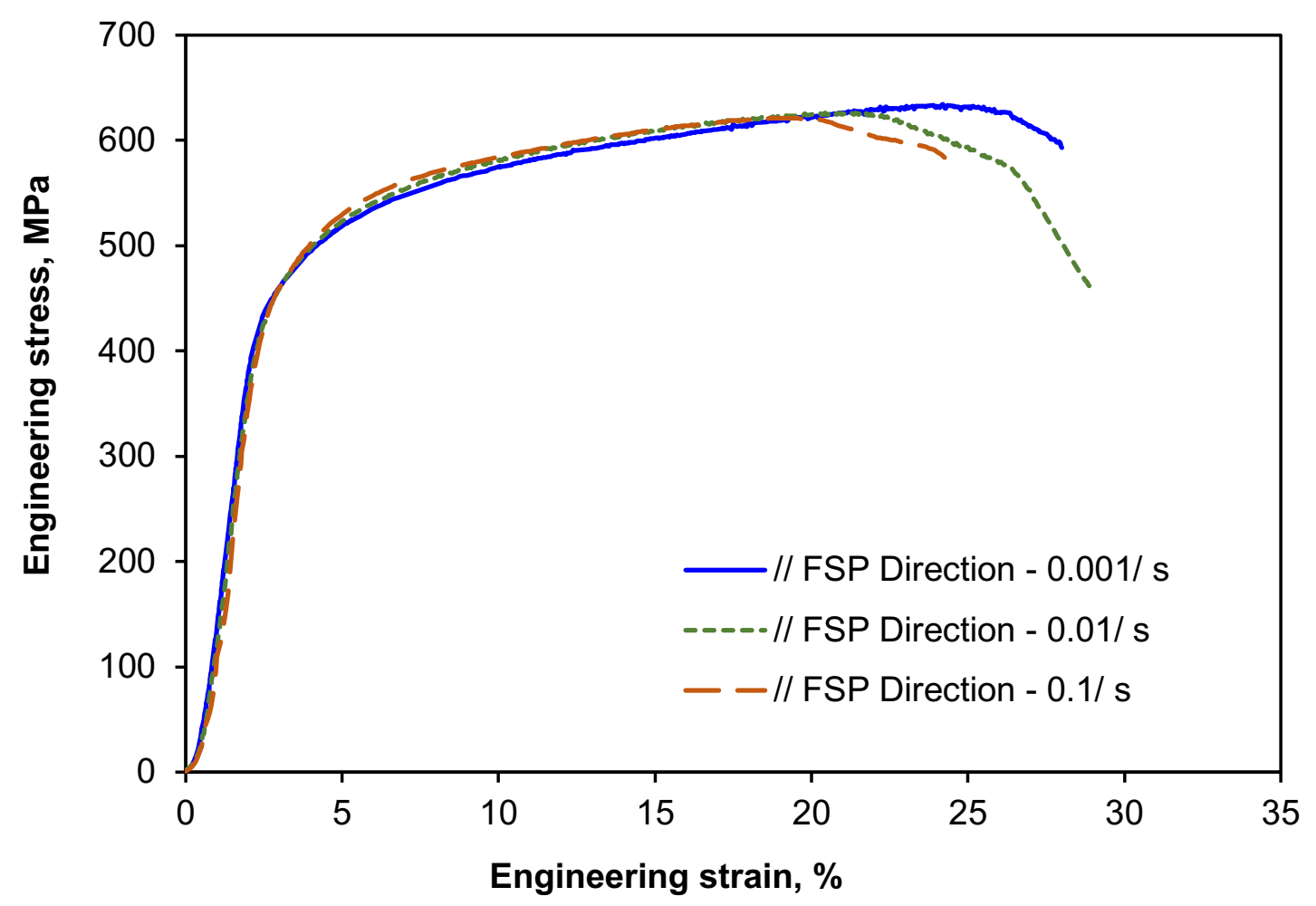

Fig. 4.4 Compression tests results of specimens parallel to the FSP direction

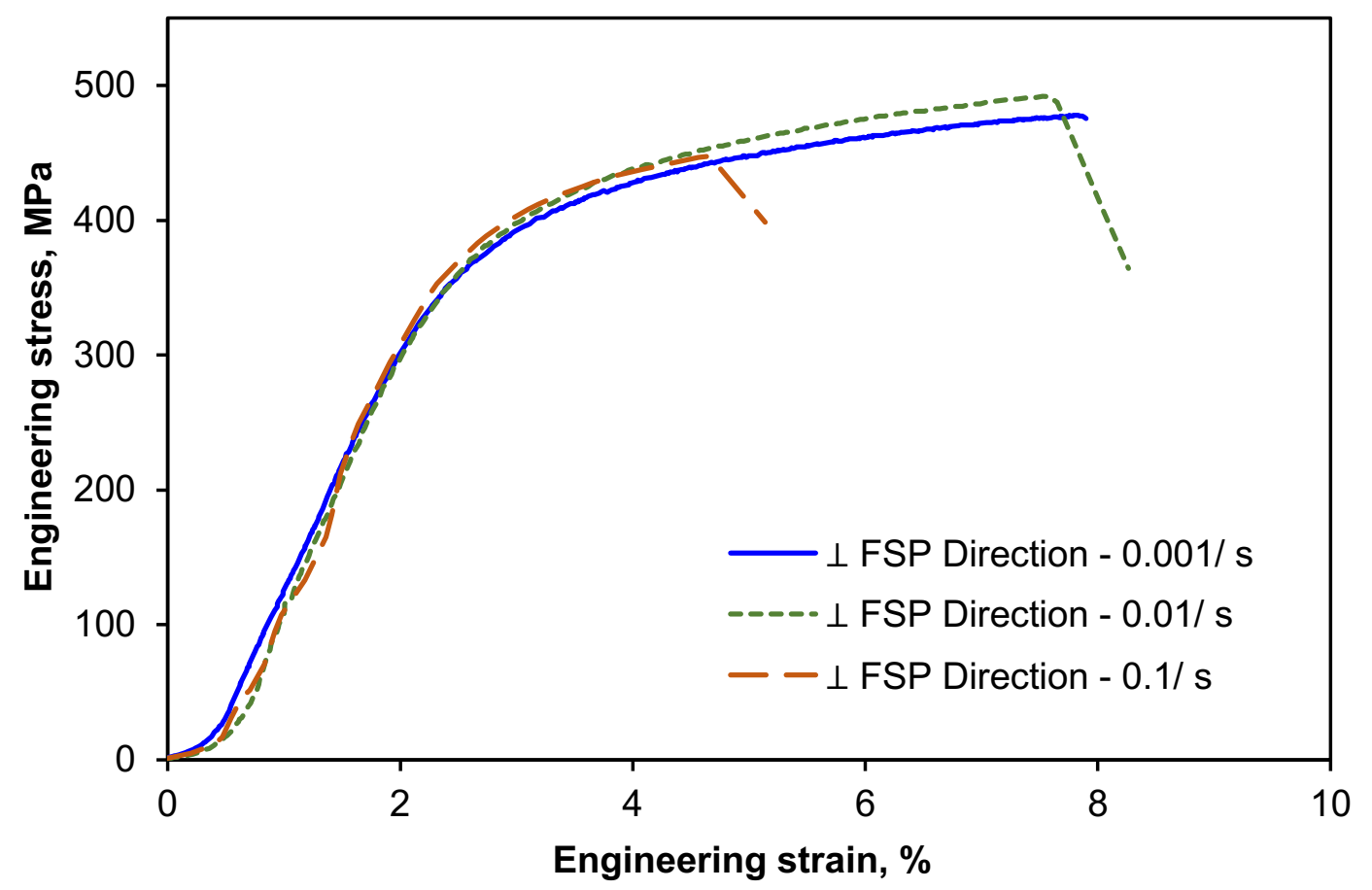

Fig. 4.5 Compression tests results of specimens perpendicular to the FSP direction 
Table 4.1 Yield and compressive strength of specimens parallel to the FSP direction

\begin{tabular}{ccc}
\hline Strain rate/ s & Yield strength/ MPa & Compressive strength/ MPa \\
\hline 0.001 & 420 & 634 \\
0.01 & 425 & 626 \\
0.1 & 425 & 621 \\
\hline
\end{tabular}

Table 4.2 Yield and compressive strength of specimens perpendicular to the FSP direction

\begin{tabular}{ccc}
\hline Strain rate/ s & Yield strength/ MPa & Compressive strength/ MPa \\
\hline 0.001 & 356 & 478 \\
0.01 & 356 & 492 \\
0.1 & 365 & 448 \\
\hline
\end{tabular}

\subsection{Tension Tests and Fractography}

\subsubsection{Results of Tension Tests}

The engineering stress - engineering strain curve and the true stress - true strain curve of tension tests are shown in Fig. 4.6. Two unusual phenomena can be observed: the non-linear elastic deformation and the appearance of a yield plateau. These two phenomena will be further discussed in section 3.4.3.

The yield strength (YS) and ultimate tensile strength (UTS) can be obtained from the stress - strain curves. The value of elongation is obtained using elongation-after-fracture measurement. The typical mechanical properties of wrought aluminum 6061 - T6 can be found from ASM handbook [79]. The comparison of the mechanical properties between the composite and the base alloy is shown as Fig. 4.7. It can be seen that the strength of aluminum alloy is greatly enhanced by the addition of CNT. Meanwhile, the elongation is much lower compared with the typical 6061 alloy, which means that the ductility was sacrificed. 


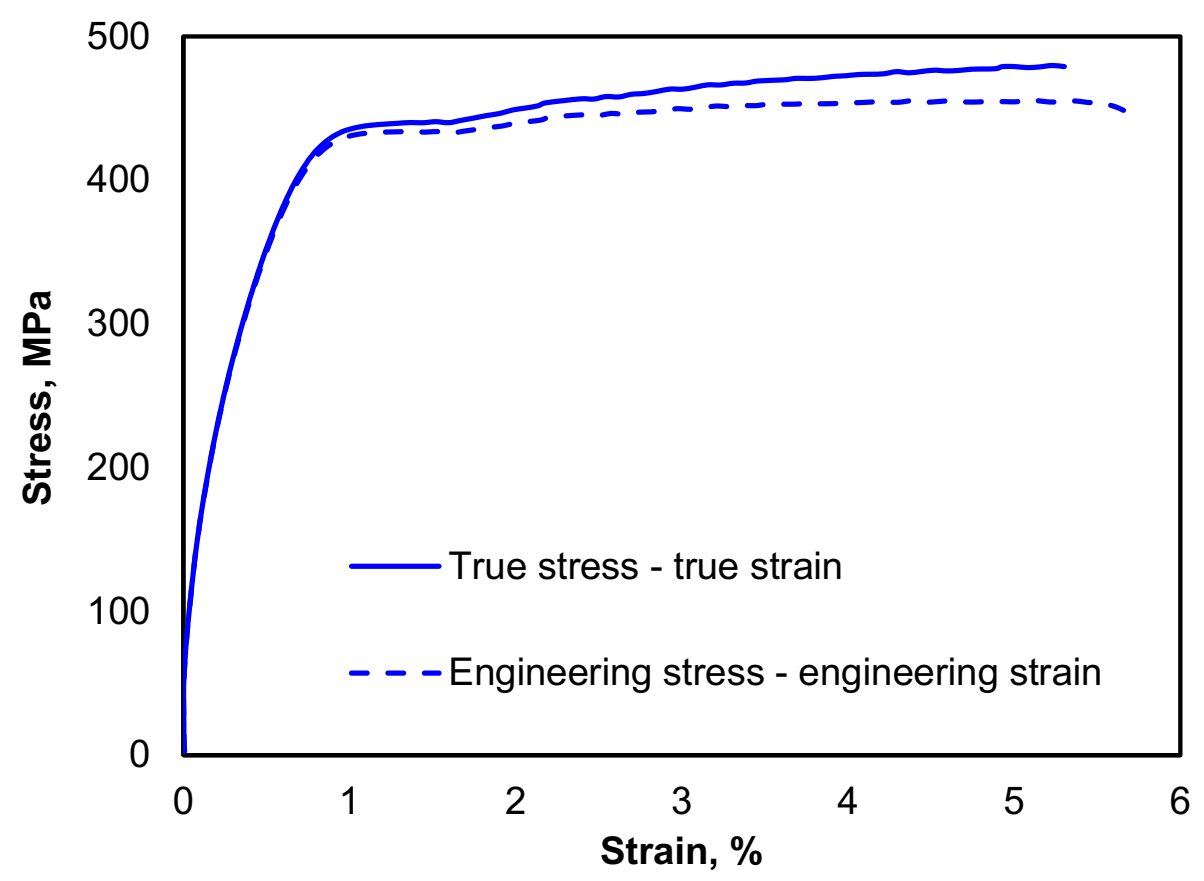

Fig. 4.6 Stress-strain curves of tension test

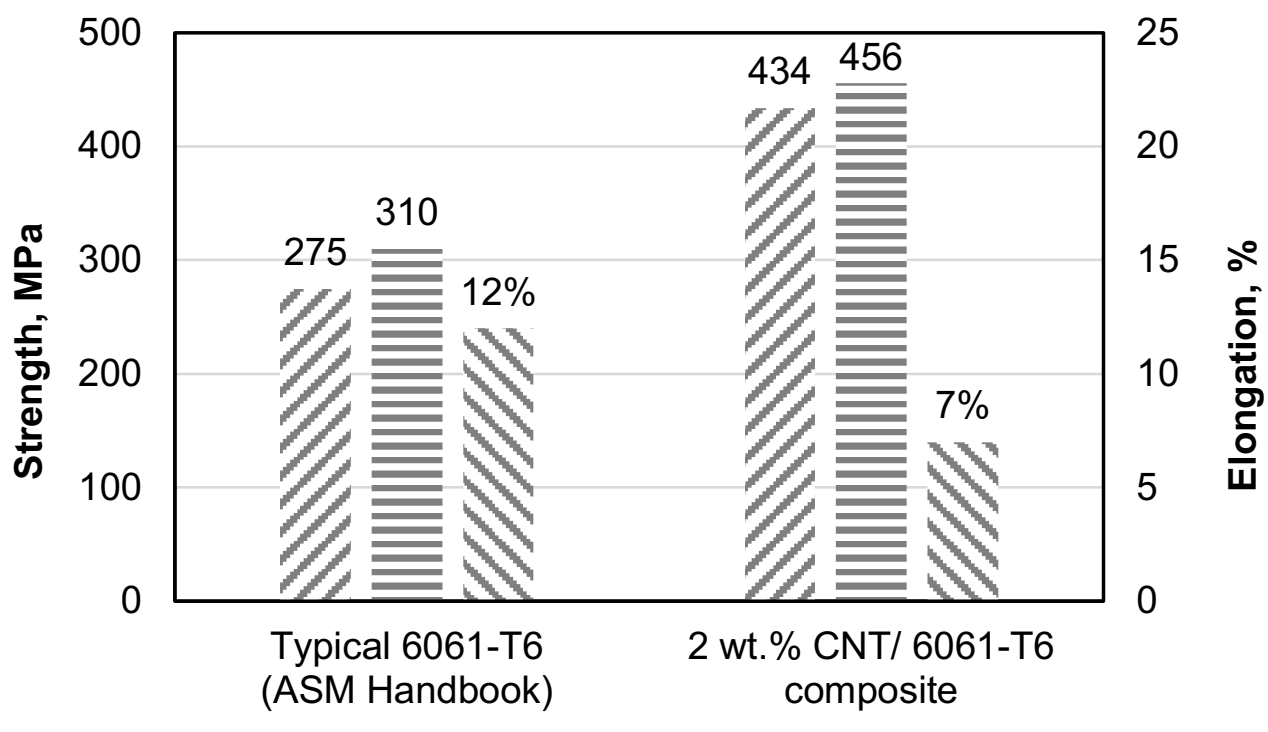

YYield Strength - Tensile Strength Elongation

Fig. 4.7 Mechanical properties of the composite and the base alloy 


\subsubsection{Fractography}

The fracture surfaces of the specimens after tension tests were observed by using scanning electronic microscope (SEM). The images are shown as Fig. 4.8
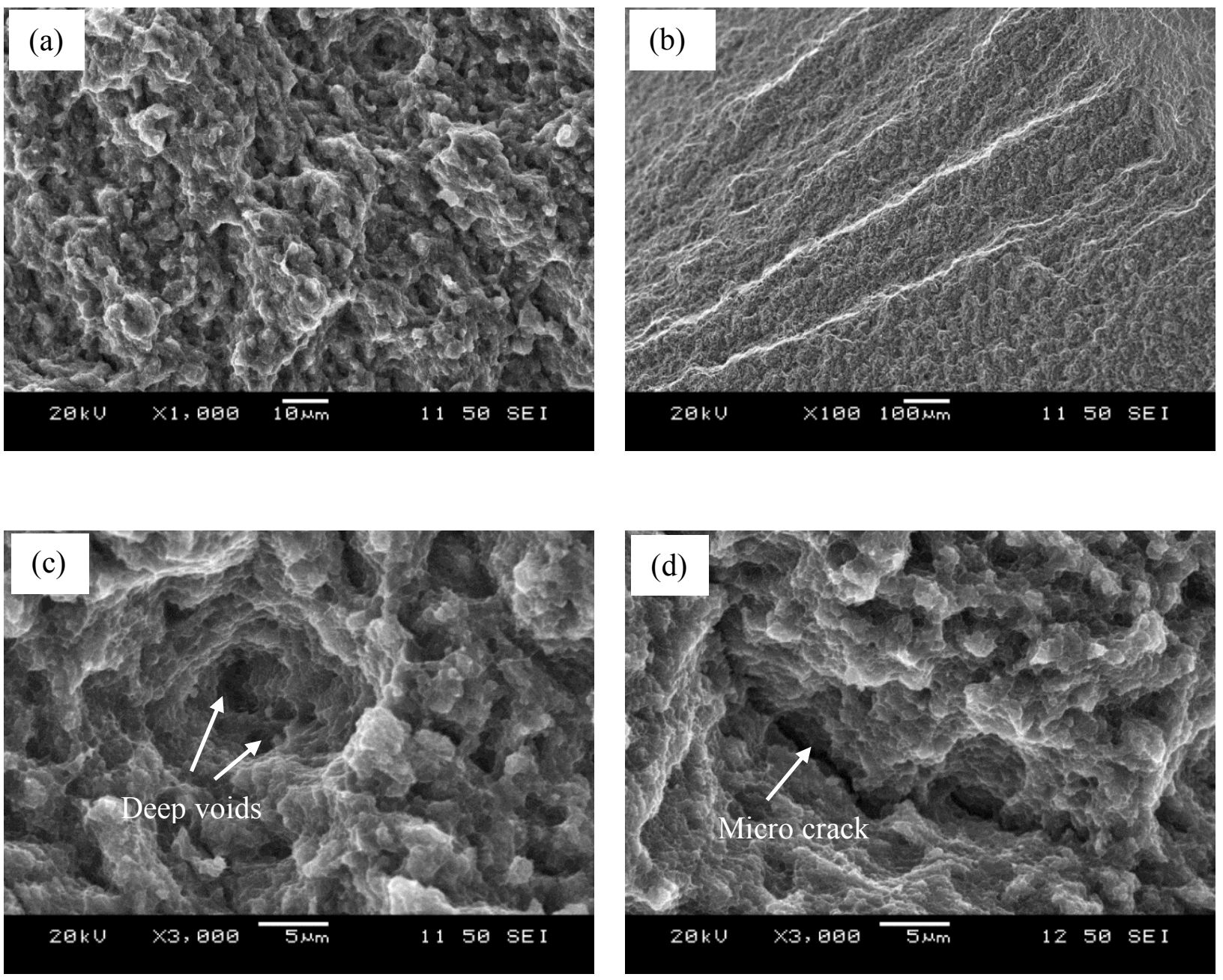


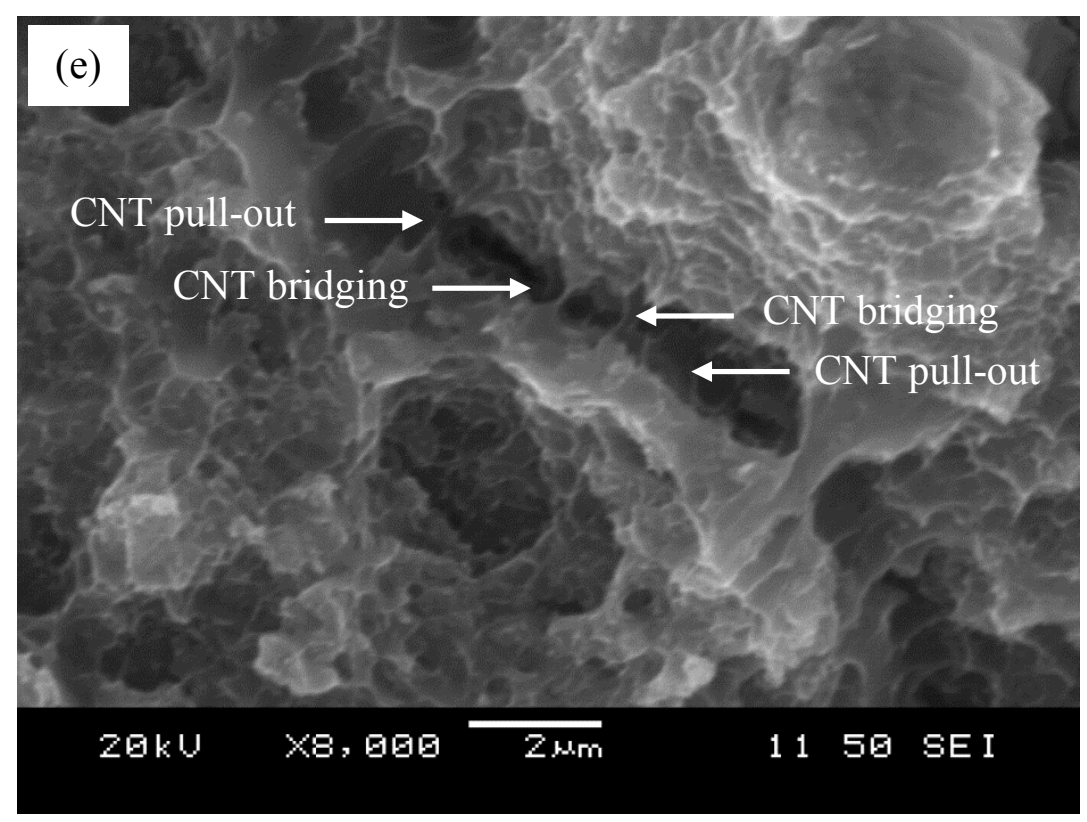

Fig. 4.8 Fracture surfaces of the specimen after tension test (a) A dimple rupture surface, (b) propagation area, (c) deep voids because of the CNT agglomerates, (d) micro crack and (e) the CNT bridging and CNT pull-out inside micro crack.

From the images of the fracture surface, a number of dimples (Fig. 4.8 (a)) as well as the fatigue crack propagation area (Fig. 4.8 (b)) can be found, implying a ductile fracture. There are some deep voids (Fig. 4.8 (c)) because of the CNT agglomerates (Fig. 4.9). Some micro cracks are clearly seen Fig. 4.8 (d)). Inside certain micro cracks, the appearance of CNT bridging and CNT pull-out are noted (Fig. 4.8 (e)). The CNT bridging and pull-out phenomena are also reported by other researchers $[\mathbf{7 6}][\mathbf{8 0}][\mathbf{8 1}]$. CNTs are bonding to the Al matrix in a "bridging" manner, increasing the Al-CNT interface strength and the fracture energy of the composites. During the deformation process, the slippage of CNT inner tube and pull-out of CNTs occurs. The process can be demonstrated in Fig. 4.10. 


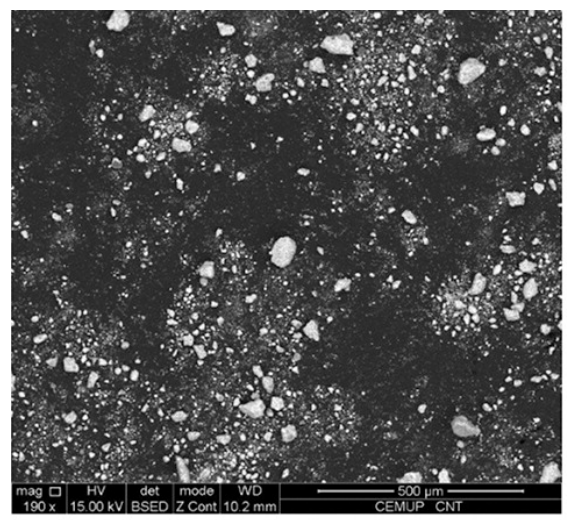

a

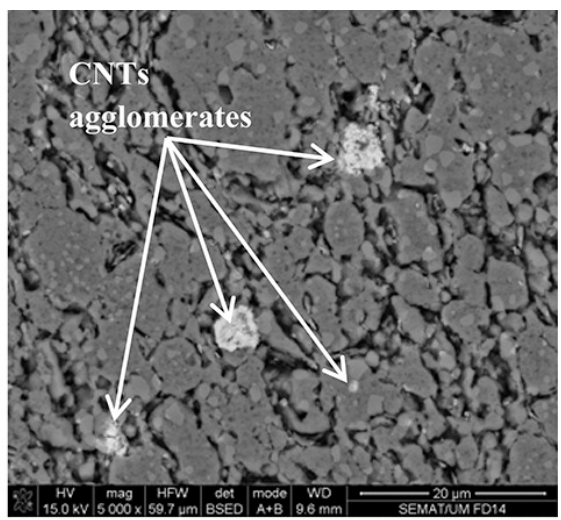

b

Fig. 4.9 Illustration of CNT agglomerates [36] (a) Microstructure in a low magnification, (b) microstructure in a high magnification.

(a) Crack bridging mechanism
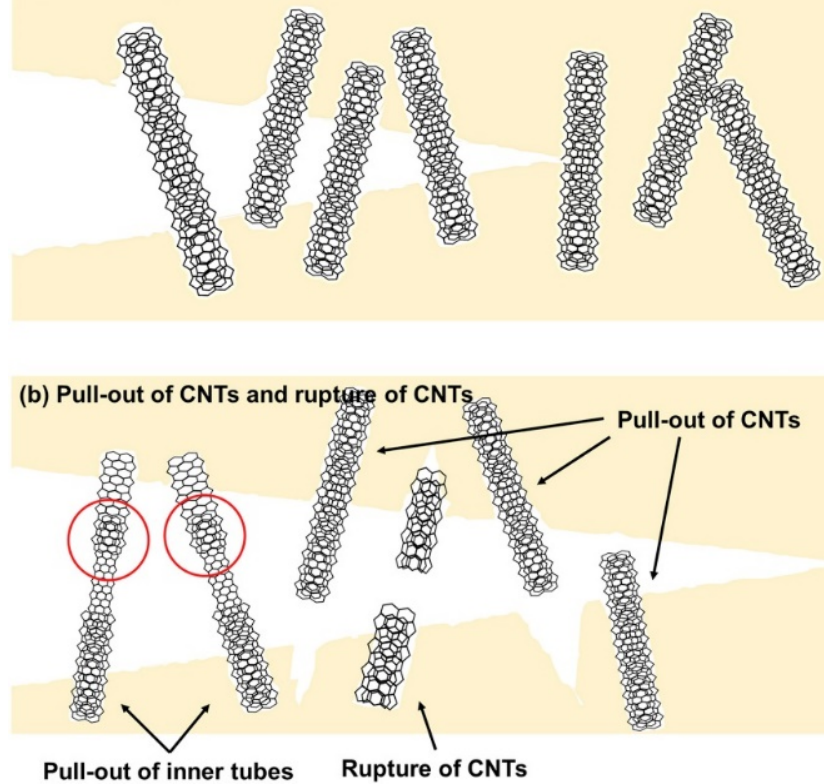

Fig. 4.10 Demonstration of CNT bridging and CNT pull-out [82] (a) Crack bridging mechanisms, (b) CNT pull-out and rupture.

The fracture patterns of CNT/ Al composites can be divided into intragranular fracture and intergranular fracture (Fig. 4.11). The intragranular fracture is mainly caused by defects inside the aluminum grains; while the intergranular fracture has two main sources (Fig. 4.12). One is because of the CNT agglomerates in the grain boundaries, which appear as deep holes after fracture; the 
other is due to the CNT embedded into the aluminum grain, which the CNT bridging and CNT pull-out between the crack can be observed in the fracture surface.

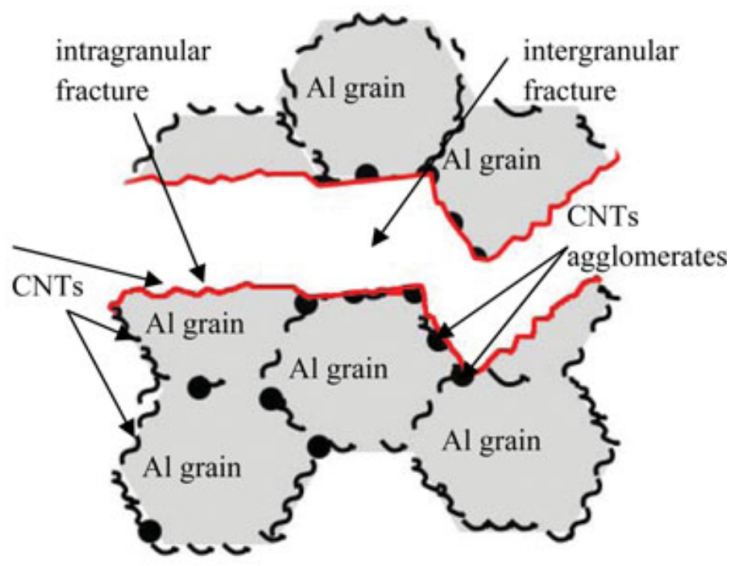

Fig. 4.11 Schematic images of the crack patterns [36]

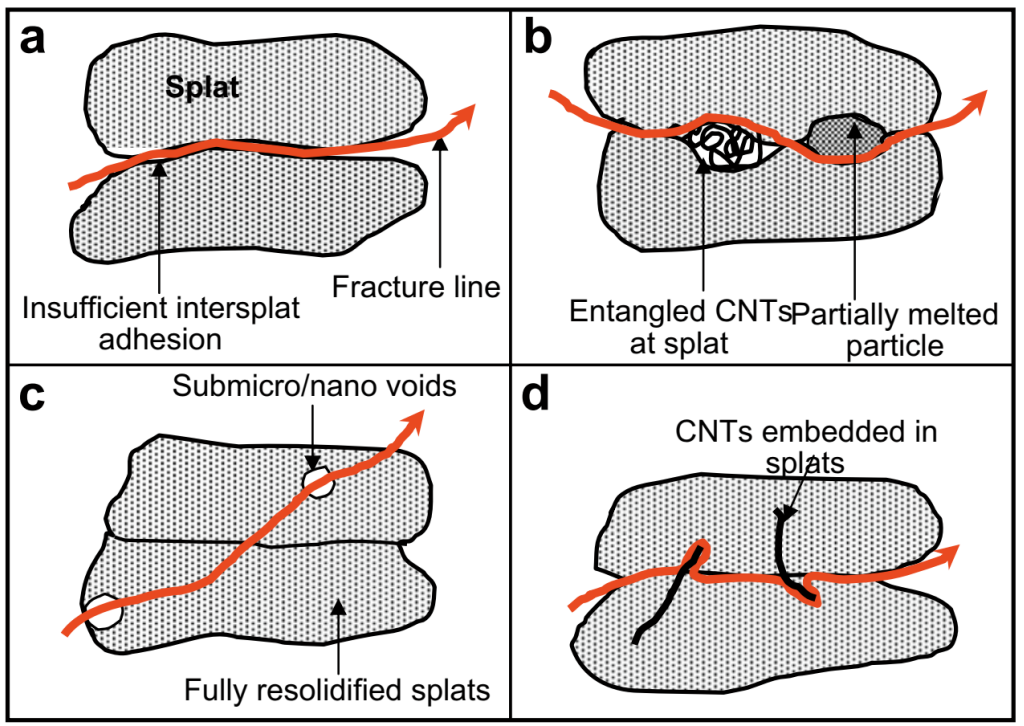

Fig. 4.12 Different fracture patterns in CNT reinforced aluminum matrix composite [83] (a)

Fracture through weak grain boundary, (b) fracture through grain boundary caused by entangled CNTs and partially melted particle, (c) intragranular fracture because of nano voids and (d) fracture due to CNT pull-out 


\subsubsection{Discussion}

Two unusual phenomena can be found from the stress-strain curves: the non-linear elastic behavior and the appearance of a yield plateau. There are reasons to believe that these two unusual phenomena are related to the addition of CNT and the fabrication process. The powder metallurgy and friction stir processing (FSP) method may change the dispersion of dislocations, which caused differences on dislocation movements and slips, making the deformation behavior dissimilar.

\section{(1) The non-linear elastic behavior}

The non-linear elastic behavior is attributed to the addition of carbon nanotubes. It was noted by several researchers such as Yakobson et al. [11] and Xiao et al. [84] that the carbon nanotubes had a nonlinear elastic behavior, mainly as a result of the tubular structure and nano-sized diameter. The nonlinear elastic behavior of carbon nanotubes is dominant in the deformation of CNT/ Al composite, causing a similar behavior in the composite as well.

\section{(2) The yield phenomenon}

The yield plateaus can be found in the results of tension tests acquired by other researchers. Carvalho et al. [36] conducted research on CNT reinforced AlSi alloy (Al-Si11-Fe0.2). The nonlinear elastic behavior and yield plateau can be observed (Fig. 4.13). The yield plateau is also found in the curve of unreinforced AlSi alloy. Both the alloy and the composite were made by ball milling followed by hot pressing. This also supports the previous statement made by the author that these two unusual phenomena are related to the fabrication process.

Liu et al. carried out the investigation with the material CNT/2009 Al. The yield plateau was found in the curves of CNT/ Al composite but not the aluminum alloy [74] (Fig. 4.14 (a)). It appeared after multi-pass FSP but not after forging [55] (Fig. 4.14 (b)). These two results indicate that the yield phenomenon is attributed to the addition of CNT and the fabrication methods. It should be pointed out that the stress-strain curves reported by Liu were obtained without the use of an extensometer, so the slope of the curves did not represent the Young's modulus.

Two-step yielding behavior in 10 vol. \% CNT/ Cu composites was reported by Kim et al. [85] (Fig. 4.15). 


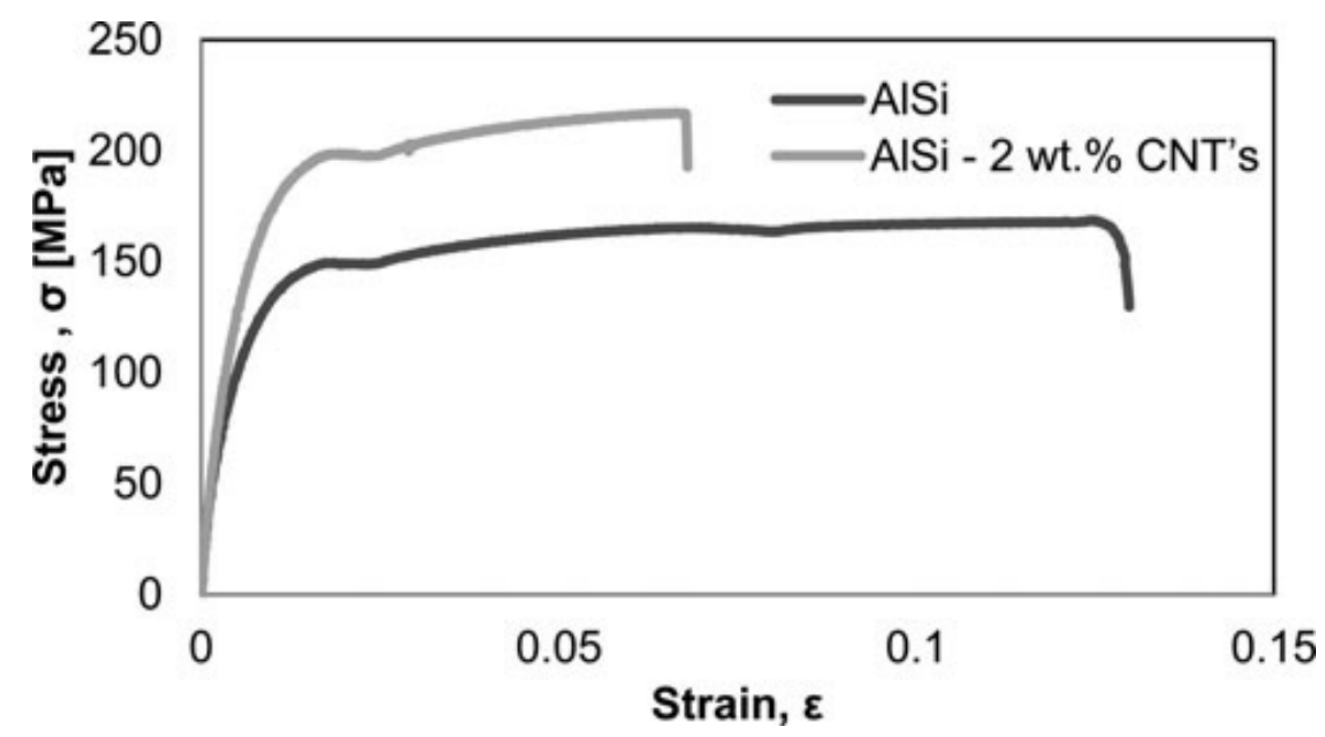

Fig. 4.13 Stress-strain curves of AlSi alloy and 2 wt.\% CNTs / AlSi composite [36]
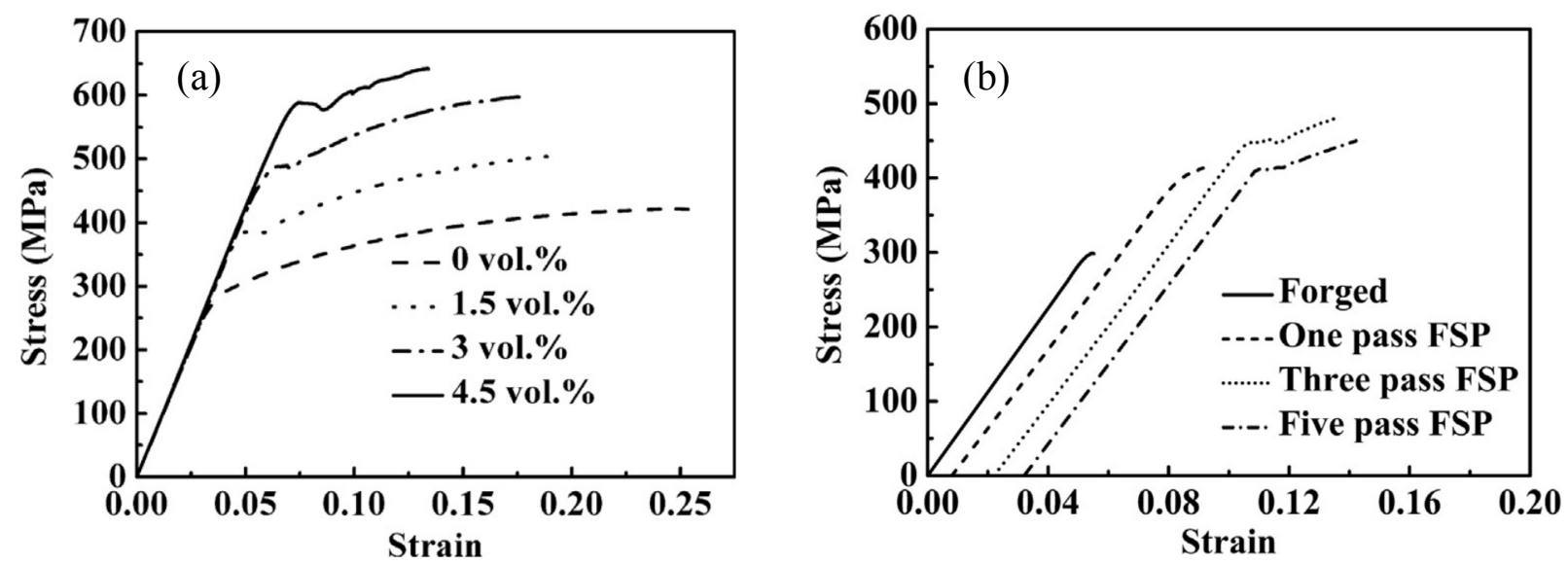

Fig. 4.14 Stress-strain curves of CNT/ 2009 Al composites (a) Stress-strain curves of FSP-rolled CNT/ 2009 Al composites with different CNT content [74] (b) stress-strain curves of 4.5\% vol. \% CNT/ $2009 \mathrm{Al}$ composites with different FSP passes [55] 


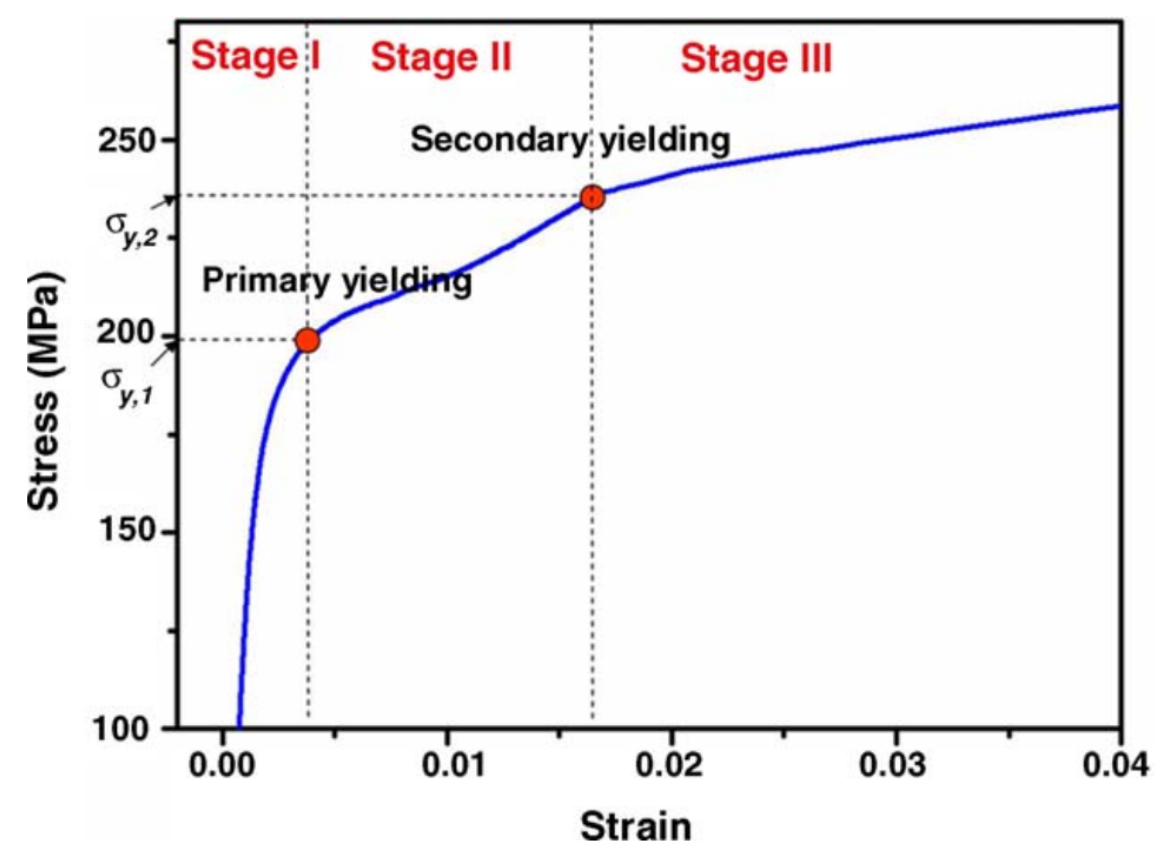

Fig. 4.15 Two-step yielding phenomenon of CNT/ Cu nanocomposite [85]

The yield phenomenon of the composite may be caused by the fibrous CNT/ Al microstructure and the CNT bridging manner.

The appearance of CNT bridging improves the crack resistance. As the crack moves forward, energy is consumed by the pull-out of the CNT and the slippage of the CNT inner tube, reducing the micro-crack propagation rate. Because of the existence of CNT bridging, the stress-strain curve contains three parts: an elastic deformation region, a CNT pull-out region and a CNT fracture region. The beginning of the yield plateau stands for the end of elastic deformation. During the yield plateau, it refers to the CNT pull-out process and atoms movement. After that, the CNT fracture starts to occur, and the material is finally fractured.

\subsubsection{Strength Coefficient $K$ and Strain Hardening Exponent $n$}

Two significant parameters of the material used for modelling and simulation can be obtained from the stress-strain curve, namely the strength coefficient $\mathrm{K}$ and the strain hardening exponent $\mathrm{n}$.

According to the Hollomon equation, the stress and the amount of plastic stress can be expressed in a form of power law relationship (Eq. (13)): 


$$
\sigma=\mathrm{K} \varepsilon_{p}{ }^{n}
$$

Here, $\mathrm{K}$ is the strength coefficient, and $\mathrm{n}$ is strain hardening exponent, also known as n-value.

To avoid the influence from the necking region, only the data points between the yield strength (YS) and ultimate tensile strength (UTS) portions of the stress-strain curve are used. A plot of true stress versus true plastic strain in log-log coordinates results in a linear curve (Fig. 4.16), representing $\log \sigma=\operatorname{nlog} \varepsilon_{p}+\log \mathrm{K}$.

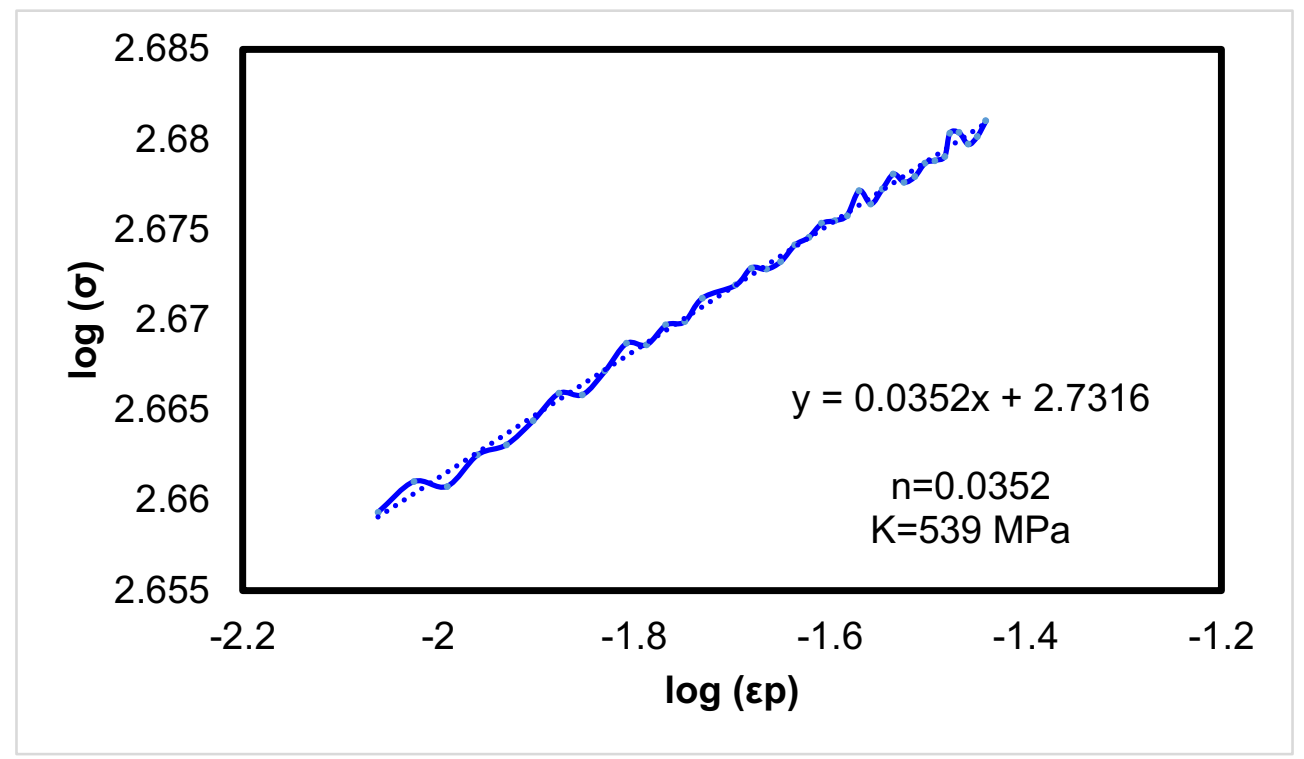

Fig. 4.16 Log-log true stress and true plastic strain curve

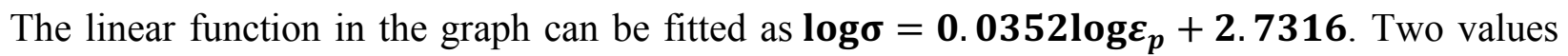
can be obtained: $n=0.0352$, and $\mathbf{K}=\mathbf{1 0}^{2.7316} \mathbf{M P a}=539 \mathrm{MPa}$.

By plotting the curve by Hollomon equation, it showed a good agreement with the stress-plastic strain curve, as shown in Fig. 4.17. 


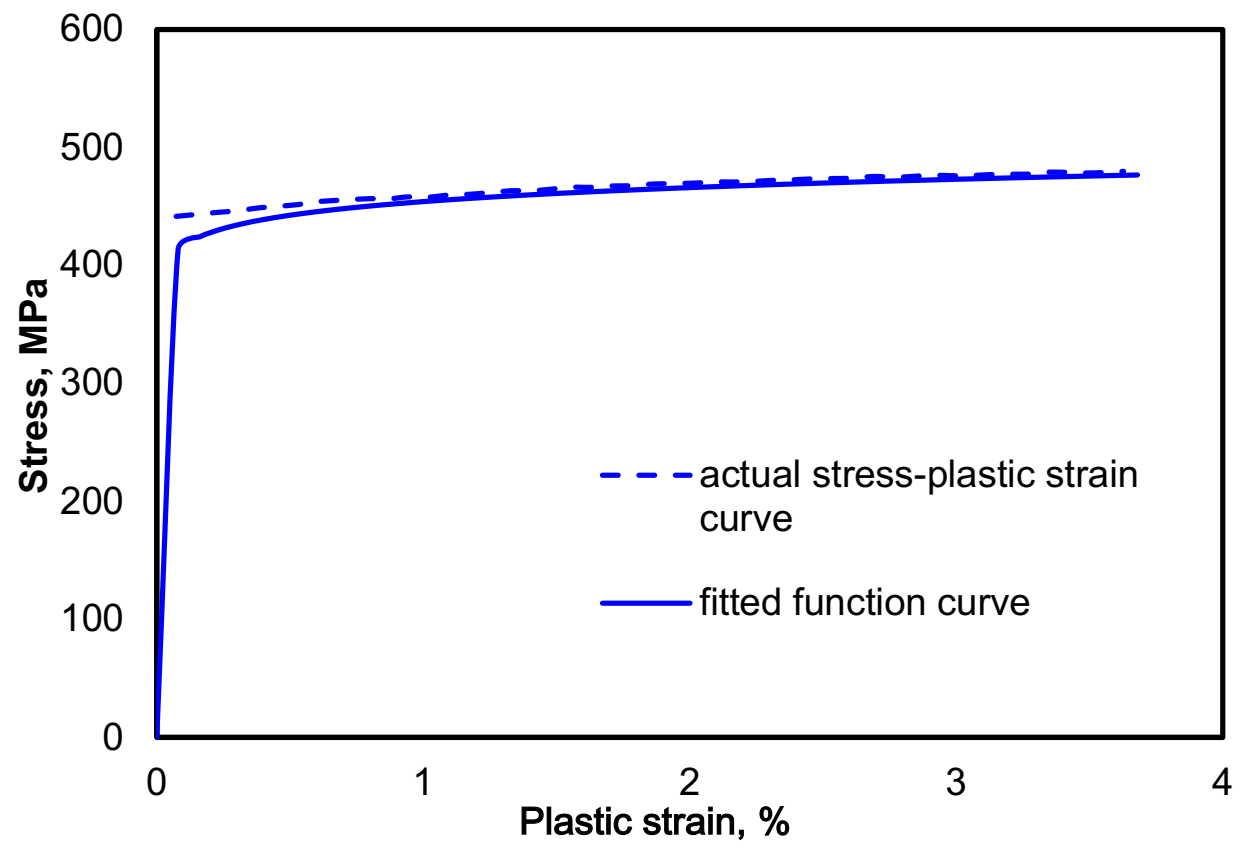

Fig. 4.17 Actual stress-plastic strain curve and the fitted function curve

\subsection{Low Cycle Fatigue (LCF) Test}

The obtained number of cycles (fatigue life) with different total strain amplitude is plotted in a logarithmic scale in Fig. 4.18. Two specimens were used at each strain amplitude. It can be seen that the number of cycles increases as the strain amplitude decreases. 


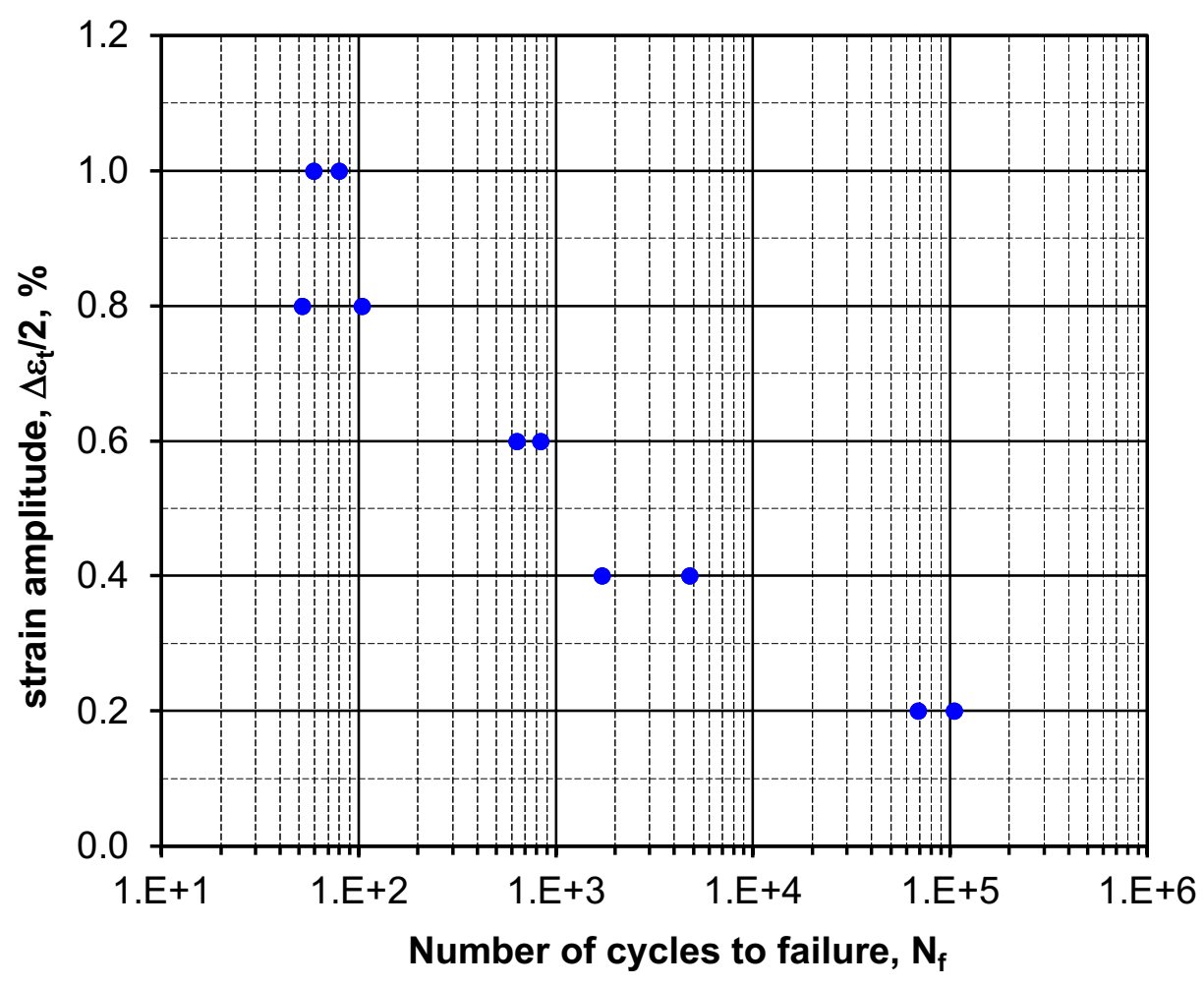

Fig. 4.18 Strain amplitude versus numbers of cycles to failure

The fatigue life is sensitive to many factors, and there is no standard fatigue life for materials. However, the fatigue life of the composite is shorter than that of wrought aluminum 6061 obtained from some literature [86][87]. The decrease of the fatigue life is possibly attributed to the CNTs agglomerates that behave like local stress concentrations, accelerating the crack growth rate [88].

Fig. 4.19 shows the cyclic stress amplitude as a function of the number of cycles at different strain amplitude on a logarithmic scale. The cyclic stress amplitude increases as the applied total strain amplitude increases. At each strain amplitude, the cyclic stress amplitude indicates a decreasing trend as the number of cycles grows, with a subsequent slight increase in the end. The decreasing trend of stress amplitude demonstrates that cyclic softening occurs during the fatigue test, while cyclic hardening occurs for extruded aluminum 6061-T6 [89]. 


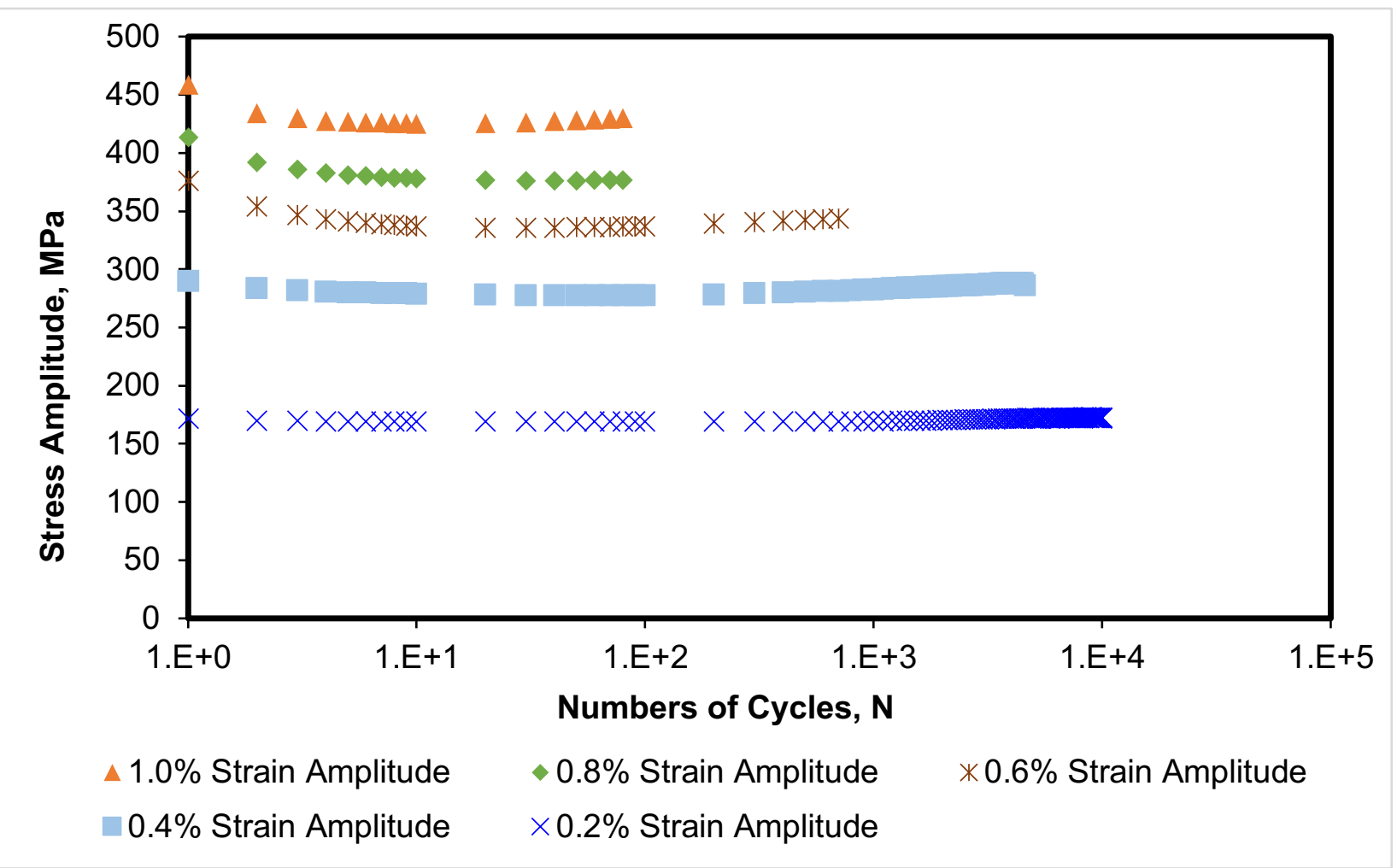

Fig. 4.19 Stress amplitude versus numbers of cycles to failure

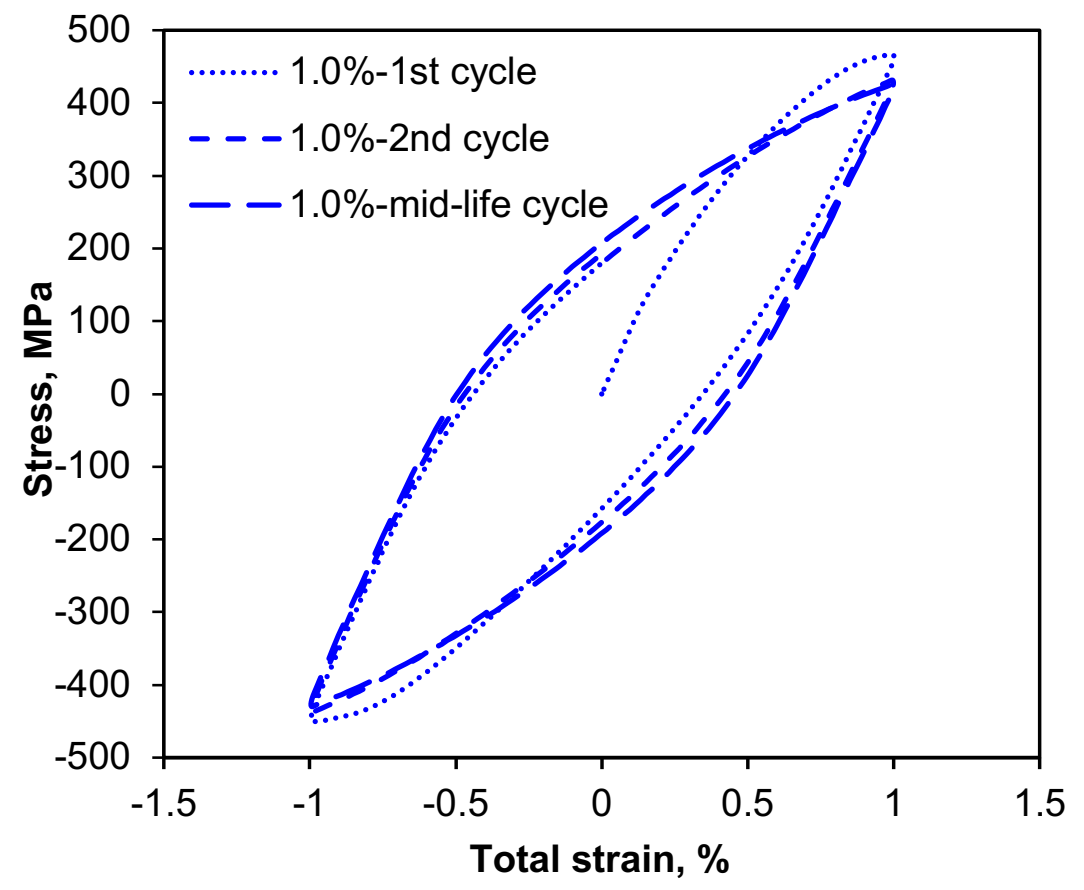

Fig. 4.20 Typical stress-strain hysteresis loops at the $1.0 \%$ strain amplitude 
Fig. 4.20 shows typical stress-strain hysteresis loops of the first, second and mid-life cycles at a total strain amplitude of $1.0 \%$. Similar to aluminum as a face-centered cubic (FCC) metal, the CNT/ 6061 Al composite exhibits nearly symmetrical hysteresis loops.

Cyclic yield strength $\sigma_{y^{\prime}}$ at each strain amplitude was obtained by the $0.2 \%$ offset method according to the ASTM standard E606/ 606M - 12. The average value was calculated as the final value of cyclic yield strength $\sigma_{y^{\prime}}$. Cyclic stress-strain and strain-fatigue life relationships can be obtained by using equations from ISO Standard 12016:2017 [90].

\section{(1) Cyclic stress-strain behavior}

There is a similar equation to Hollomon's equation for the cyclic stress-strain curve (Eq. (14)),

$$
\sigma_{a}=\frac{\Delta \sigma}{2}=\mathrm{K}^{\prime}\left(\frac{\Delta \varepsilon_{\mathrm{p}}}{2}\right)^{\mathrm{n}^{\prime}}
$$

Cyclic stress-strain curves are usually expressed by a Ramberg-Osgood type relationship (Eq. (15))

$$
\frac{\Delta \varepsilon}{2}=\frac{\Delta \varepsilon_{e}}{2}+\frac{\Delta \varepsilon_{p}}{2}=\frac{\Delta \sigma}{2 E}+\left(\frac{\Delta \sigma}{2 K^{\prime}}\right)^{1 / n^{\prime}}
$$

Where,

$n^{\prime}$ is cyclic strain hardening exponent, which is the slope of $\lg \sigma_{a}=\lg \Delta \varepsilon_{p} / 2$ plot.

$K^{\prime}$ is cyclic strength coefficient, which is the stress intercept at $\varepsilon_{p}=1$ on $\lg \sigma_{a}-\lg \Delta \varepsilon_{p} / 2$ plot.

\section{(2) Strain-Fatigue life relationship}

Results of low cycle fatigue tests are often used to express the functional cyclic stress-strain relationship and the strain-life relationship of a material. The total strain amplitude is expressed in terms of the elastic strain amplitude and the plastic strain amplitude components (Eq. (16)). 


$$
\frac{\Delta \varepsilon_{\mathrm{t}}}{2}=\frac{\Delta \varepsilon_{\mathrm{e}}}{2}+\frac{\Delta \varepsilon_{\mathrm{p}}}{2}=\frac{\Delta \sigma}{2 E}+\frac{\Delta \varepsilon_{\mathrm{p}}}{2}
$$

Based on the Basquin formula,

$$
\frac{\Delta \sigma}{2}=\sigma_{a}=\sigma_{f^{\prime}}\left(2 N_{f}\right)^{b}
$$

Based on the Coffin-Manson formula,

$$
\Delta \varepsilon_{p} / 2=\varepsilon_{f^{\prime}}\left(2 N_{f}\right)^{c}
$$

Upon combining the Eq. (16) with Eq. (17) and Eq. (18), the strain-life relationship can be given in Eq. (19).

$$
\frac{\Delta \varepsilon}{2}=\frac{\Delta \varepsilon_{e}}{2}+\frac{\Delta \varepsilon_{p}}{2}=\frac{\Delta \sigma}{2 E}+\left(\frac{\Delta \sigma}{2 K^{\prime}}\right)^{1 / n^{\prime}}=\frac{\sigma_{f^{\prime}}}{E}\left(2 N_{f}\right)^{b}+\varepsilon_{f^{\prime}}\left(2 N_{f}\right)^{c}
$$

After analyzing all the equations, the parameters obtained can be shown in Table 4.3.

Table 4.3 Parameters obtained from low cycle fatigue tests

Low Cycle fatigue parameters

Cyclic yield strength, $\sigma_{y}{ }^{\prime}, \mathrm{MPa}$

Cyclic strain hardening exponent, $\mathrm{n}^{\prime}$

Cyclic strength coefficient, $\mathrm{K}^{\prime}, \mathrm{MPa}$

Fatigue strength coefficient, $\sigma_{\mathrm{f}}{ }^{\prime}, \mathrm{MPa}$

Fatigue strength exponent, $b$

Fatigue ductility coefficient, $\varepsilon_{\mathrm{f}}{ }^{\prime}$

Fatigue ductility exponent, c
Value

331

0.16

951

855

$-0.13$

0.18

$-0.71$ 
Fig. 4.21 shows the comparison of monotonic and cyclic stress-strain curve. The cyclic stressstrain curve is under monotonic stress-strain curve, indicating cyclic softening, which is in accordance with what is discussed in earlier sections.

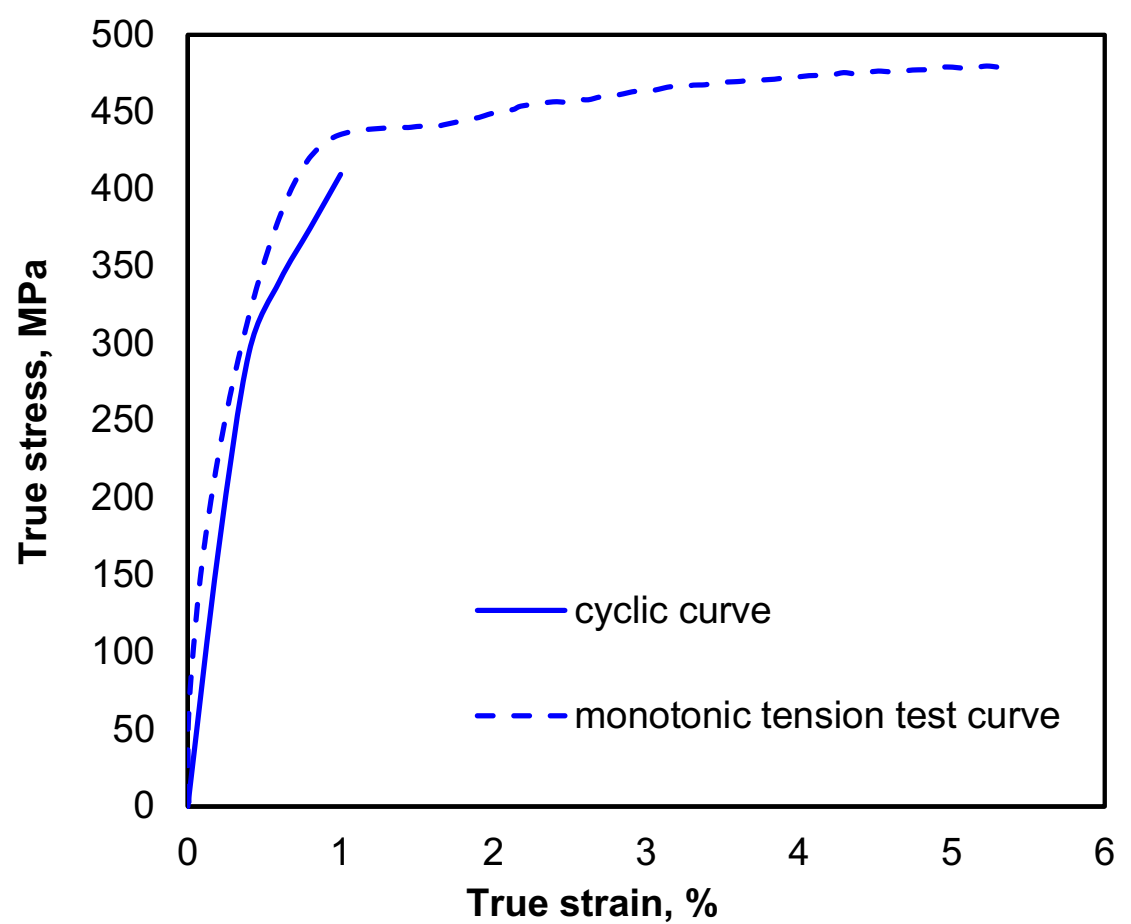

Fig. 4.21 The comparison of monotonic and cyclic stress-strain curve 


\section{Calculation Model for Young's Modulus}

Young's modulus, also known as the elastic modulus, is one of the most important parameters to evaluate the mechanical properties of solid materials. Young's modulus is defined as the slope of the elastic deformation region in the stress-strain curve. It demonstrates the resistance of the material to elastic deformation, and is usually used to evaluate the stiffness of the material.

Young's modulus of the composite is improved due to the addition of CNT in aluminum matrix. The Young's modulus for typical aluminum alloy is $70 \mathrm{GPa}$. The average value of the experimental results is $88.6 \mathrm{GPa}$ obtained by the fatigue testing system. In terms of aluminum matrix composite with 2 wt.\% content of CNT, the Young's moduli are respectively reported as $85.85 \mathrm{GPa}, 85.67$ GPa and $86 \mathrm{GPa}$ by George et al. [39], Girisha et al. [52] and Liu et al. [53]. All the values are close to the measured experimental value.

Various models have been proposed to calculate the Young's modulus of composite and they have been also applied to CNT reinforced composites. Several of the most commonly used models are discussed, and the calculated values by using different models will be compared with the experimental values.

\subsection{Rule of Mixture (Combined Voigt - Reuss Model)}

The rule of mixture is used to predict Young's modulus and tensile strength of the composites reinforced with fibers. It is usually considered valid only for continuous and unidirectional fibers. It contains two models, the Voigt model for axial loading (Eq. (20)) and the Reuss model for transverse loading (Eq. (21) and Eq. (22)). Considering the CNT was randomly aligned in CNT/ Al composites, so the combined equation is given as Eq. (23):

$$
\begin{aligned}
& E_{L}=E_{f} V_{f}+E_{m}\left(1-V_{f}\right) \\
& \frac{1}{E_{T}}=\frac{V_{f}}{E_{f}}+\frac{V_{m}}{E_{m}}
\end{aligned}
$$




$$
\begin{aligned}
& E_{T}=\frac{E_{f} E_{m}}{E_{f}\left(1-V_{f}\right)+E_{m} V_{f}} \\
& E_{C}=\frac{3}{8} E_{L}+\frac{5}{8} E_{T}
\end{aligned}
$$

\subsection{Cox Model}

One of the earliest analytical models to explain the reinforcing effect of short fibers on the strength and modulus of composite materials was described by Cox in 1952 [91]. The work of Cox is now commonly referred to as shear lag theory in the literature, and the equation for Young's modulus is usually described as Cox's model. However, in Cox's paper, the equation was not directly given. The model has been developed by various researchers. By comparing different equations from literature [24]Error! Reference source not found.[39][92], one equation was summarized by the a uthor, shown as below:

$$
\begin{aligned}
& \mathrm{E}_{\mathrm{c}}=\mathrm{E}_{\mathrm{f}} \mathrm{V}_{\mathrm{f}}\left(1-\frac{\tanh \frac{\beta \mathrm{l}}{2}}{\frac{\beta \mathrm{l}}{2}}\right)+\mathrm{E}_{\mathrm{m}}\left(1-\mathrm{V}_{\mathrm{f}}\right) \\
& \beta=\frac{1}{\mathrm{r}} \sqrt{\frac{2 \mathrm{E}_{\mathrm{m}}}{\mathrm{E}_{\mathrm{f}}\left(1+v_{\mathrm{m}}\right) \ln \left(1 / \mathrm{V}_{\mathrm{f}}\right)}}
\end{aligned}
$$

The Cox model is intended to be used for short fibers reinforced composite. It is valid only for unidirectional fibers, but not for randomly aligned fibers. Only the Young's modulus from longitudinal direction $\mathrm{E}_{\mathrm{L}}$ could be obtained without the value of $\mathrm{E}_{\mathrm{T}}$.

\subsection{Halpin - Tsai Equations}

Another commonly used model is Halpin-Tsai equations. It works very well for short whisker reinforced composites, and has been found to closely predict mechanical properties of CNT reinforced metal matrix composites with small CNT content. 
In Halpin-Tsai equations, $E_{C}$ can be expressed by two different equations of $E_{L}$ (Eq. (26), Eq. (27) and Eq. (28)) and $E_{T}$ (Eq. (29) and Eq. (30)).

$$
\mathrm{E}_{\mathrm{L}}=\mathrm{E}_{\mathrm{m}}\left(1+\xi_{\mathrm{L}} \eta_{\mathrm{L}} \mathrm{V}_{\mathrm{f}}\right) /\left(1-\eta_{\mathrm{L}} \mathrm{V}_{\mathrm{f}}\right)
$$

Where,

$$
\xi_{\mathrm{L}}=2 \mathrm{l} / \mathrm{d}
$$

and

$$
\begin{aligned}
& \eta_{L}=\frac{\left(E_{f} / E_{m}\right)-1}{\left(E_{f} / E_{m}\right)+\xi_{L}} \\
& E_{T}=E_{m}\left(1+\xi_{T} \eta_{T} V_{f}\right) /\left(1-\eta_{T} V_{f}\right)
\end{aligned}
$$

Where,

$\xi_{\mathrm{T}}=2$

and

$$
\eta_{T}=\frac{\left(E_{f} / E_{m}\right)-1}{\left(E_{f} / E_{m}\right)+\xi_{T}}
$$

Finally, the same equation to calculate the Young's modulus of the composite is applied as the one used in rule of mixture (Eq. (31)):

$$
E_{C}=\frac{3}{8} E_{L}+\frac{5}{8} E_{T}
$$

\subsection{Calculation and Discussion}

The dimensions of as-received CNTs have an outer diameter of $20 \mathrm{~nm}$ and a length of $5 \mu \mathrm{m}$. During the fabrication process, the CNT shortened due to strong shear strain in the FSP stage. It is 
reasonable to use $1 \mu \mathrm{m}$ as the length of shortened CNT [55][93][94]. The calculated values and experimental values are shown in Table 5.1.

Table 5.1 Comparison of calculated values of Young's moduli

\begin{tabular}{ccccccc}
\hline $\begin{array}{c}\text { Rule of } \\
\text { Mixture } \\
/ \mathrm{GPa}\end{array}$ & $\begin{array}{c}\text { Cox Model } \\
/ \mathrm{GPa}\end{array}$ & $\begin{array}{c}\text { Cox Model } \\
\text { (Shortened } \\
\mathrm{CNT}) / \mathrm{GPa}\end{array}$ & $\begin{array}{c}\text { Halpin-Tsai } \\
\text { Equation } \\
/ \mathrm{GPa}\end{array}$ & $\begin{array}{c}\text { Halpin-Tsai } \\
\text { Equation } \\
\text { (Shortened } \\
\mathrm{CNT}) / \mathrm{GPa}\end{array}$ & $\begin{array}{c}\text { Experimental } \\
\text { Value } \\
/ \mathrm{GPa}\end{array}$ \\
\hline $\mathrm{E}_{\mathrm{L}}$ & 121.9 & 120.2 & 113.5 & 119.5 & 111.9 & - \\
$\mathrm{E}_{\mathrm{T}}$ & 72.1 & - & - & 75.8 & 75.8 & - \\
$\mathrm{E}_{\mathrm{c}}$ & 90.8 & 120.2 & 113.5 & 92.2 & 89.3 & 88.6 \\
\hline
\end{tabular}

From the calculated results, it can be seen that the results of the Young's modulus from longitudinal orientation were similar by using all these three models, but all of them were larger than the experimental value. When the value for random orientations were calculated, the rule of mixture and Halpin-Tsai equation showed a good agreement with the experimental value. When the shortened CNT dimensions were used in the calculation, the calculated value and experimental value were even closer.

The rule of mixture is commonly considered valid only for continuous fiber reinforced composites. However, it can be noticed that in our case, although the carbon nanotubes are not continuous fibers, the rule of mixture still works well. This may be explained from two aspects. On one hand, the carbon nanotubes are randomly aligned in the aluminum matrix, which makes the values combined from two different orientations closer to the actual value; on the other hand, the Young's modulus of carbon nanotube is much higher than of aluminum, making the influence of carbon nanotube more dominant.

The Cox model showed good agreement on the Young's modulus in the longitudinal direction in our case. The main problem for the Cox model is that it can be only used for unidirectional fibers, and there is no way to calculate the Young's modulus in the transverse direction. 


\section{Summary and Future Work}

\subsection{Summary}

Aluminum alloys are widely used in various industrial fields such as automotive and aerospace, thanks to their low density, good mechanical properties and excellent corrosion resistance. In order to further improve their strength, carbon nanotube reinforced aluminum matrix composite has been developed and studied recently. Carbon nanotube is a nano-sized tube-shaped carbon with remarkable mechanical properties such as extremely high Young's modulus and tensile strength.

This investigation mainly studied the microstructure, mechanical properties and fatigue properties of 2 wt.\% CNT/ $6061 \mathrm{Al}$ composite. 6061 is one of the most commonly used wrought aluminum alloys with good mechanical properties and heat-treatability. The composite is fabricated by powder metallurgy and friction stir processing, followed by heat treatment to get a T6 temper condition.

The addition of carbon nanotubes greatly improves the strength of aluminum 6061 alloy. Both the yield strength and tensile strength are much higher than the base alloy, but the ductility is lower. The Young's modulus is $88.6 \mathrm{GPa}$ based on the experimental value, larger than the $70 \mathrm{GPa}$ value of typical aluminum alloy. The enhancement of strength is due to four strengthening mechanisms working simultaneously, namely load transfer, thermal mismatch, Orowan looping and grain refinement strengthening. It is widely reported that the maximum strength is obtained with the addition of 2 wt. $\%$ content of CNT.

Two phases are identified by XRD tests, including aluminum and $\mathrm{Al}_{4} \mathrm{C}_{3}$. The $\mathrm{Al}_{4} \mathrm{C}_{3}$ phase is a needle-shaped carbide with the similar dimension compared to CNT, and it is generated due to the chemical reaction between $\mathrm{CNT}$ and aluminum matrix. $\mathrm{Al}_{4} \mathrm{C}_{3}$ is effective for the load transfer and interfacial boding enhancement. The absence of the second phase $\mathrm{Mg}_{2} \mathrm{Si}$ is caused by the fabrication process and its absence makes the effect of heat treatment insignificant.

Two unusual phenomena are found from the stress-strain curve of the tension tests. The non-linear elastic behavior is caused by the domination of the non-linear elastic behavior of CNT, while the 
yield phenomenon is mainly attributed to the CNT bridging manner in aluminum matrix. Both of the phenomena are believed related to the fabrication method.

The cyclic softening of the composite can be seen in the low cycle fatigue tests.

Two mathematical models are discussed to predict the yield strength and to calculate the Young's modulus.

Three models have been developed to predict the yield strength of the composite, including arithmetic summation method, compounding method and modified Clyne model. After analyzing and comparing each model, the author put forward a model based on the format of modified Clyne model.

Three main models are used to calculate the Young's modulus of the composite, including rule of mixture, Cox model and Halpin-Tsai equation. By comparing the values calculated by three models and the experimental value, both rule of mixture and Halpin-Tsai showed a good agreement.

\subsection{Contributions}

The contributions of the current research include:

(1) For the first time analyze the reason and the effect of the absence of $\mathrm{Mg}_{2} \mathrm{Si}$ phase in the CNT reinforced aluminum matrix composite.

(2) For the first time point out and analyze the reasons of the non-linear elastic deformation and yield phenomenon in the stress-strain curve of tension test for the composite.

(3) Compare and analyze the prediction models for yield strength and put forward a model based on the strengthening mechanisms.

(4) Compare the calculation models for Young's modulus and verified their accuracy by comparing the calculated values with experimental values. 


\subsection{Future Work}

This study could be extended in experimental directions to obtain deeper understanding about the effect of the addition of CNT in aluminum alloy and FSP fabrication methods. Two more groups of materials can be used to make some comparisons, including the 6061 aluminum alloy without the addition of CNT made by FSP and the extruded 6061 aluminum alloy. By comparing the materials made by FSP with or without the addition of CNT, the effect of the addition of CNT could be further studied and understood. By comparing the aluminum alloys made by FSP and extrusion, the effect of FSP will be known better.

More theoretical research could be conducted to validate the prediction model for yield strength by doing detailed calculation for each of the factors. The contributions of each factor in strengthening mechanisms should be evaluated and the model that the author put forward could be verified. 


\section{Reference List}

[1] Iijima, S. (1991). Helical microtubules of graphitic carbon. Nature, 354(6348), 56-58.

[2] Kroto, H. W., Heath, J. R., O'Brien, S. C., Curl, R. F., \& Smalley, R. E. (1985). C60: Buckminsterfullerene. Nature, 318(6042), 162-163.

[3] Novoselov, K. S., Geim, A. K., Morozov, S. V., Jiang, D., Zhang, Y., Dubonos, S. V., ... \& Firsov, A. A. (2004). Electric field effect in atomically thin carbon films. Science, 306(5696), 666-669.

[4] Geim, A. K., \& Novoselov, K. S. (2007). The rise of graphene. Nature materials, 6(3), 183191.

[5] Iijima, S., \& Ichihashi, T. (1993). Single-shell carbon nanotubes of 1-nm diameter. Nature, $363,603-605$.

[6] Bethune, D. S., Klang, C. H., de Vries, M. S., Gorman, G., Savoy, R., Vazquez, J., \& Beyers, R. (1993). Cobalt-catalysed growth of carbon nanotubes with single-atomic-layer walls. Nature, 363(6430), 605-607.

[7] Prasek, J., Drbohlavova, J., Chomoucka, J., Hubalek, J., Jasek, O., Adam, V., \& Kizek, R. (2011). Methods for carbon nanotubes synthesis - review. Journal of Materials Chemistry, 21(40), 15872.

[8] Eatemadi, A., Daraee, H., Karimkhanloo, H., Kouhi, M., \& Zarghami, N. (2014). Carbon nanotubes: properties, synthesis, purification, and medical applications. Nanoscale Research Letters, 9(1), 1-13.

[9] Krishnan, A., Dujardin, E., Ebbesen, T. W., Yianilos, P. N., \& Treacy, M. M. J. (1998). Young's modulus of single-walled nanotubes. Physical Review B, 58(20), 14013.

[10] Treacy, M. J., Ebbesen, T. W., \& Gibson, J. M. (1996). Exceptionally high Young's modulus observed for individual carbon nanotubes. Nature, 381(6584), 678. 
[11] Yakobson, B. I., \& Avouris, P. (2001). Mechanical Properties of Carbon Nanotubes. Carbon Nanotubes, 327(2001), 287-327.

[12] Dervishi, E., Li, Z., Xu, Y., Saini, V., Biris, A. R., Lupu, D., \& Biris, A. S. (2009). Carbon Nanotubes: Synthesis, Properties, and Applications. Particulate Science and Technology, $27(2), 107-125$.

[13] Thostenson, E. T., Ren, Z., \& Chou, T. W. (2001). Advances in the science and technology of carbon nanotubes and their composites: a review. Compos. Sci. Technol., 61, 18991912.

[14] Baughman, R. H., Zakhidov, A. a, \& de Heer, W. a. (2002). Carbon nanotubes --- the route toward applications. Science, 297(5582), 787-792.

[15] Sinott, S. B., \& Andrews, R. (2001). Carbon nanotubes: synthesis, properties, and applications. Critical Reviews in Solid State and Materials Sciences, 26(3), 145-249.

[16] Dai, H. (2002). Carbon Nanotubes : Synthesis , Integration, and Properties, 1035-1044.

[17] Andrews, R., Jacques, D., Qian, D., \& Rantell, T. (2002). Multiwall carbon nanotubes: Synthesis and application. Accounts of Chemical Research, 35(12), 1008-1017.

[18] Cui, H., Zhou, O., \& Stoner, B. R. (2000). Deposition of aligned bamboo-like carbon nanotubes via microwave plasma enhanced chemical vapor deposition. Journal of Applied Physics, 88(10), 6072.

[19] ASM International Handbook, V. 2. (1990). Properties and selection: Nonferrous alloys and special-purpose materials. ASM Metals Handbook, 2, 1300.

[20] Vencl, A., Bobic, I., Arostegui, S., Bobic, B., Marinković, A., \& Babić, M. (2010). Structural, mechanical and tribological properties of A356 aluminium alloy reinforced with $\mathrm{A} 12 \mathrm{O} 3, \mathrm{SiC}$ and $\mathrm{SiC}+$ graphite particles. Journal of Alloys and Compounds, 506(2), 631639. 
[21] Ramnath, B. V, Elanchezhian, C., Annamalai, R. M., Aravind, S., Atreya, T. S. A., Vignesh, V., \& Subramanian, C. (2014). Aluminium metal matrix composites - A review. Reviews on Advanced Materials Science, 38(1), 55-60.

[22] Liu, Z. Y., Xiao, B. L., Wang, W. G., \& Ma, Z. Y. (2014). Effect of carbon nanotube orientation on mechanical properties and thermal expansion coefficient of carbon nanotube-reinforced aluminum matrix composites. Acta Metallurgica Sinica (English Letters), 27(5), 901-908.

[23] Zare, H., Jahedi, M., Toroghinejad, M. R., Meratian, M., \& Knezevic, M. (2016). Microstructure and mechanical properties of carbon nanotube reinforced aluminum matrix composites synthesized via equal-channel angular pressing. Materials Science and Engineering A, 670, 205-216

[24] Bakshi, S. R., Lahiri, D., \& Agarwal, a. (2010). Carbon nanotube reinforced metal matrix composites - a review. International Materials Reviews, 55(1), 41-64.

[25] Shirvanimoghaddam, K., Hamim, S. U., Karbalaei Akbari, M., Fakhrhoseini, S. M., Khayyam, H., Pakseresht, A. H., ... Naebe, M. (2017). Carbon fiber reinforced metal matrix composites: Fabrication processes and properties. Composites Part A: Applied Science and Manufacturing, 92, 70-96.

[26] Fan, G., Yu, Z., Tan, Z., Li, Z., \& Zhang, D. (2014). Evolution, control, and effects of interface in CNT/Al composites: A review. Acta Metallurgica Sinica (English Letters), $27(5), 839-843$.

[27] Kwon, H., Estili, M., Takagi, K., Miyazaki, T., \& Kawasaki, A. (2009). Combination of hot extrusion and spark plasma sintering for producing carbon nanotube reinforced aluminum matrix composites. Carbon, 47(3), 570-577.

[28] Singla, D., Amulya, K., \& Murtaza, Q. (2015). CNT Reinforced Aluminium Matrix Composite-A Review. Materials Today: Proceedings, 2(4-5), 2886-2895. 
[29] Liu, Z. Y., Xu, S. J., Xiao, B. L., Xue, P., Wang, W. G., \& Ma, Z. Y. (2012). Effect of ballmilling time on mechanical properties of carbon nanotube reinforced aluminum matrix composites. Composites Part A: Applied Science and Manufacturing, 43(12), 2161-2168.

[30] Choi, H. J., Shin, J. H., \& Bae, D. H. (2012). The effect of milling conditions on microstructures and mechanical properties of Al/MWCNT composites. Composites Part A: Applied Science and Manufacturing, 43(7), 1061-1072.

[31] Laha, T., Agarwal, A., McKechnie, T., \& Seal, S. (2004). Synthesis and characterization of plasma spray formed carbon nanotube reinforced aluminum composite. Materials Science and Engineering A, 381(1-2), 249-258.

[32] Laha, T., Kuchibhatla, S., Seal, S., Li, W., \& Agarwal, A. (2007). Interfacial phenomena in thermally sprayed multiwalled carbon nanotube reinforced aluminum nanocomposite. Acta Materialia, 55(3), 1059-1066.

[33] Bakshi, S. R., Singh, V., Balani, K., McCartney, D. G., Seal, S., \& Agarwal, A. (2008). Carbon nanotube reinforced aluminum composite coating via cold spraying. Surface and Coatings Technology, 202(21), 5162-5169

[34] Ma, Z. Y., Liu, Z. Y., Xiao, B. L., \& Wang, W. G. (2013). Fabrication of carbon nanotube reinforced aluminum matrix composites via friction stir processing. TMS Annual Meeting, (v), 21-28.

[35] Travessa, D. N., da Rocha, G. V. B., Cardoso, K. R., \& Lieblich, M. (2017). Carbon Nanotube-Reinforced Aluminum Matrix Composites Produced by High-Energy Ball Milling. Journal of Materials Engineering and Performance.

[36] Carvalho, O., Buciumeanu, M., Miranda, G., Costa, N., Soares, D., \& Silva, F. S. (2016). Mechanisms governing the tensile, fatigue, and wear behavior of carbon nanotube reinforced aluminum alloy. Mechanics of Advanced Materials and Structures, 23(8), 917925. 
[37] Kelly, A., \& Tyson, A. W. (1965). Tensile properties of fibre-reinforced metals: copper/tungsten and copper/molybdenum. Journal of the Mechanics and Physics of Solids, 13(6), 329-350.

[38] Bakshi, S. R., \& Agarwal, A. (2011). An analysis of the factors affecting strengthening in carbon nanotube reinforced aluminum composites. Carbon, 49(2), 533-544.

[39] George, R., Kashyap, K. T., Rahul, R., \& Yamdagni, S. (2005). Strengthening in carbon nanotube/aluminium (CNT/Al) composites. Scripta Materialia, 53(10), 1159-1163.

[40] Zhang, Z., \& Chen, D. L. (2006). Consideration of Orowan strengthening effect in particulate-reinforced metal matrix nanocomposites: A model for predicting their yield strength. Scripta Materialia, 54(7), 1321-1326.

[41] Choi, H. J., Min, B. H., Shin, J. H., \& Bae, D. H. (2011). Strengthening in nanostructured 2024 aluminum alloy and its composites containing carbon nanotubes. Composites Part A: Applied Science and Manufacturing, 42(10), 1438-1444.

[42] Mokdad, F., Chen, D. L., Liu, Z. Y., Xiao, B. L., Ni, D. R., \& Ma, Z. Y. (2016). Deformation and strengthening mechanisms of a carbon nanotube reinforced aluminum composite. Carbon, 104, 64-77.

[43] Mokdad, F., Chen, D. L., Liu, Z. Y., Ni, D. R., Xiao, B. L., \& Ma, Z. Y. (2017). Hot deformation and activation energy of a CNT-reinforced aluminum matrix nanocomposite. Materials Science and Engineering A, 695(April), 322-331.

[44] Srivastava, a K., Xu, C. L., Wei, B. Q., Kishore, R., \& Sood, K. N. (2008). Microstructural features and mechanical properties of carbon nanotube reinforced aluminum - based metal matrix composites. Sciences-New York, 15(June), 247-255.

[45] Park, J. G., Keum, D. H., \& Lee, Y. H. (2015). Strengthening mechanisms in carbon nanotube-reinforced aluminum composites. Carbon, 95, 690-698.

[46] Pérez-Bustamante, R., Gómez-Esparza, C. D., Estrada-Guel, I., Miki-Yoshida, M., LiceaJiménez, L., Pérez-García, S. A., \& Martínez-Sánchez, R. (2009). Microstructural and 
mechanical characterization of Al-MWCNT composites produced by mechanical milling. Materials Science and Engineering A, 502(1-2), 159-163.

[47] Liao, J. Z., \& Tan, M. J. (2012). Improved Tensile Strength of Carbon Nanotube Reinforced Aluminum Composites Processed by Powder Metallurgy. Advanced Materials Research, 500, 651-656.

[48] Esawi, A. M. K., Morsi, K., Sayed, A., Taher, M., \& Lanka, S. (2010). Effect of carbon nanotube $(\mathrm{CNT})$ content on the mechanical properties of CNT-reinforced aluminium composites. Composites Science and Technology, 70(16), 2237-2241.

[49] Carvalho, O., Miranda, G., Soares, D., \& Silva, F. S. (2013). CNT-reinforced aluminum composites: Processing and mechanical properties. Ciencia E Tecnologia Dos Materiais, $25(2), 75-78$.

[50] Liao, J. Z., Tan, M. J., \& Santoso, A. (2011). High Strength Aluminum Nanocomposites Reinforced with Multi-Walled Carbon Nanotubes. Advanced Materials Research, 311-313, 80-83.

[51] Pérez-Bustamante, R., Estrada-Guel, I., Antúnez-Flores, W., Miki-Yoshida, M., Ferreira, P. J., \& Martínez-Sánchez, R. (2008). Novel Al-matrix nanocomposites reinforced with multi-walled carbon nanotubes. Journal of Alloys and Compounds, 450(1-2), 323-326.

[52] Girisha, L., \& George, R. (2014). Study on Properties of Multi Walled Carbon Nanotube Reinforced Aluminum Matrix Composite through Casting Technique, 3(4), 1372-1375.

[53] Liu, Z. Y., Xiao, B. L., Wang, W. G., \& Ma, Z. Y. (2017). Modelling of carbon nanotube dispersion and strengthening mechanisms in Al matrix composites prepared by high energy ball milling-powder metallurgy method. Composites Part A: Applied Science and Manufacturing, 94(51471171), 189-198.

[54] Esawi, A. M. K., Morsi, K., Sayed, A., Taher, M., \& Lanka, S. (2011). The influence of carbon nanotube (CNT) morphology and diameter on the processing and properties of 
CNT-reinforced aluminium composites. Composites Part A: Applied Science and Manufacturing, 42(3), 234-243.

[55] Liu, Z. Y., Xiao, B. L., Wang, W. G., \& Ma, Z. Y. (2014). Analysis of carbon nanotube shortening and composite strengthening in carbon nanotube/aluminum composites fabricated by multi-pass friction stir processing. Carbon, 69(November), 264-274.

[56] Liu, Z. Y., Xiao, B. L., Wang, W. G., \& Ma, Z. Y. (2012). Singly dispersed carbon nanotube/aluminum composites fabricated by powder metallurgy combined with friction stir processing. Carbon, 50(5), 1843-1852.

[57] Izadi, H., \& Gerlich, A. P. (2012). Distribution and stability of carbon nanotubes during multi-pass friction stir processing of carbon nanotube/aluminum composites. Carbon, 50(12), 4744-4749.

[58] Esawi, A. M. K., Morsi, K., Sayed, A., Gawad, A. A., \& Borah, P. (2009). Fabrication and properties of dispersed carbon nanotube-aluminum composites. Materials Science and Engineering A, 508(1-2), 167-173.

[59] Zhang, X. X., Wei, H. M., Li, A. B., Fu, Y. D., \& Geng, L. (2013). Effect of hot extrusion and heat treatment on CNTs-Al interfacial bond strength in hybrid aluminium composites. Composite Interfaces, 20(4), 231-239.

[60] Zhao, K., Liu, Z. Y., Xiao, B. L., Ni, D.-R., \& Ma, Z.-Y. (2017). Origin of Insignificant Strengthening Effect of CNTs in T6-Treated CNT/6061Al Composites. Acta Metallurgica Sinica (English Letters).

[61] Liao, J. Z., Tan, M. J., \& Bayraktar, E. (2013). Tension-Tension Fatigue Behaviour of Carbon Nanotube Reinforced Aluminium Composites. Materials Science Forum, 765, $563-567$.

[62] Shin, S. E., \& Bae, D. H. (2018). Fatigue behavior of Al2024 alloy-matrix nanocomposites reinforced with multi-walled carbon nanotubes. Composites Part B: Engineering, 134, 6168. 
[63] Senthil Saravanan, M. S., Kumaresh Babu, S. P., \& Sivaprasad, K. (2014). Mechanical properties and corrosion behavior of carbon nanotube reinforcedAA 4032 nanocomposites. Experimental Techniques, 38(1), 48-52.

[64] Samuel Ratna Kumar, P. S., Robinson Smart, D. S., \& John Alexis, S. (2017). Corrosion behaviour of Aluminium Metal Matrix reinforced with Multi-wall Carbon Nanotube. Journal of Asian Ceramic Societies, 5(1), 71-75.

[65] Arsenault, R. J. (1984). The strengthening of aluminum alloy 6061 by fiber and platelet silicon carbide. Materials Science and Engineering, 64(2), 171-181.

[66] Sanaty-Zadeh, A. (2012). Comparison between current models for the strength of particulate-reinforced metal matrix nanocomposites with emphasis on consideration of Hall-Petch effect. Materials Science and Engineering A, 531, 112-118.

[67] Kim, C. S., Sohn, I., Nezafati, M., Ferguson, J. B., Schultz, B. F., Bajestani-Gohari, Z., ... Cho, K. (2013). Prediction models for the yield strength of particle-reinforced unimodal pure magnesium $(\mathrm{Mg})$ metal matrix nanocomposites (MMNCs). Journal of Materials Science, 48(12), 4191-4204.

[68] Ramakrishnan, N. (1996). An analytical study on strengthening of particulate reinforced metal matrix composites. Acta Materialia, 44(1), 69-77.

[69] Zhang, Z., \& Chen, D. L. (2006). Consideration of Orowan strengthening effect in particulate-reinforced metal matrix nanocomposites: A model for predicting their yield strength. Scripta Materialia, 54(7), 1321-1326.

[70] Mirza, F. A., \& Chen, D. L. (2012). An Analytical Model for Predicting the Yield Strength of Particulate-Reinforced Metal Matrix Nanocomposites with Consideration of Porosity. Nanoscience and Nanotechnology Letters, 4(8), 794-800.

[71] Mirza, F., \& Chen, D. (2015). A Unified Model for the Prediction of Yield Strength in Particulate-Reinforced Metal Matrix Nanocomposites. Materials, 8(8), 5138-5153. 
[72] T. W. Clyne and P. J. Withers, An Introduction to Metal Matrix Composites, Cambridge Solid State Science Series, Cambridge University Press (1993).

[73] Chen, B., Li, S., Imai, H., Jia, L., Umeda, J., Takahashi, M., \& Kondoh, K. (2015). An approach for homogeneous carbon nanotube dispersion in Al matrix composites. Materials and Design, 72, 1-8.

[74] Liu, Z. Y., Xiao, B. L., Wang, W. G., \& Ma, Z. Y. (2013). Developing high-performance aluminum matrix composites with directionally aligned carbon nanotubes by combining friction stir processing and subsequent rolling. Carbon, 62, 35-42.

[75] Borrego, L. P., Abreu, L. M., Costa, J. M., \& Ferreira, J. M. (2004). Analysis of low cycle fatigue in AlMgSi aluminium alloys. Engineering Failure Analysis, 11(5), 715-725.

[76] Deng, C. F., Wang, D. Z., Zhang, X. X., \& Li, A. B. (2007). Processing and properties of carbon nanotube reinforced aluminum composites. Materials Science and Engineering A, 444(1-2), 138-145.

[77] Chen, B., Shen, J., Ye, X., Imai, H., Umeda, J., Takahashi, M., \& Kondoh, K. (2016). Solidstate interfacial reaction and load transfer efficiency in carbon nanotubes (CNTs)reinforced aluminum matrix composites. Carbon, 114, 198-208.

[78] Kondoh, K., Fukuda, H., Umeda, J., Imai, H., \& Fugetsu, B. (2014). Microstructural and mechanical behavior of multi-walled carbon nanotube reinforced Al-Mg-Si alloy composites in aging treatment. Carbon, 72, 15-21.

[79] ASM International Handbook, V. 2. (1990). Properties and selection: Nonferrous alloys and special-purpose materials. ASM Metals Handbook, 2, 1300.

[80] Najimi, A. A., \& Shahverdi, H. R. (2017). Microstructure and mechanical characterization of Al6061-CNT nanocomposites fabricated by spark plasma sintering. Materials Characterization, 133(September), 44-53. 
[81] Rikhtegar, F., Shabestari, S. G., \& Saghafian, H. (2017). Microstructural evaluation and mechanical properties of Al-CNT nanocomposites produced by different processing methods. Journal of Alloys and Compounds, 723, 633-641.

[82] Cha, J., Jun, G. H., Park, J. K., Kim, J. C., Ryu, H. J., \& Hong, S. H. (2017). Improvement of modulus, strength and fracture toughness of CNT/Epoxy nanocomposites through the functionalization of carbon nanotubes. Composites Part B: Engineering, 129, 169-179.

[83] Laha, T., Chen, Y., Lahiri, D., \& Agarwal, A. (2009). Tensile properties of carbon nanotube reinforced aluminum nanocomposite fabricated by plasma spray forming. Composites Part A: Applied Science and Manufacturing, 40(5), 589-594.

[84] Xiao, T., \& Liao, K. (2002). Nonlinear elastic properties of carbon nanotubes subjected to large axial deformations. Physical Review B - Condensed Matter and Materials Physics, 66(15), 1534071-1534074.

[85] Kim, K. T., Cha, S. Il, Hong, S. H., \& Hong, S. H. (2006). Microstructures and tensile behavior of carbon nanotube reinforced $\mathrm{Cu}$ matrix nanocomposites. Materials Science and Engineering A, 430(1-2), 27-33.

[86] Itoh, T., Nakata, T., Sakane, M., \& Ohnami, M. (1999). Nonproportional Low Cycle Fatigue of 6061 Aluminum Alloy Under 14 Strain Paths. Multiaxial Fatigue and Fracture European.

[87] Unigovski, Y. B., Grinberg, A., \& Gutman, E. M. (2013). Low-cycle fatigue of the light advanced materials. Procedia Engineering, 66, 713-722.

[88] Goh, C. S., Wei, J., Lee, L. C., \& Gupta, M. (2008). Ductility improvement and fatigue studies in Mg-CNT nanocomposites. Composites Science and Technology, 68(6), 14321439.

[89] Brammer, A. T., Jordon, J. B., Allison, P. G., \& Barkey, M. E. (2012). Strain-Controlled Low-Cycle Fatigue Properties of Extruded 6061-T6 Aluminum Alloy. Journal of Materials Engineering and Performance. 
[90] Standardization, ISO. (2017). ISO 12106:2017 - Metallic Materials - Fatigue Testing Axial-Strain-Controlled Method - Second Edition.

[91] Cox, H. L. (1952). The elasticity and strength of paper and other fibrous materials. British Journal of Applied Physics, 3(3), 72-79.

[92] Facca, A. G., Kortschot, M. T., \& Yan, N. (2006). Predicting the elastic modulus of natural fibre reinforced thermoplastics. Composites Part A: Applied Science and Manufacturing, 37(10), 1660-1671.

[93] Mansoor, M., \& Shahid, M. (2016). Carbon nanotube-reinforced aluminum composite produced by induction melting. Journal of Applied Research and Technology, 14(4), 215224.

[94] Nouri, N., Ziaei-Rad, S., Adibi, S., \& Karimzadeh, F. (2012). Fabrication and mechanical property prediction of carbon nanotube reinforced Aluminum nanocomposites. Materials and Design, 34, 1-14. 